LOCKHEED MATTIN

ENVIRONMENTAL RESTORATION PROGRAM
RECFIVED

FFR 2 y 1996

OSTI
Technical Report for a Fluidless

Directional Drilling System

Demonstrated at Solid Waste Storage Area 6 Shallow Buried Waste Sites 
This report has been reproduced directly from the best available copy.

Available to DOE and DOE contractors from the Office of Scientific and Technical Information, P.O. Box 62, Oak Ridge, TN 37831; prices available from 615-576-8401 (fax 615-576-2865).

Available to the public from the National Technical Information Service, U.S. Department of Commerce, 5285 Port Royal Rd., Springfield, VA 22161. 
ORNL/ER-335

Energy Systems Environmental Restoration Program

ORNL Environmental Restoration Program

\section{Technical Report for a Fluidless Directional Drilling System \\ Demonstrated at Solid Waste Storage Area 6 \\ Shallow Buried Waste Sites}

Date Issued—September 1995

Prepared for

U.S. Department of Energy

Office of Environmental Management

under budget and reporting code EW 20

managing the

Environmental Restoration Activities at

OAK RIDGE NATIONAL LABORATORY

Oak Ridge, Tennessee 37831

managed by

LOCKHEED MARTIN ENERGY SYSTEMS, INC.

for the

U. S. DEPARTMENT OF ENERGY

under contract DE-AC05-84OR21400 


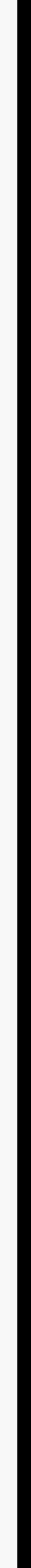




\section{CONTENTS}

ABBREVIATIONS $\ldots \ldots \ldots \ldots \ldots \ldots \ldots \ldots \ldots \ldots \ldots \ldots \ldots \ldots \ldots \ldots, \mathrm{v}$

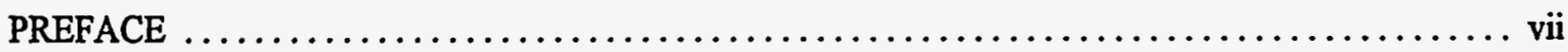

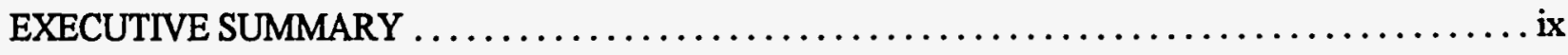

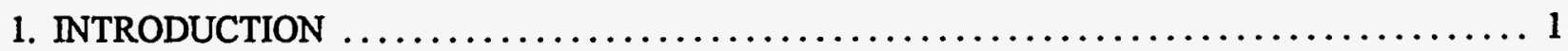

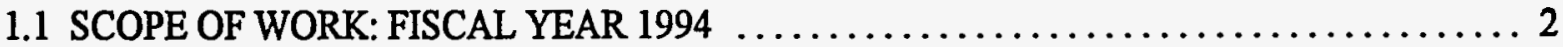

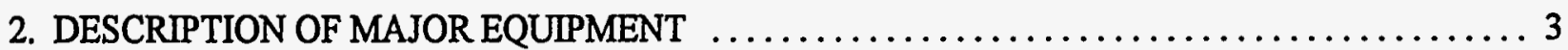

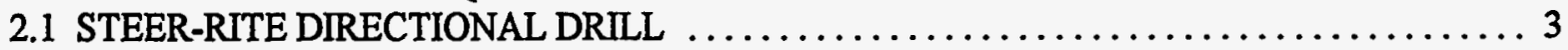

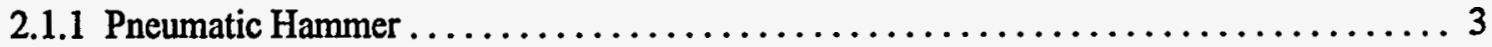

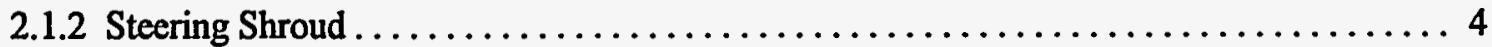

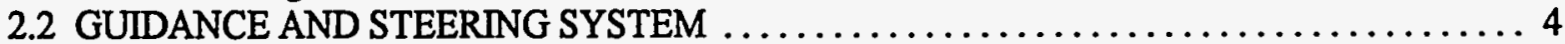

2.2.1 Radio Detection ......................................... 5

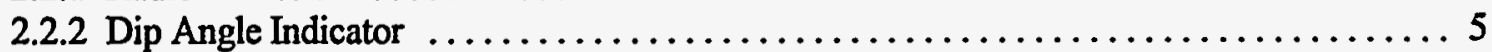

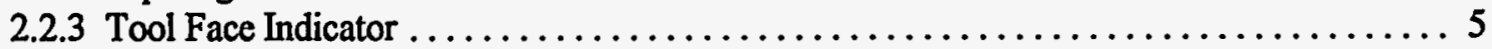

2.3 TOOL MODIFICATIONS FOR ENVIRONMENTAL COMPLIANCE $\ldots \ldots \ldots \ldots \ldots 5$

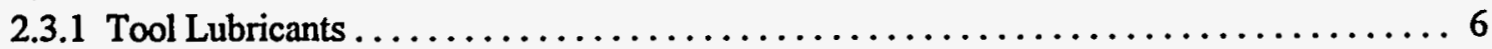

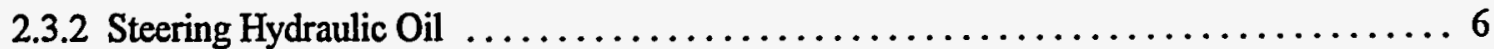

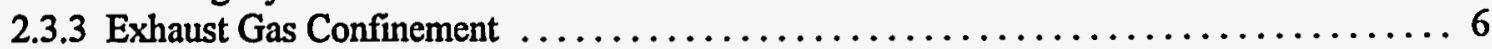

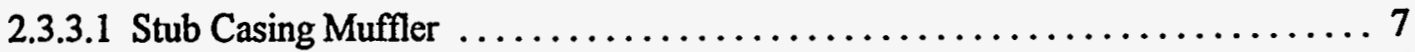

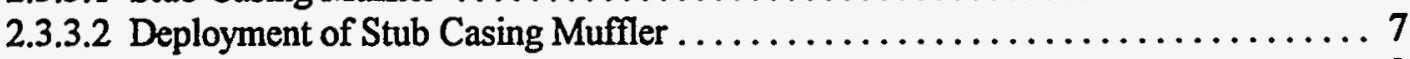

2.4 SEAMIST MEMBRANE TECHNOLOGY $\ldots \ldots \ldots \ldots \ldots \ldots \ldots \ldots \ldots \ldots \ldots \ldots, \ldots$

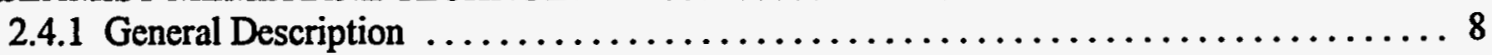

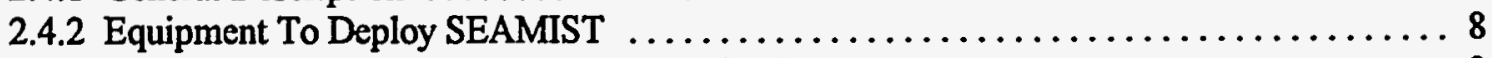

2.4.3 Advantages/Limitation of SEAMIST Technology ...................... 9

3. DIRECTIONAL DRILLING DEMONSTRATIONS AT SEG AND

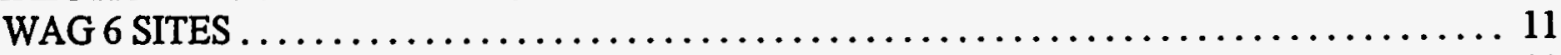

3.1 HORIZONTAL TEST BORE AT THE SEG SITE $\ldots \ldots \ldots \ldots \ldots \ldots \ldots \ldots \ldots \ldots \ldots \ldots \ldots \ldots$

3.3 WAG 6 DEMONSTRATION PERFORMANCE CRITERIA $\ldots \ldots \ldots \ldots \ldots \ldots \ldots \ldots$

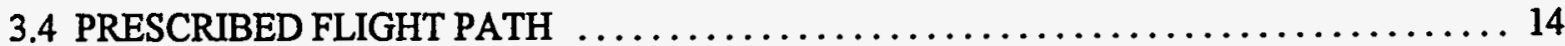

3.4.1 Survey Controls . ........................................ 14

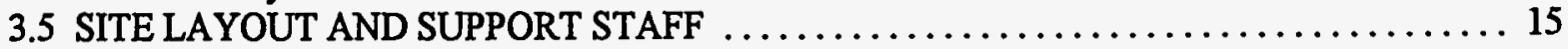

3.6 SEQUENCE OF DRILLING ACTIVITIES ON WAG $6 \ldots \ldots \ldots \ldots \ldots \ldots \ldots \ldots \ldots \ldots \ldots$

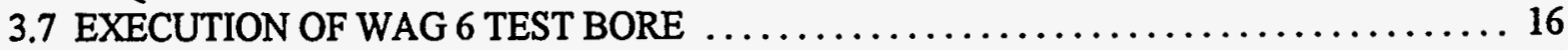

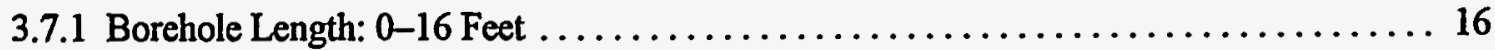

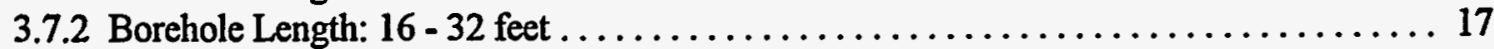

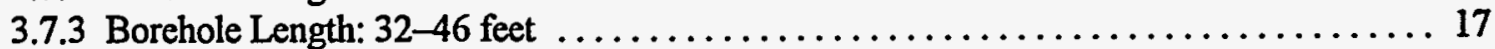

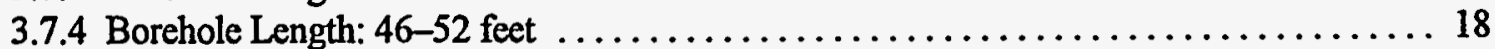

3.7.5 Borehole Length: $52-63$ feet .................................... 18

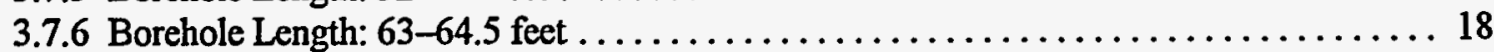

3.7.7 Borehole Length: $64.5-80$ feet $\ldots \ldots \ldots \ldots \ldots \ldots \ldots \ldots \ldots \ldots \ldots \ldots \ldots, 18$ 


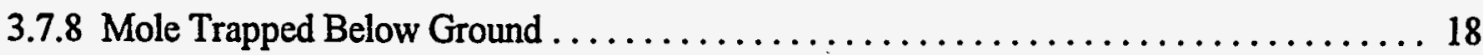

3.7.9 Rescue of Mole, Completion of Test Bore . . . . . . . . . . . . . . . . . . . 19

3.8 INSTALLATION OF SEAMIST MEMBRANE $\ldots \ldots \ldots \ldots \ldots \ldots \ldots \ldots \ldots \ldots \ldots \ldots \ldots$

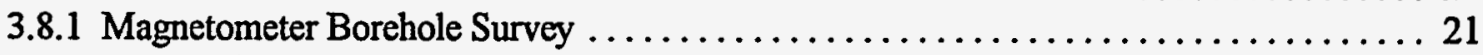

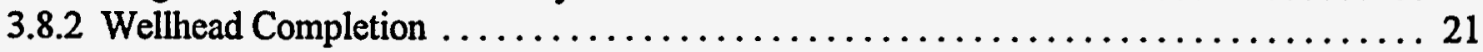

4. EVALUATION OF TEST BORE VERSUS PERFORMANCE CRITERIA $\ldots \ldots \ldots \ldots \ldots \ldots \ldots 23$

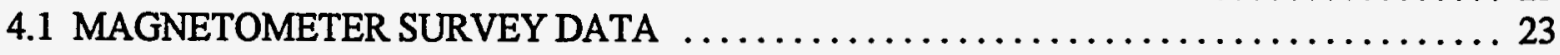

4.1.1 Comparison Between Magnetometer and Radio Detection Data . . . . . . . . . 23

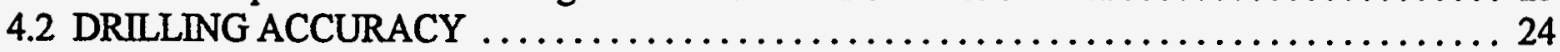

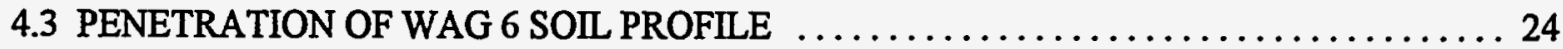

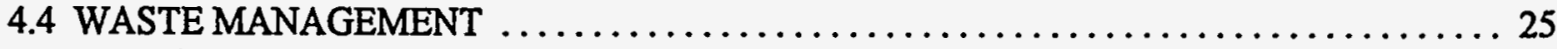

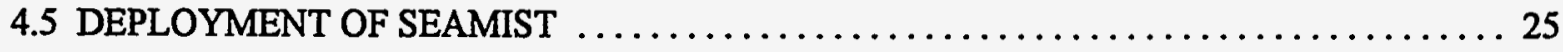

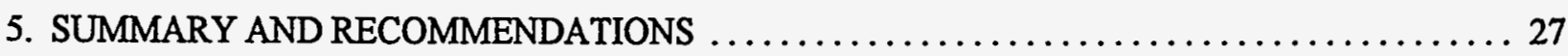

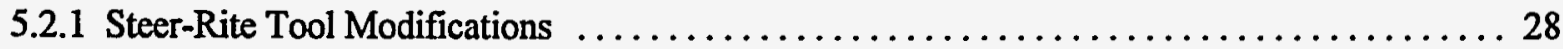

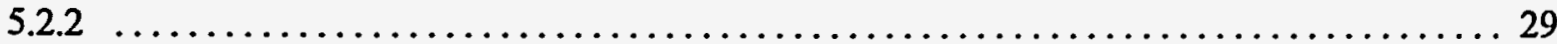

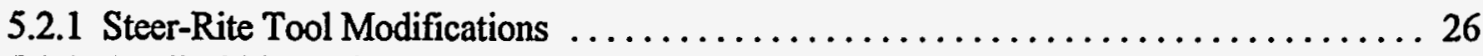

5.2.2 Applicability and Further Development of Steer-Rite Mole $\ldots \ldots \ldots \ldots \ldots \ldots \ldots 27$

5.2.3 Applicability and Further Development of SEAMIST for ER Applications . . . . . . 27

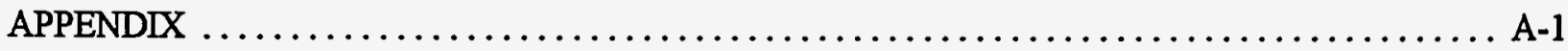




\section{ABBREVIATIONS}

ALARA

AW

ER

ESD

FDD

HEPA

ISV

MMES

ORNL

PVC

SEAMIST

SEG

TDEC

WAG as low as reasonably achievable

thin drill rods

Environmental Restoration

Environmental Sciences Division

fluidless directional drilling

high energy particulate air

in situ vitrification

Martin Martin Marietta Energy Systems

Oak Ridge National Laboratory

polyvinyl chloride

Science \& Engineering Associates Membrane, Instrumentation, and Sampling Technique

Scientific Ecology Group, Inc.

Tennessee Department of Health \& Environmental Conservation

Waste Area Grouping 


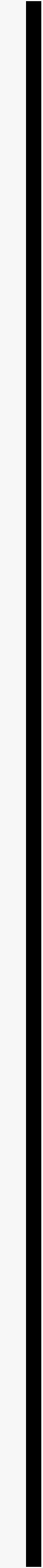




\section{PREFACE}

This report on a Fluidless Directional Drilling System Demonstrated at the Solid Waste Storage Area 6 Shallow Buried Waste Site documents remedial action technology development activities performed in accordance with the Record of Agreement, dated June 23, 1994, between the Department of Energy, the Tennessee Department of Environment and Conservation and the Environmental Protection Agency. The Record of Agreement for Oak Ridge National Laboratory WAG 5 recognizes the need to develop or adapt and demonstrate innovative technologies for all phases of site remediation. This work was performed under Work Breakdown Structure 1.4.12.06.02 (Activity Data Sheet 3306, "WAG 6"). 



\section{EXECUTIVE SUMMARY}

The purpose of the research was to demonstrate a fluidless directional drilling and monitoring system (FDD) specifically tailored to address environmental drilling concerns for shallow buried waste. The major concerns are related to worker exposure, minimizing waste generation, and confining the spread of contamination. All three concerns are addressed if a "fluidless" directional drill forms the framework for the drilling program. The economics of the research was driven by the need for a very low cost, potentially disposable drilling system. The FDD is potentially applicable to Environmental Restoration (ER) activities for the Oak Ridge National Laboratory Waste Area Grouping 6 (WAG 6) shallow buried waste disposed in unlined trenches. Major ER activities for directional drilling are to develop a drilling system for leachate collection directly beneath trenches, and to provide localized control over leachate release to the environment. Other ER FDD activities could include vadose zone and groundwater monitoring of contaminant transport.

The operational constraints pointed the research in the direction of purchasing a steerable impact hammer, or "mole", manufactured by Steer-Rite Ltd. of Racine, Wisconsin. This drill was selected due to the very low cost $(\$ 25,000)$ associated with procuring the drill, steering module, instrumentation and service lines. The impact hammer is a self propelled drill which penetrates the soil by compacting cut material along the sidewalls of the borehole. Essentially, it forces its way through the subsurface. Although the pneumatic hammer exhausts compressed air which must be handled at the borehole collar, it does not generate soil cuttings or liquids. This is the basis for the term "fluidless." A stub casing muffler was attached to the entrance hole for controlling exhaust gas and any airborne releases. Other environmental compliance modifications made to the equipment included operating the tool without lubrication, and using water instead of hydraulic fluid to actuate the steering fins on the tool.

There were two drilling demonstrations conducted during August 1994 to investigate the Steer-Rite mole's capability for directional drilling in saprolite (predominant WAG 6 overburden soil) and compacted clay shale typically found at WAG 6 . The first demonstration was undertaken at the Bear Creek Valley facility of the Scientific Ecology Group, Inc. (SEG), in compacted clay shale. The Steer-Rite mole was not powerful enough to penetrate this soil formation effectively. The drilling was stopped after 24 feet with a penetration rate of 2 inches per 15 minute. The second demonstration was conducted in a radiologic controlled zone at WAG 6 . The results from this demonstration indicated that the mole could not be guided accurately enough, within $+1-24$ inches of the prescribed flight path. The mole steered poorly when it bored from an uphill toward downhill location through a soft organic clayey soil. The maximum deviation of the mole from the prescribed flight path was about six feet. After about 65 feet of impact boring, the service lines to the mole became entangled by soil collapsing into the borehole. The tension which developed in the service lines caused the mole to switch inadvertently into reverse boring mode. This situation was remedied by digging a shallow pit down to the mole, and manually switching the mole into forward boring mode. Thereafter, the mole bored itself out of the ground with no further trouble.

Once the mole surfaced, the horizontal borehole was lined using the "SEAMIST" everting membrane technology. This technology lines the borehole with a continuous membrane using compressed air to force the membrane into the borehole. The SEAMIST membrane allows instrumentation to be retrieved from the borehole while simultaneously deploying another set of instruments from the opposite end of the horizontal borehole. The WAG 6 demonstration successfully deployed a SEAMIST membrane with a sock-likecotton absorber attached its exterior. This cotton absorber could be used to retrieve continuous smear samples along the entire borehole. The inflated membrane stabilized the sidewalls of the borehole, as it was kept inflated by a solar powered air compressor. A magnetometer survey of the borehole location was conducted inside 
the SEAMIST membrane. The results from the magnetometer survey agreed very well with the survey data gathered using a low cost radio detection device and transmitter.

The existing Steer-Rite FDD system is inadequate for drilling beneath WAG 6 trenches, and cannot be relied upon for time critical work. However, it did not generate any soil cuttings or drilling fluids, thus minimizing drilling waste management. Furthermore, the exhaust gases can be controlled with the stub casing muffler used during this field study, with some slight modifications. The most appropriate use of this impact tool is drilling shallow (10 feet or less) horizontal boreholes up to 100 feet long for site characterization and monitoring. The Steer-Rite tool must be modified so that it would carry a flexible casing into the borehole, thus preventing borehole collapse around the air and control lines. This modification will prevent the mole from going into reverse due to the control lines being trapped while the mole keeps moving . This modification to the tool is estimated to cost approximately $\$ 5,000$.

Development of an FDD system to place boreholes beneath WAG 6 trenches reliably would require approximately $\$ 300,000$ and one year to complete. The development process would be a co-operative effort with drilling industry experts. This process would include a world-wide technology search, specification development, design, fabrication, and testing. All phases would be highly interactive with ER management.

The SEAMIST membrane proved to be a very effective way to line a borehole. The SEAMIST membrane lined a 92 foot long hole in approximately 15 minutes. The membrane makes a simple task of performing a magnetometer survey along the entire length of the borehole. In addition, other large montoring devices, or sondes, can be easily pulled through borehole inside the SEAMIST membrane. 


\section{INTRODUCTION}

The purpose of the research was to demonstrate a fluidless directional drilling (FDD) and monitoring system specifically tailored to address environmental drilling concerns for shallow buried waste. The major concerns are related to worker exposure, minimizing waste generation, and confining the spread of contamination. All three concerns are addressed if a "fluidless" directional drill forms the framework for the drilling program. The economics of the research was driven by the need for a very low cost, throw-away drilling system. This constraint was added due to the high likelihood of chemical and radiological materials contaminating the drilling tools beyond free releasable limits (even after attempts to decontaminate the drill).

The motivation for applying an FDD technology is Environmental Restoration (ER) activities for the Waste Area Grouping 6 (WAG 6) shallow buried waste disposed in unlined trenches. See Figure 1 for the WAG 6 Site Location Map. A major ER activity for directional drilling is to develop a drilling system for leachate collection directly beneath trenches and to provide localized control over leachate release to the environment. Other directional drilling activities include vadose zone and groundwater monitoring of contaminate transport. In the case of leachate collection beneath trenches it appears that the maximum trench depth is about 15 feet, which is generally due to the limitation of the equipment used to excavate the trenches. In terms of the ground water flows, a major component of flow is strike parallel flow at the overburden/rock interface. The trench construction and geophysical constraints require a drilling and monitoring system which functions effectively to a depth of $20-25$ feet. This depth is about 5 to 10 feet below the anticipated trench bottom depths for WAG 6 burial units. Horizontal borehole lengths should be on the order of 200 to 400 feet, which is the likely range for the length of leachate collectors beneath burial trench groups.

The operational constraints cited above pointed towards examining a steerable impact hammer, or "mole", manufactured by Steer-Rite Ltd. of Racine, Wisconsin. This mole was selected due to the very low price $(\$ 25,000)$ for the mole, steering module, instrumentation, and service lines. The impact hammer is a self propelled drill which penetrates the soil by compacting cut material along the sidewalls of the borehole. Although the pneumatic hammer exhausts compressed air which must be handled at the borehole collar, it generates no soil cuttings or liquids. This aspect of the drilling is termed "fluidless", and greatly minimizes health physics and waste management concerns. A drawback of impact boring is the impedance zone formed along the sidewalls of the borehole. The mole creates this impedence zone as it forces its way through the soil, remolding and recompacting soil around the sides of the bore. The current field study was not concerned with examining the influence of this impedance zone upon the hydraulic characteristics of the horizontal well. If an impedance zone is formed, it can be removed by a back-reaming device during horizontal well completion. It was of prime importance to examine whether or not the mole could effectively penetrate the existing WAG 6 soils. The penetration effectiveness was determined by measuring both penetration rate of the drill and its ability to bore along a pre-determined flight path. Other drill characteristics examined during this study included its ability to be launched and retrieved at the ground surface, its capibility of moving forward or reverse, and its ability to steer along a tight radius of curvature (50 feet).

Once the drilling operation is finished, the horizontal borehole must be completed by installing a membrane tightly against the inside the open hole. During this research, the well was compleed using the SEAMISTeverting membrane technology (Section 2.4). This technology lines the borehole with a continuous membrane which can deploy various instruments mounted on the membrane's outer surface. The membrane allows instrumentation to be retrieved from the borehole while simultaneously deploying another set of instruments from the opposite end of the horizontal borehole on a second SEAMIST membrane. The retrievability of SEAMIST permits the horizontal bore to be used initially for site characterization and 
modified over time to support environmental restoration activities. The WAG 6 demonstration deployed a SEAMIST membrane with a cotton absorber to retrieve continuous smear samples along the entire borehole. The sidewalls of the borehole were stabilized by the membrane which was kept inflated using a solar powered air compressor.

\subsection{SCOPE OF WORK: FISCAL YEAR 1994}

There were two drilling demonstrations conducted during the month of August 1994 to investigate the capability of the Steer-Rite mole for directional drilling in saprolite (predominate overburden soil) and compacted clay shale typically found at WAG 6. The first demonstration was undertaken at the Bear Creek Valley facility of the Scientific Ecology Group, Inc. (SEG), (see plan location in Figure 1). This site allowed the drill crew and health physicists to become familiar with the drilling and waste handling procedures in an uncontaminated and carefully controlled setting. This dress rehearsal allowed the actual work to be done in an ALARA manner at WAG 6. Furthermore, the SEG test allowed a broad audience (DOE, MMES, Jacobs, TDHE) to witness the event without the restrictions associated with working in a radiation controlled zone. Lastly, the SEG site represented an extreme test of the Steer-Rite mole's ability to penetrate compact clay shale, which may be the predominate soil formation near the bottom of many WAG 6 trenches.

The WAG 6 drilling demonstration was conducted in a radiologic controlled zone following a prescribed work plan. All aspects of the directional drilling technology were demonstrated at WAG 6, from boring the hole, to completing the well utilizing the SEAMIST membrane technology. The last activity demonstrated at WAG 6 was to pull a magnetometer through the borehole, using the SEAMIST membrane to shuttle the sonde through the horizontal well. The magnetometer survey data was compared to the radio detection data collected during the drilling phase. This comparison allows discussion of the accuracy obtainable with a low cost steering system versus a high priced magnetometer-based system (a magnetometer costs approximately $\$ 40,000$ if lost in the borehole). 


\section{DESCRIPTION OF MAJOR EQUIPMENT}

This chapter presents the detailed information concerning all the hardware used for the drilling test program, well completion, and in situ instrumentation used to characterize the sub-surface. Mechanical drawings are used to illustrate the internal hammering mechanism used to propel the Steer-Rite drill. The interaction between the mole's anvil and steering fins is presented so that the reader can understand how the mole develops a reactive torque which makes steering possible. The steering capabilities of the mole would be useless unless the location of the mole could be accurately measured in the field. Several sections of this chapter are devoted to discussing the onboard instrumentation and surface readout device. The readout device provides the drill operator real time data for tool face orientation, dip angle of the drill and pressure level of the steering fins. The surface heading and depth of the bore was measured using a radio detection device. A brief discussion is provided for understanding the operation of this device.

Once the flight path is completed the uncased borehole must be lined. For the WAG 6 demonstration, the final liner consisted of a pressurized membrane with a continuous cotton absorber pressed against the soil surface. The membrane system has a trade name of SEAMIST. The general procedures used to deploy the SEAMIST membrane are presented, along with the logic for selecting this well completion technique over more conventional wellscreens.

\subsection{STEER-RITE DIRECTIONAL DRILL}

The directional drilling tool selected for demonstration is based upon a steerable pneumatic hammer, manufactured by Steer-Rite, Ltd. of Racine, Wisconsin. This tool was selected because it is commercially available, and appeared applicable for the shallow depths and short drives required by shallow buried waste applications. Since the mole remolds and recompacts soil against the sidewalls of the borehole, no soil cuttings are ejected out the borehole, thus the term "fluidless" directional drilling. Another major reason for examining this tool was the very low purchase price $(\$ 25,000)$ to procure the entire system.

The Steer-Rite system consists of three essential parts: pneumatic hammer, steering shroud, and electronic guidance system. The specific components which comprises these elements are discussed in the following sections along with the tool modifications required to accommodate the environmental constraints of drilling in a radiologically-controlled zone.

\subsubsection{Pneumatic Hammer}

The pneumatic hammer of the Steer-Rite System consists of a percussion tool (model IP 95) manufactured by Essig, a German company. This hammer requires about $100 \mathrm{scfm}$ at 7 bars to operate the anvil portion of the hammer. The hammer exhaust is at much lower pressures $(0.5 \mathrm{bar})$, and is ejected out the tail end of the tool. The exhaust volume has not been measured but it is believed to be at least $100 \mathrm{cfm}$ since there is little gas volume lost into the soil as the drill penetrates the fine grained saprolite soils. The pneumatic hammer has only three main parts:

1. The outer body casing shown in the upper portion of the photograph in Figure 2.

2. The sliding piston shown in the center of the disassembled tool (see Figure 2) 
3. The collet sleeve/spring/control valve assembly which actuates the piston of the hammer. The inlet hose is connected to the tail of the collet sleeve via a back end nut. This is the mechanism which also allows the mole to be placed into a reverse mode of operation.

An exploded view of the internal parts of the Essig mole are contained on the mechanical drawing in Figure 3.

\subsubsection{Steering Shroud}

The most defining feature of the Steer-Rite system is its ability to steer through the ground. The steering is accomplished using a finned shroud (Pathfinder 2000 by Steer-Rite, Ltd). The shroud encases the Essig mole. The mole steers by activating and de-activating two of the three steering fins illustrated in Figure 4. The interaction of the steering fins and $12^{\circ}$ inclined plane at the tool face allows the operator to control the mole's direction. Pressurization (depressurization) of the steering fins is a key feature: if the steering fins are pressurized then they produce a reactive torque against the soil. The reactive torque places the mole into a counterclockwise roll as the drill is propelled forward. As the mole rotates through an angle of $360^{\circ}$ the net soil reaction against the mole's inclined plane nose of the mole creates a net zero force perpendicular to the direction of travel. Therefore, the mole will travel forward, albeit along a slightly spiral path. If the steering fins are depressurized then the fins remain in-line with the drill body, creating no reactive torque. The mole will tend to travel in the vector direction of the soil reaction force on its inclined plane nose.

As the drill hammers itself forward there is about one full rotation of the steering shroud for each drill length advanced, (assuming that the steering fins are pressurized during the entire advance). The Steer-Rite drill used during this technology demonstration was about 6 feet 9.5 inches long. It would create a nominal diameter borehole of about 4.5 inches.

\subsection{GUIDANCE AND STEERING SYSTEM}

The steerability of the pneumatic mole is closely linked to the instrumentation used to locate the mole's position and determine the direction in which the mole is tending to travel. The length of the directional bore was measured using foot markers fixed to the air line carried in by the drill. The depth of the mole was measured using a radio transmitter and detection/timer mounted in a surface walk over device. The length of the borehole and depth of radio sonde were manually recorded on field data logs. The surface location of the radio detection points were preserved by driving a flag into the ground over the point where the radio transmitter was detected. The flag locations were tied back into survey monument points. During the technology demonstrations, a shallow radio sonde capable of transmitting 18 feet through soil was taped to the air cable about 12 inches behind the tail of the mole. This transducer could be replaced with a more powerful radio sonde. The more powerful sonde would fit in a compartment in the drill's nose, allowing the mole's nose position to be detected. This arrangement would allow more precise steering than dragging the radio sonde behind the mole, because the nose of the drill is about eight feet ahead of the radio transmitter when the transmitter is dragged behind.

The tendency of the mole to change depth was determined by the use of a dip angle indicator (accuracy of $+/-0.1^{1}$ ) mounted in a sensor pack rigidly attached to the tail of the drill. The steering direction of the mole was monitored from the output of a tool face roll indicator (accuracy of $+/-5^{\circ}$ ), which was also mounted in the sensor pack. The dip angle and roll indicator were powered by a battery in the command module located at the surface. The command module also housed the LCD data display for the dip angle and analog pointer 
for the roll indicator. A small hand pump for pressurizing the steering fins was mounted on the side of the command module. The photograph in Figure 5 illustrates the location of the pump and each output device. The interpretation of the dip angle and roll indicator details related to the use of the instrumentation output are discussed more fully in the following sub-sections.

\subsubsection{Radio Detection}

The radio detection and transmitter were manufactured by Radiodection, Inc. of the U.K. The boretrace unit used to detect the radio transmission is a hand held unit with internal antennas, timing circuitry, metering and display to pick up a $33 \mathrm{Khz}$ radio transmission. The boretrace model used during these tests was model $33 \mathrm{Kz}$ 10/ML 1021. The photograph in Figure 6 portrays the type of radio detection device and illustrates its use.

\subsubsection{Dip Angle Indicator}

When the mole is diving into the ground the dip angle will be displayed as a negative number on the command console. The magnitude of the dip is relative to a horizontal plane. Positive display angles indicate a mole tending to climb out of the ground. The dip angle indicator must be periodically calibrated prior to use. The was done before the SEG demonstration and also WAG 6. The dip angle calibration charts are contained in Appendix A for the WAG 6 site. In general, the dip angle readout and calibrated values are the same when the mole tool face is oriented in the major clock positions of 12:00 and 6:00. When the mole is oriented at 3:00 and 9:00 there is a slight change in the output and calibration data.

\subsubsection{Tool Face Indicator}

The tool face indicator drives a pointer mounted on a clock face attached to the command module. Tool face indicator corresponds to the large dial mounted within the square frame pictured in the photograph in Figure 5. As the mole rotates there is a direct correspondence between the tool face orientation and the pointer direction. The display pointer indicates the direction in which the mole would tend to steer if the steering fins are depressurized. For instance, if the steering fins are depressurized and the pointer were at the 12:00 position, then the mole would tend to steer upward. If the mole continued in this steering mode (vanes depressurized), then the mole would continue to daylight at a build-up rate of about $1^{0}$ per foot of advance (57 foot radius of curvature). The clock position of 12:00 would not change during this maneuver. The photograph in Figure 7 indicates the relative position of the tool face as it breaks the ground surface. Note that the soil reactive force tended to push against the inclined plane portion of the mole. The tool face indicator was at the $12: 00$ position during this surfacing maneuver.

When the steering vanes are pressurized then the mole tends to travel along a straight line at the dip angle set at the start of the maneuver. The tool face indicator rotates in a counterclockwise fashion through 360 degrees for each drill length of advancement.

\subsection{TOOL MODIFICATIONS FOR ENVIRONMENTAL COMPLIANCE}

The major driving force for this research was the development of an environment-friendly directional drilling system for shallow buried waste. The quality of the environment was not to be compromised by the drilling, i.e., drilling could not introduce contaminants into the surrounding soil. Environmental compliance related to use of lubricants, hydraulic oils, and exhausting of gases from the Steer-Rite mole had to be 
addressed. The following sections discuss the tool and drilling modifications employed to satisfy compliance requirements for drilling in a radiologically-controlled zone.

\subsubsection{Tool Lubricants}

Due to the simplicity of the hammer and short drives required for the WAG 6 shallow buried trenches, the hammer was operated with a dry graphite lubricant rather than oil. First, the tool was run at the surface to assure that no dry lubricant was ejected with the exhaust gas. The simplicity of the hammer design allowed for operation without conventional lubricants. During the SEG demonstration the hammer operated for up to five hours generating $+/-50 \mathrm{~g}$ forces as it tried to penetrate through a compact clay shale. When the hammer was backed out of the borehole and retrieved to the surface, the outside of the hammer was cool to the touch. Therefore, the lack of conventional lubrication did not seem to cause heat generation problems. Elevated tool temperatures were a concern since one of the proposed flight paths for the mole was to traverse within five feet of the bottom of several WAG 6 trenches. If a thermally hot mole inadvertently strayed into trench waste, it could ignite combustibles. Due to the observed low operating temperatures of the mole, there is no concern that the mole could cause a trench fire if it penetrates a waste with low ignition point.

Operation of the hammer without conventional lubricants does not place a severe penalty on long term maintenance costs. The entire Essig hammer (IP 95) could be replaced for approximately $\$ 6,500$ if it were prematurely worn.

\subsubsection{Steering Hydraulic Oil}

The hydraulic system used to pressurize the steering fins on the mole normally used a "bio-degradable" hydraulic oil. If a leak developed in the hydraulic system then there was a likelihood of the fluid being released into the soil. It was deemed more acceptable to use water in-place-of the hydraulic fluid normally used in the Steer-Rite tool. Therefore, if the hydraulic system or steering fin seals leaked during drilling, then only small amounts (several liters) of clean water would be injected into the surrounding soil formation. The term injected is used since the water is typically under about 1,500 psi during a steering maneuver. If a leak developed then the water reservoir mounted on the command console could be refilled periodically. This would allow the steering system of the mole to remain functional if a small leak developed. Obviously, if a leak occurred then the mole would be retrieved to the surface at the earliest possible moment.

The hydraulic fittings used by Steer-Rite for actuating the steering fins are made of carbon steel. These fittings would tend to rust if water was used as the hydraulic fluid. Therefore, all the hydraulic fittings on the mole purchased by MMES were stainless steel.

\subsubsection{Exhaust Gas Confinement}

Preliminary discussions with WAG 6 health physics personnel indicated a need to confine the exhaust gas from the Essig mole. Uncontrolled releases of exhaust gas into the borehole and out into the air were not permitted. There was concern related to release of airborne contaminants as the exhaust gas caused dust to be ejected out the borehole collar. To solve this problem, a stub casing muffler was designed and constructed to control exhaust gases. The muffler design had to accommodate control of the exhaust gases while allowing unrestricted movement of the four lines pulled into the borehole by the mole. Furthermore, since the mole tended to rotate as it bored through the ground, the muffler had to allow the service lines to be periodically rotated so that they would not become entangled. The detailed design and procedures used to deploy the stub casing muffler are discussed in the next two sub-sections. 


\subsubsection{Stub Casing Muffler}

The stub casing muffler was made completely of standard four inch PVC pipe and fittings, which were pressed fit together and held in place by screws. No pipe glue was allowed since the volatile organics of the glue would set off the air detector situated near the borehole collar. The mechanical drawing used to fabricate the stub casing muffler is depicted in Figure 8. The front-end of the muffler consists of a 10 foot section of standard four inch PVC pipe. This is the casing which is initially hammered into the ground by the Steer-Rite mole. Immediately behind this casing is a $\mathrm{T}$ section which is used to attach a supervac hose. The three $45^{\circ}$ $Y$ sections, shown in the figure, were used to pass the compressed air line, instrumentation line and GM cable through the muffler. The steel pull-in cable passed directly out the end of the muffler. The steel cable was oriented coaxially with the muffler to minimize eccentricity and misalignment when the mole pulled the muffler into the ground.

All four service cables were threaded through a split rubber stopper which was wedged into holes drilled through the caps of the PVC pipe. The rubber stoppers were split so that the connectors of each service line could be slipped through the stopper, and then jam the stopper back into the hole to re-establish an air tight seal.

\subsubsection{Deployment of Stub Casing Muffler}

The strategy used to deploy the stub casing muffler was to have the mole hammer itself into the ground until about a foot of the mole's tail was exposed at the surface, see photograph in Figure 9.1. The tail of the mole is sufficiently above the ground such that no dust is generated by the exhaust gas. The mole would then be turned off, and the stub casing muffler attached to the back end of the drill, as illustrated in Figure 9.2. The drill had a 5/16 inch diameter stainless steel pull-in cable attached to its tail. This cable was pulled through the stub casing muffler and clamped to the end of the casing shown in Figure $9 \mathrm{c}$. The steel cable is coaxial with the muffler so that no eccentricity is created as the mole pulls the muffler into the ground. The other service lines depicted in the photograph are: a $1 / 4$ inch geiger mueller cable, instrumentation cable for dip and roll, and air pressure line. Each service cable has a split rubber stopper which is jammed into the opening of each arm of the muffler. The stopper forms an air tight seal, while also allowing cable connectors to pass through the arm of each muffler. A super vacuum was attached to the front-end of the muffler so that it would intercept any exhaust gas ejected from the mole The supervac capacity was $200 \mathrm{scfm}$, which is about double the air supplied to the mole. The exhaust gas and particulates captured by the supervac were passed through a HEPA filter system. Once the muffler was tied to the mole the supervac was engaged and the mole turned on. The mole continued to hammer itself and the stub casing muffler into the ground until about 7 feet of the casing were in the ground. The retaining clamp at the end of the muffler was released from the pull in cable. The mole was then allowed to bore freely through the ground, along the flight path specified for the borehole. The body of the mole periodically rotated to accomplish particular steering maneuvers, for instance if the mole had to bore along a straight line. To minimize the potential for the service cables to become entangled the stub casing muffler had to be periodically rotated to untangle the service cables.

The photographs in Figure 10a and $b$ illustrate the type of swipe samples sued to obtain a gross gamma count from the exhaust ejected from the stub casing muffler. 


\subsection{SEAMIST MEMBRANE TECHNOLOGY}

Mr. Carl Keller, formerly of Science \& Engineering Associates (SEA), invented the Membrane, Instrumentation, and Sampling Technique (MIST) for rapid deployment of instrumentation through cased or self-supporting boreholes, hence the patented tradename SEA_MIST. More recently, the patent rights to the SEAMIST technology have been purchased by Eastman Cherrington, of Houston, Texas. This directional drilling company is the sole fabricator and distributor of the membrane technology. Although the SEAMIST technology had to be procured on a sole source basis the unique nature of the technology has significant advantages for site characterization and environmental restoration activities related to shallow buried waste. The combination of horizontal directional drilling and the SEAMIST technology allow deployment and retrieval of various packages beneath shallow buried waste. These two technologies lead to a strategy which is . . . never plug and abandon a horizontal borehole, but rather, adapt the borehole to future restoration needs .... The ability to change the restoration activity with time permits significant reduction in the initial cost of the horizontal borehole, and possibly cost reductions in the environmental restoration activities. The following discussion will describe the general features of the SEAMIST membrane, advantages/limitations, and application with horizontal directional drilling to support site characterization and environmental restoration activities for shallow buried waste.

\subsubsection{General Description}

The SEAMIST membrane technology consists of relatively simple pieces such as: a long cylindrical membrane, a storage canister, and a cord/tether which ties the membrane and storage canister together. The assembly procedure for the SEAMIST membrane requires running a continuous cord from a winching sled through the inside of the storage canister and out to a pressure fitting at the tip of the SEAMIST membrane (depicted in Figure 11a). The right end of the membrane is attached to the storage canister by using a wellhead fitting. The left end of the membrane is sealed with a pressure fitting, which also allows attachment of the cord inside of the membrane. The free end of the cord and open end of the canister are attached to a special winching sled. This device allows compressed air to fill the canister, thus inflating the membrane. The membrane is loaded into the storage canister, by cranking on the tether, which causes the membrane to be pulled inside of itself, see Figure 11b).

\subsubsection{Equipment To Deploy SEAMIST}

The equipment used to deploy the SEAMIST membrane at WAG 6 are contained in the series of photographs contained Figure 12.1 to 12.4. The first photograph illustrates the winching sled used to crank the cord and membrane into or out of the borehole. The cord is wound around a winch, and then passes through several blocks until the cord is located coaxially with the hose canister shown in the foreground of the photograph. The cord enters the fire hose canister through a pressure fitting. The hose canister is attached to the front-of the winching sled via a camlok connection. Compressed air is feed into the canister near the camlok fitting. The hose canister then extends from the winching sled toward the collar of the borehole for a length equal to that of the membrane. An overall view of the hose canister and winching sled can be see in the photograph in Figure 12.2. The hose canister terminates at the camlok fitting connected to the right hand side of the wellhead shown in the photograph of Figure 12.3. The collar of the borehole is lined with a standard four diameter piece of PVC which has a six inch belled end. The bell end of the PVC has a flange connection pushed into the bell, which is identified by an arrow in the photograph in Figure 12.3. The open end of the SEAMIST membrane is attached to this flange using a series of hose clamps. The air hose attached to the flange connection in Figure 12.3 is used as a secondary source of compressed air to keep the SEAMIST membrane inflated when the hose canister is disconnected from the wellhead. The SEAMIST membrane and 
cord pass through the bell end of the PVC, and are deployed inside of the horizontal borehole. The inflated membrane, shown in Figure 12d, has broken through to the surface at the original entry point of boring (i.e. initial penetration point for Steer-Rite drill).

For the WAG 6 demonstration a continuous cotton absorber was attached to the outside of the SEAMIST membrane. This allowed a continuous soil smear to be obtained along the entire length of the borehole. The cotton absorber approach for obtaining samples is only possible due to the retrievability of the SEAMIST membrane. Other unique features of the membrane are discussed in the following sub-section, along with several limitations of the technology.

\subsubsection{Advantages/Limitation of SEAMIST Technology}

The major limitation associated with the SEAMIST technology is associated with the need for the borehole to remain open so that the membrane can be deployed into the hole. Installation of SEAMIST into an unstable vertical borehole is a challenge since it is difficult to install SEAMIST while simultaneously pulling the casing out of the hole. A horizontal borehole allows a relatively straight forward installation of SEAMIST if the horizontal hole is drilled with an entry and exit hole. In this manner casing can be pulled out of the borehole while the SEAMIST membrane is simultaneously deployed through the other open end of the borehole. In the case of the WAG 6 demonstration the saprolite residuum soil was relatively stabile and the borehole only had some slight caving in of the soil. Collapsed soil debris was recompacted against the sidewalls of the borehole by pulling in a short piece of pipe ahead of the SEAMIST membrane.

The SEAMIST membrane technology has several other unique features which makes it an important companion to horizontal directional drilling. The final stage of installing a horizontal well is associated with lining the borehole. Conventional well completion technology typically involves dragging a perforated casing through the borehole, and leaving the casing in the ground to form a well. Pull back of a casing into the borehole can generate large tensile stresses in the casing due to sidewall friction. If the tensile forces are large due to long boreholes or tight radii of curvature then the well casing may tear apart. Furthermore, large tensile forces require a slant drill rig at the surface with enough power to overcome the imposed forces on the casing. Conversely, the SEAMIST membrane is "everted" through the borehole such that the membrane is merely ejected outside of itself. Once the membrane contacts the soil there is no additional relative displacement between the membrane and soil. The method of "everting" the SEAMIST membrane requires use of a small air compressor. If the SEAMIST membrane is deployed into a shallow dry borehole then the air pressure is relatively low (5 psi). Larger air pressures are required to overcome static water pressure, if present in the borehole.

The inflated SEAMISTmembrane can follow any regular or irregular horizontal directional borehole. The SEAMIST membrane is an excellent choice for well completion for boreholes with tight radii of curvature. The Steer-Rite mole bored a hole with radii of curvature which varied from about 40 to 1000 feet. The SEAMIST membrane had no difficulty lining the irregular hole bored and required only 15 minutes to line the 92 foot long hole drilled at WAG 6.

The SEAMIST technology offers great flexibility in the type of and spatial interval over which samples can be extracted from a horizontal borehole. At WAG 6 a continuous cotton absorber was attached to the outside of a solid SEAMIST membrane. In this manner soil smear samples could be collected along the entire borehole length. No prejudice was involved with selecting the initial location for extracting samples. The sampling strategy is to retrieve the cotton absorber while simultaneously shuttling in a second SEAMIST membrane into the hole vacated by the first membrane. The extracted cotton absorber will be analyzed for 
contamination. The solid SEAMIST membrane will be retro-fitted with appropriate sampling devices (lysimeters, water sampling ports, etc.) to obtain discrete samples at the locations where contamination was detected by the cotton absorber. The SEAMIST membrane isolates each individual sampling port so that a better definition of the spatial distribution of contaminants is obtained. It was planned to extract the first SEAMIST membrane at WAG 6 in early Summer 1995, while installing a second membrane with a continuous cotton absorber.

The above discussion shows how the SEAMIST membrane can be easily integrated into a horizontal borehole sampling plan. The additional attraction of SEAMIST is the manner in which the integrity of the samples are preserved in the field and level of worker protection. When deploying and retrieving a membrane all contaminated samples are either underground or inside of its storage canister. Thus sampling can be achieved in an ALARA manner. When the SEAMIST membrane is pulled back into its canister the surface in contact with the contaminated soil is not in contact with the walls of the canister. Therefore, as long as the membrane remains intact, the storage canister cannot become contaminated. There is no cross contamination of samples since the samples are wrapped inside the SEAMIST membrane and never come into direct contact with other sections of the membrane. 


\section{DIRECTIONAL DRILLING DEMONSTRATIONS AT SEG AND WAG 6 SITES}

One of the primary purposes of this technology demonstration was to examine the Steer-Rite directional drill's ability to penetrate the soil formations which lie beneath the trenches at WAG 6 . These soil types varied between a shallow overburden of residuum called saprolite, to weathered shales at the overburden/soil contact. It was understood from the beginning that the Steer-Rite mole could not penetrate weathered rock. However, it was of interest to examine how slowly the mole progressed through compacted clay shale, and whether or not the mole could be drilled along the overburden / rock contact zone. This zone is believed to be a major zone for transport of contaminants and would be an important place to deploy a SEAMIST sampling membrane. Other objectives of the demonstration which required quantificationare listed below:

(1) Test the ability of the Steer-Rite tool to penetrate the WAG 6 soil formation and be steered along a predetermined path.

(2) Examine the accuracy with which a low cost radio detection navigation system can monitor the real time position of the tool as it penetrates the ground. Comparisons were made to a magnetometer survey which is considered a more accurate method to survey a horizontal borehole.

(3) Conduct the demonstration without generating any spoil (liquid,soil), and minimize other waste handling associated with the work.

(4) Deploy a SEAMIST membrane through a horizontal borehole with exit and entry points at the surface. Shuttle a large sonde (magnetometer) through the pressurized SEAMIST membrane.

Two test sites were selected for the directional drilling demonstration. The first site was located at the SEG Bear Creek Valley facility, shown previously on the site location map in Figure 1. The soils stratigraphy at the SEG site was predominately compact clay shale, which had standard penetration counts of $80+$ within the top five feet of the soil profile. Since the SEG site was uncontaminated this site was considered as a dress rehearsal so that all the production workers (drillers, helpers) and site safety people could become familiar with the various activities and how the actual process worked. The main drilling demonstration was conducted in a radiologic control zone within the confines of the WAG 6 trench disposal area. All work conducted at WAG 6 was performed in conformance to an approved health and safety plan.

An important aspect of the drilling demonstration was related to establishing performance criteria prior to conducting the work. These criteria allowed an unbiased evaluation of the results from the demonstration. These criteria were only applicable to the WAG 6 site, since the SEG demonstration was only a dress rehearsal.

\subsection{HORIZONTAL TEST BORE AT THE SEG SITE}

The SEG demonstration was conducted over two and one-half days from August 10, 1994 to August 12, 1994. The SEG demonstration represented the first time in which all the components of the directional drilling research were brought together at a single site. This allowed the drill operator and all support help to become familiar with the activities associated with handling the mole's service lines, controlling the exhaust gas through the stub casing muffler, and make sure that all equipment was functional prior to mobilizing to the 
radiologic zone at WAG 6 . During this time the health physicist and site safety officer reviewed the work rules for conducting the drilling operation and also critique the drilling operation under actual working conditions.

The initial intent for SEG drilling demonstration was to install a borehole with a length of about 80 feet, down to a maximum depth of about 10 feet. However, the Steer-Rite mole could not bore this flight path due to the compact clay shale which was encountered within the top five feet of the soil horizon. The mole could only penetrate for a distance of about 24 feet along the borehole, with a maximum depth of nearly 5.4 feet. Although the Steer-Rite drill did not complete the required drilling, the following information was collected:

(1) when the drill's progress had slowed to a snail's pace (about an inch per minute), its path could be redirected by backing the drill up and rolling it over. This maneuver would allow the mole to climb out of the highly resistant material, and to increase its forward progress. This is an important maneuver if the mole is to bore along the contact between the overburden and shale formation at WAG 6.

(2) The maximum penetration rate for the mole boring through $80+$ blow count compact clay shale was about 2 inches per 15 minutes of drilling. This penetration rate would require about 7 days of continuous impact boring to form a 100 foot long hole. Obviously this penetration rate is not within acceptable limits.

(3) The mole was retrieved from the ground by placing it into reverse. It then began to pound itself out of the ground along the 24 foot long path. The mole was used to hammer the stub casing muffler from the ground. The muffler was removed from the hole collar when the mole still had about 8 feet to bore. When the muffler was removed the tail of the mole became misaligned and began plowing the ground. A shallow pit had to be dug to unblock the tail of the mole and allow the mole to hammer itself out. Attempts were made to pull the mole out of the ground using the 5/16 inch diameter steel cable attached to the mole. This proved to be an ineffective means for assisting the mole out of the ground. It is much better to assure that the borehole stays open and then use the mole's own power to retrieve the tool from the ground.

(4) No surface soil was disturbed nor any soil cuttings were brought to the surface.

(5) The exhaust gas from the stub casing muffler was not totally confined by the muffler and supervac. The health physicist notified all workers that there would be very careful air monitoring upon start-up of the drilling at WAG 6 . If airborne contaminants were detected then they would upgrade the site to Level C with air purifying respirators.

(6) The geiger mueller counter pulled in by the Steer-Rite was functional over about 5 hours of borehole drilling. Only background reading were recorded.

\subsection{DIRECTIONAL DRILLING DEMONSTRATION AT WAG 6}

The general site location plan for WAG 6 is presented in Figure 13. The directional drilling test site is located in the northwest quadrant of WAG 6 at the edge of the West Waste Disposal Area. This area was selected for the test since there are a limited number of sources of contamination which could pass through the test area. It would be relatively straight forward to identify which trenches were the most probable source of contamination. The inventory of the closest trench cluster indicated that there were significant levels of 
tritium disposed into the trenches identified as $277,282,290,293$, and 304 in Table 1, with the greatest source of tritium (273 curies) disposed into Trench 304 . If general radiation scans of samples indicated radioactivity, then the rad-chemistry for the research could be limited to tritium scans. Unlike the SEG site which had compact clay shale near the surface, the WAG 6 test area has soil conditions which appear to be more favorable for demonstrating impact boring. Generally, the soil profile should consist of a shallow overburden typically a residuum (saprolite), which is underlain by varying layers of weathered shale. Bedrock should be at a depth of about 20 feet below the surface in the test area or at about El. 785. Due to a mishap in the drilling program a shallow test pit had to be dug. This open pit revealed a soil strata totally different from the expected saprolite. The pit excavation uncovered a soft to medium stiff wet organic clay layer. The impact the changed soil conditions had on the drilling are discussed in subsequent sections.

\subsection{WAG 6 DEMONSTRATION PERFORMANCE CRITERIA}

Prior to performing the technology demonstration a prescribed flight path was selected for the WAG 6 test, see next section for discussion. The flight path served as a basis for evaluating the ability of the SteerRite mole to be guided along a certain path. Another important performance criteria would be that the borehole formed by the Steer-Rite drill would be able to accommodate a SEAMIST membrane as the well completion technique. An evaluation of the SEAMIST membrane involved whether or not a sonde could be pulled through and retrieved out of the membrane. The specific criteria used to evaluate the performance of the Steer-Rite mole and SEAMIST membrane included the following:

(1). Drilling Accuracy: The mole should always stay within $+/-24$ inches of the prescribed flight path for its entire length and termination point.

(2). Penetration of WAG 6 Soil: Should demonstrate that the Steer-Rite drill posses enough power to penetrate the soil formation within the top 15 feet of WAG 6. A 100 foot long borehole should take a maximum of two days to complete

(3). Waste Management: The mole should be surfaced launched and retrieved (i.e. no starting or retrieval pit excavation), and complete the bore without generating any spoil to the surface.

(4). SEAMIST Membrane: Should demonstrate that the SEAMIST membrane can be installed into borehole created using Steer-Rite drill. Should also show that a magnetometer survey can be conducted inside a pressurized membrane, and that membrane can maintain the integrity of the borehole.

If all these criteria could be satisfied, then the Steer-Rite mole and activities associated with the SEAMIST membrane would be considered appropriate for use in the WAG 6 stratigraphy. The mole would possess enough power and installation speed to be a candidate drill for installing directional drilled holes beneath WAG 6 trenches. Boreholes under trenches would support an important suite of environmental restoration technologies, leachate collection, bottom-up in situ vitrification (ISV), grout bottom seal.

\subsection{PRESCRIBED FLIGHT PATH}

The original borehole orientation for this technology demonstration had two flight paths specified at WAG 6. One path was planned to be about 25 feet deep and 200 feet long and be installed along the southern edges of the 277-282-290-293-304 trench group shown in Figure 14. Installation of a directional bore beneath 
a trench was viewed as an activity which would support environmental restoration activities of shallow buried waste. However, the proposed location of the directional bores would have complicated the data analysis/reduction of an ongoing intra-trench water level monitoring program by the Environmental Sciences Division (ESD). Therefore, a second set of test bores had to be planned.

The new set of directional bores were still conducted in the general area of trenches 277-282-290-293304. The plan location of the new bores was approximately twenty-five feet to the south (from true north) of trench 277 shown on the WAG 6 location plan in Figure 14. Both bores were planned to be coplanar and thus had the same well orientation, which was South $53^{\circ}$ East. The orientation of these wells was selected so that each well could intercept leachate migrating out of the adjacent trench cluster. The shorter (about 70 feet) and shallower bore (10 feet) was drilled first (No. 1), and was planned to intercept any leachate migration which was transported due to shallow storm flow through the adjacent upland trenches. The second longer ( 180 feet) and deeper ( 20 feet) borehole was to be drill along the contact of the overburden and weathered shale. Hydrogeologists have indicated that the deeper migration route of contaminants is strike parallel to the bedding planes of the residuum saprolite and bedrock, which strikes off at about N $45^{\circ} \mathrm{E}$ with a dip of 20 to 40 degrees to the southeast, (see insert in Figure 14). Thus the deeper borehole was planned to intercept strike parallel flow at the overburden/rock contact. Unfortunately, the second deeper test bore was never installed during the demonstration. During the first borehole installation, the drill inadvertently went into reverse and required a shallow pit to be dug in order to rescue the drill. Since the drill did not satisfy all the required criteria specified under Section 3.3, drilling the second borehole was not deemed to be warranted.

The remaining details of specifying the flight path planned for Test Bore No. 1 is related to the radius of curvature and elevation changes of the flight path which are drawn in Figure 15. The borehole installation starts at the surface (El. 804) and penetrates the ground at an angle of $35^{\circ}$. The drill continues along this straight line trajectory for about 16 feet. This will allow the mole to gain depth and permit installation of the straight 10 feet section of the stub casing muffler. Thereafter, the drill would commence a steering maneuver to create a 36.6 foot long path with a radius of curvature of 65 feet. At the end of the curved section the mole would steer along another 16 foot straight section and break ground at an angle of about $18^{\circ}$. The total planned flight path was about 68.6 feet.

The projected outline of the adjacent trenches (277-282-290-293-304) has been superimposed upon the elevation view of the prescribed flight path (Figure 15). The outline of the trenches was drawn by projecting a perpendicular line from the prescribed flight path to the corners of each trench. Since the ground surface of the trenches is above the ground surface of the test section, the upper portion of the trenches plots above the ground surface of the test section in Figure 15. The invert elevation of the trenches is at a 15 foot depth. The majority of the directional bore intercepts the mid-section of Trench 277 , and portions of trenches 282 290. If contamination is detected then it should be straight forward to ascribe which section of these trenches represents the source of contamination.

\subsubsection{Survey Controls}

Survey controls had to be established into order to relate the directional drilled path measured using the radio detection device to that measured using the magnetometer. The radio detection device data used as a reference origin point 55 shown on the survey plan in Figure 16. The ORNL grid coordinates of this point corresponded to 16977.1536 North, 23732.0331 East, with a ground surface elevation of 804.0115. The orientation of the $X$ axes which defined the plan location of the flight path had its orientation defined by point 55 and 56. The $Y$ offset distance corresponds to a perpendicular line to the $X$ axe, $(X-Y$ is the local coordinate axis system used to reference the radio detection measurements). 
The other survey control points shown in Figure 16 were used to determine the ground surface elevation for calculating the flight paths using radio detection and magnetometer data.

\subsection{SITE LAYOUT AND SUPPORT STAFF}

The WAG 6 test site was in a radiologic controlled zone. As such very specific health, safety and control of worker location had to be exercised. The active drilling area for the first test bore was roped off with Hazwoper tape to form a corridor which was about 25 feet wide by 125 feet long. The size of the exclusion zone in relationship to the test bore can be seem in the photograph in Figure 17. Entry into and out of the exclusion zone was controlled by a step off mat, located by the yellow disposal bags on the left side of the photograph. The stub casing muffler was situated in the middle of the exclusion zone. The supervac and air monitor were within a few feet of the stub casing muffler, as shown in the photograph in Figure 18.

Typically, there were from two to four workers within the exclusion zone at any time, with the site health physicists or safety officer as an escort. All work was conducted in Level D with company provided clothing. The two laborers within the exclusion zone were responsible for keeping the service lines to the mole in good order. Periodically, the surveyor would make radio detection soundings to locate the mole and place flags on the ground to mark the surface location of the mole.

All other supporting staff and equipment were located in the clean zone, which included: the Steer-Rite drill operator and command console, air compressor to operate the drill, SEAMIST membrane storage canister and winching sled, and winching truck

\subsection{SEQUENCE OF DRILLING ACTIVITIES ON WAG 6}

The sequence of activities executed at WAG 6 to drill the horizontal boreholes and install the SEAMIST membrane are drawn in the sketch in Figure 19. The six activities illustrated in this figure are:

(1). Surface launch of the Steer-Rite drill with an initial ground penetration until about a foot of the mole's tail is still protruding above the ground. This action will assure that no exhaust gas creates an airborne hazard prior to installing the stub casing muffler.

(2). The stub casing muffler is then attached to the tail of mole. The supervacs are engaged and the mole recommences boring. The specific details of installing the stub casing muffler were described previously in Section 2.3.3.2.

(3). The mole bores along the prescribed flight path, carrying along all the service lines, steel pull back cable, and frankfurter geiger mueller probe.

(4). Once the mole completes the drilling the pull-back cable is attached to a short piece of pipe, referred to as a "pig" in Figure 19d. This device is used to clear the borehole of any collapsed soil debris which may lie in the path of the SEAMIST membrane.

(5). Use compressed air to deploy the SEAMIST membrane while simultaneously pulling the "pig" through the borehole using a winch truck. 
(6). Perform a magnetometer survey of the borehole geometry lined with the pressurized SEAMIST membrane.

\subsection{EXECUTION OF WAG 6 TEST BORE}

The execution of the first test bore commenced at WAG 6 on August 17, 1994 at 9:00 a.m. The set of imposed vane pressures (col. 3) and tool face orientations (col. 2) measured along the length of borehole (col. 4) are summarized on Table 2, along with the measured dip angle (col. 5) of the mole. This table also contains the values for the depth of the radio sonde (col. 9) and coordinate locations which define the spatial location of the radio sonde data. The $\mathrm{X}$ data points (col. 7) correspond to the horizontal distance down range from the collar of the borehole. The $Y$ distances (col 8) are the transverse offset of the radio sonde, with negative values corresponding to a position which is downhill of the prescribed flight path. The origin of the X-Y coordinate axes was defined by the stake location which marked the collar of the borehole (Stake 55). The orientation of the X-Y axes was set by the direction of Stakes 55 - 56 which established the prescribed flight path in the down range direction (see Section 3.4.1 for survey controls setup for the test site). The ground surface elevations (col. 6) correspond to the elevations calculated at the radio sonde detection points. The methodology and data used to calculate the ground elevations at the radio detection points is summarize on the tables contained in Appendix B.

For ease in visualizing the movement of the mole and steering maneuvers used to guide the mole the plan view and vertical section (elevation) of the flight path measured using the radio detection device has been superimposed over the prescribed flight path plotted on Figure 20. The borehole lengths cited in the following discussion (Table 2) correspond to the length of the compressed air hose attached to the Steer-Rite drill plus the length of the mole itself, which was about 6.8 feet. The $X-Y$ distances cited in Table 2 correspond to the location of the radio sonde which was attached to the tail of the mole, i.e. borehole length and radio sonde location are about 8 feet apart.

It should also be noted that the ground surface elevation over the course of the flight path dropped by about 6.5 feet (EI. 804 to 797.6) over a length of 65 feet. Therefore, the drill had to dive at least 6.5 feet to remain just under the ground surface.

\subsubsection{Borehole Length: 0-16 Feet}

The mole was initially hammered into the ground at the entry point of No. 1 bore (Figure 20) with the tool face oriented at 12:00 and the vanes depressurized. The tool made an initial angle of about 35 degrees with the ground surface, and was pointed down range along the $X$ coordinate axes. After 6.0 feet of penetration the tool face was still pointed in the 12:00 position while the dip angle had decreased from -35 to about -29 degrees, (see Table 2, col $2 \& 5$ ). Since the vanes were not pressurized between drilling lengths of 6.0 to 16.0 feet the mole tended to steer into a flatter angle of -11.3 degrees. This allowed the stub casing muffler to be installed without rotating the mole, i.e. stub casing muffler attached to mole after six feet of penetration.

\subsubsection{Borehole Length: 16 - 32 feet}

Starting at 16 feet of penetration ( $X$ distance of about 8 feet) the vanes were pressurized ( $1000 \mathrm{psi}$ ) so that the mole would begin to dive at a nearly constant angle. The actual dip angle varied between -11.3 to -7.3 
degrees over the interval of 16 to 32 feet, which was due in part to the wobbly nature in which the moles steers a straight course.

At 23 feet into the bore $(X=15$ feet), a radio sonde reading was taken which indicated that the mole was at a depth of about 3.7 feet. The mole had actually dived 5.1 feet below the ground surface elevation of the entry point. The radio detection readings indicated that the mole was starting to veer downhill with a $\mathrm{Y}$ offset distance of about 1.1 feet (near Stake No. 62). The $Y$ offset measured with the radio detection device is plotted in the plan view drawn in the upper half of Figure 20.

From 23 to 32 feet the mole dove into the ground at a nearly constant angle of around 7 to 8 degrees. Since the vanes were pressurized $(+2000 \mathrm{psi})$ the mole continuously rolled in a counterclockwise fashion from the 3:00 position to the 9:00 position. Once in this orientation the vanes could be depressurized so that the mole would steer downward (6:00 position) and gain depth more quickly

When the mole was 27 feet into the test bore ( $X=20$ feet) a problem developed with the geiger mueller counter. The needle on the readout device pegged off scale at about 50,000 dpm. This caused concern since this was the first time that the GM probe had recorded gross gamma counts above background, which was typically below $40 \mathrm{dpm}$. The health physicist closely monitored the exhaust gas for gross gamma readings( see previous photograph in Figure 10), but did not obtain any readings above background. The HP determined that the GM probe probably had malfunctioned and that it was not giving correct readings. The boring continued under close watch of the health physicists. After the test the GM probe was retrieved from the ground. It appeared that the Steer-Rite tool vibration ( $+/-50 \mathrm{~g}$ 's) over an extended period of several days of testing (SEG \& WAG 6) is to extreme an environment for the GM probe to remain functional.

\subsubsection{Borehole Length: $32-46$ feet}

Over the borehole length interval of 32 to 46 feet the mole bored ahead at nearly the same tool face orientation (about 7:00), since the vanes were depressurized. This also allowed the mole to gain diving angle which increased from -7 to around -13 degrees.

After 43 feet into the bore ( $X=35$ feet) the mole was only 4.3 feet below the surface. The apparent slow gain in depth is due to the sloping ground surface which has dropped from El 804 at the borehole collar to El. 800.5. Therefore, the mole has actually dropped about 7.8 vertical feet over the 43 feet of borehole length.

The radio detection survey indicated that the mole was veering more severely downhill. At 43 feet (borehole length) the $\mathrm{Y}$ offset distance is nearly 3 feet downhill from the prescribed location shown in Figure 20.

\subsubsection{Borehole Length: $46-52$ feet}

Over this interval the vane pressures were increased $(+2000 \mathrm{psi})$ and the mole dove at a nearly constant angle of -10 degrees. In order to keep the dip angle constant the mole had to rotate in a counterclockwise fashion from the $8: 00$ position to the $9: 30$ position. This is nearly a complete revolution ( 360 degrees) of the mole. It appears to take one length of the mole to achieve a 360 degree rotation of the mole, $(52-46=6$ feet is nearly the same length as the mole). 
Over this short interval the mole gained momentum in its downhill slide veering farther and farther away from the specified flight path. The surface survey flag near Stake No. 77 (X $=40$ feet) is nearly 5 feet downhill from the prescribed location.

\subsubsection{Borehole Length: 52 - 63 feet}

Since the mole was tending to continually veer more and more downhill, the Steer-Rite driller attempted to make a left hand turn which would cause the mole to steer uphill toward the specified flight path. The maneuver started at 53 feet by depressurizing the vanes when the mole was at the 8:00 position, This orientation would also allow the mole to increase its depth at a faster rate (dip angle increase from -9 to -13.8 degrees).

At the end of this interval the mole had stabilized its downhill sliding at a distance of about 5.9 feet $(\mathrm{X}$ $=55$ feet). Furthermore, the mole was now at its deepest point, nearly 5.6 feet below the surface, and 11.3 feet below the entry collar of the borehole.

\subsubsection{Borehole Length: 63-64.5 feet}

Over this 1.5 foot interval the mole was continuously driven forward and then put into reverse in an effort to unlock the steering fins. It was the opinion of the Steer-Rite operator that when the fins were depressurized they did not fully retract. This he believed was due to the use of water to actuate the fins instead of the oil based fluid typically used in the pressurized system.

\subsubsection{Borehole Length: $64.5-80$ feet}

Since the length of the borehole was getting close to the end of the prescribed flight path, it was decided to put the mole into a climbing mode. Therefore, at 64.5 feet the vanes were depressurized with the tool face oriented at 12:00. This allowed the mole to climb upward at an increasing rate (from -6.5 to +5.4 degrees).

At 73 feet the mole started to rotate counterclockwise from the 12:00 toward the 10:30 position. It appears that the steering fins were partially locked since the mole was rolling. A backing maneuver was performed to try and unlock the steering fins. The mole was reoriented into the 1:00 position. Thereafter, the steering fins were depressurized and the mole gained altitude at an increasing rate. At 80 feet the dip angle was measured as +17.1 degrees.

Over this interval the downhill sliding of the mole slowed and remained stabilized at a distance of about 6 feet from the $X$ axes.

\subsubsection{Mole Trapped Below Ground}

The last data set (vane pressure, roll, dip angle) listed on Table 2 was recorded at 16:25 on August 17, 1994. In order to obtain stable readings the air supply to the mole must be turned off, if not the vibration of the drill causes fluctuations in the dip and roll angle values. When the air supply line was reopened the mole did not appear to be advancing through the ground, i.e. air supply line not pulled into borehole. After checking the equipment for malfunction, the Steer-Rite operator determined that the drill had inadvertently been placed into reverse mode. This action would occur if the air supply line were put into tension during the drilling. When the mole was shut down for instrumentation readings, then the tension in the air line reset the valve inside the mole to make it go into reverse. It appears that the tension in the air lines was created by 
partial collapse of soil into the borehole and onto the air line. It appears to have been a partial collapse since exhaust gas was still being ejected through the stub casing muffler.

\subsubsection{Rescue of Mole, Completion of Test Bore}

Several attempts were made to pull on the air line to reset the valve on the Essig mole and place the tool into a forward mode of operation. However, the compressed air line was very elastic and typically had to be stretched by about 10 to 15 feet before the stretching stopped. The extreme elasticity of the air hose would make it difficult to cause movement of the partially buried air line which would then cause movement of the air line to reset the value in the tail of the mole.

The next morning (8/18/94) the compressed air was again turned on, but the mole was still in reverse mode of operation. Since the mole could not be placed into a forward motion it was decided to try and back the mole out of the $\mathbf{8 0}$ foot long borehole. The initial attempt to try and back the mole out under its own power produced limited results. The mole only backed up by a few feet. A truck winch (estimated 5,000\# pull capacity) was attached to the 5/16 inch steel cable attached to the mole. The combined force of the mole's hammer and pull by the truck winch were not sufficient to back the mole more than a few feet.

It was decided that a shallow pit should be dug to expose the tail of the mole and manually reset the valve to place the mole in a forward motion. The site health and safety officer developed an excavation work plan and obtained the required approvals to perform the excavation. The excavation commenced on the afternoon of 8/18/94 using the excavator shown in the photograph in Figure 21. Two health physicists and the site safety officer were the only workers allowed next to the trenches during the excavation. Gross gamma and HNu scans were periodically performed within the excavated area. Periodically a radio detection scan was performed to determine the additional soil required for removal. In the top 3.7 feet reworked saprolite fill was encountered, then a sudden change in soil type occurred. The excavator become to remove a wet, gray, organic smelling clayey silt, which appeared to have a soft to medium stiff consistency, see photograph in Figure 22. After removing another 18 inches of the organic soil, the backhoe uncovered a tree trunk, about four inches in diameter. This tree lay across the path of the mole and could have caused the air lines to become snagged on its branches. It appears that this area of WAG 6 was once a marshy area which was leveled and then had fill placed over the organic soil.

The excavation continued until the pit was about seven feet deep ( 84 inches) by 4 feet wide and 15 feet long. Pieces of highly weathered shale was encountered in the floor of the pit. The walls of the pit stood vertical for the entire time ( 5 hours) the excavation was open. The unbraced height of the excavation indicates the organic soil had to have an unconfined compression strength of at least $300 \mathrm{psf}$, a soft consistency.

Once the tail of the mole was exposed in the floor of the pit, a shovel with an extended handle was used to press down on the airline, shown in the left foreground of the photograph in Figure 22. This action pulled the airline back and reset the valve into a forward motion.

When the mole was re-started it did not initially move forward, but rather just oscillated back and forth at the bottom of the pit. This was due to the lack of side shear on the mole, which is needed to keep the mole from slipping backwards as it tries to hammer itself forward into the ground. The tip of the extended shovel had to apply some normal force to increase the side friction on the body of the tool. Thereafter, the mole gripped the soil and moved forward, hammering itself out of the ground. It only took another 15 minutes for the mole to complete the test bore. If the mole had not been turned off to take a final instrumentation reading, 
it is believed that the tool would have hammered itself out of the ground, and there would have been no need for the excavated pit.

When the mole surfaced the health physicist tool swipes of the tool body and determined that there was no gross gamma surface radiation on the Steer-Rite tool.

The excavation was secured with barriers and signage, and work ceased for the day (8/18/94) at around $18: 30$

\subsection{INSTALLATION OF SEAMIST MEMBRANE}

There were two horizontal bores (70 and 180 feet long) originally planned for the WAG 6 demonstration. This required two SEAMIST membranes which were 110 and 225 feet long. Each membrane was about 5.5 inches in diameter, and was manufactured of 200 denier nylon which was urethane coated. Due to the mishap with the Steer-Rite drill, only the 110 foot long SEAMIST membrane was installed inside a 91.7 foot long borehole. This length was measured during the magnetometer survey of the borehole. The 110 foot long membrane had a 60 foot long flannel cotton absorber (wick sampler), attached to the outside of the membrane. There was a break in the cotton flannel absorber every 10 feet, with the break being about 4 four inches. The photograph in Figure 23 shows the cotton absorber and the break point exposed inside the pit use to rescue the Steer-Rite drill. This photograph was taken from the downhill side where the backhoe was setup, note backhoe teeth in the wall of the pit. The SEAMIST membrane continues through this wall and along the borehole, until it exits at the original collar of the borehole. The photograph, shown previously in Figure 12d, shows about 16 feet of membrane sticking out the original entry point of the borehole. The 16 feet was calculated as: 91.7 foot borehole +2.3 feet attached to the wellhead at the exit point +16 feet at entry point $=110$ foot long membrane.

The membrane, shown in Figure 12d, cuts across the exclusion control zone and into the clean zone. Therefore, the extra long membrane allowed the preparation for the magnetometer survey to be performed by workers operating in the clean zone. It should be noted that the exposed surface of the SEAMIST membrane handled by the workers had never come into soil contact as it was deployed through the borehole.

The SEAMIST membrane exposed in the rescue pit was covered with a piece of four inch PVC cut in half along the longitudinal direction. The PVC was then covered with a lean mix of concrete, and all the excavated soil was placed back into the pit. No excavated soil had to be removed from the site since no contamination was detected.

The detailed procedures and equipment used to deploy the SEAMIST membrane into the borehole has been previously discussed under Section 2.4 . The activities used to deploy the SEAMIST membrane were previously illustrated in Figure 12.

\subsubsection{Magnetometer Borehole Survey}

The SEAMIST membrane makes an ideal conduit for performing inhole surveys. The compressed air environment inside the membrane assures that an instrument slid inside the SEAMIST membrane will not encounter wet conditions. The cord inside the membrane can be used to pull the instrument through the borehole. A magnetometer was chosen as the test instrument because it would provide an accurate borehole 
survey. This survey was used as a standard for comparison to the radio detection survey performed during execution of the borehole.

Prior to performing the magnetometer survey the SEAMIST membrane was cinched off, see Figure 24, to keep the membrane pressurized inside the borehole. The pressure fitting at the tip of the membrane was removed so that the magnetometer sonde could be placed inside the membrane. The magnetometer was placed inside of a nylon jack, to assure easy passage through the SEAMIST membrane. One end of the magnetometer was attached to the SEAMIST tether/cord, see Figure 25, while the other end of the magnetometer was attached to the instrumentation cable. The double ended cabling system allowed the magnetometer to be pulled back and forth through the SEAMIST membrane. The readout equipment used to perform the magnetometer survey is pictured in the foreground of the photograph in Figure 26.

The magnetometer survey took approximately 15 minutes to be performed over the 91.7 foot length of measured borehole. The table of output from the magnetometer survey is contained in Table 3 . The details of the results from this survey are compared with the radio detection survey in the next chapter.

\subsubsection{Wellhead Completion}

Once the magnetometer survey was completed, the storage canister for the SEAMIST membrane had to be detached from the wellhead of the directional bore. This was accomplished by pinching off the membrane, and turning on the auxiliary air pressure source. Once the membrane was pinched off, the storage canister could be de-coupled from the wellhead by unfastening the camlok fitting. Thereafter, the open end of the wellhead, shown in photograph in Figure 27, was stuffed with about 50 feet of tether/cord, and was sealed with a camlok cover.

The wellhead was encased within a concrete mat and surround by a low cinder block wall and steel posts (Figure 28a). The membrane was kept inflated using a solar powered air compressor. The photograph in Figure 28b shows the arrangement of solar panels, air pump, and final wellhead configuration. The air pump is being maintained about twice a month and has been fully functional since $8 / 21 / 94$. The air pressure inside the membrane typically varies from about 2 to $5 \mathrm{psi}$. 


\section{EVALUATION OF TEST BORE VERSUS PERFORMANCE CRITERIA}

There were four major criteria established at the start of the directional drilling test program which would be used to define success or failure of the work, see previous Section 3.3. Most of these criteria are based upon waste management considerations and ability for the mole to drill along a prescribed flight path. Although the discussion of the test bore in Section 3.7 indicated that the mole did not steer along the prescribed flight path, the evaluation of the accuracy of installation was based upon data collected using a radio detection device. Before finalizing judgment upon the capabilities of the Steer-Rite drill it would be important to determine the accuracy of the radio detection device. It is assumed that the survey conducted with the magnetometer inside of the SEAMIST membrane would provide the most accurate borehole survey. After comparing the data collected using the magnetometer and radio detection system, then a more definitive evaluation of the Steer-Rite mole to satisfy the success/failure criteria can be made.

\subsection{MAGNETOMETER SURVEY DATA}

The data collected using the magnetometer has been summarized from the computer printout shown in Table 3. The raw data was based upon a magnetic survey, and therefore, had to be converted to survey coordinates which could be related to the local coordinate system (X - Y axis) used to prescribe the directional drill flight path. The coordinates for the collar of the borehole (initial penetration point) are listed on Table 3 as a latitude of $16977.15 \mathrm{~N}$ and departure of $23732.03 \mathrm{E}$, (ORNL coordinate grid). The ground surface elevation was measured as 804.01 at the borehole collar. The magnetic survey data had to be covered to the ORNL grid. This was accomplished by reorienting the magnetic data by subtracting the magnetic declination at WAG 6 (2.5 ${ }^{\circ}$ west) from the offset of the ORNL grid from true North. which $34-12^{\prime \prime}$ east (see compass insert on Figure 14). The magnetic correction is calculated as 31.71 east. This correction was used to arrive at the latitude and departure listed in columns 7 and 8 on Table 3. These ORNL coordinate points were then plotted and the local X-Y coordinates were determined. This required another coordinate axis transformation of the magnetometer data in order to compare the magnetometer data to the radio detection data which was based upon the local X-Y coordinate system. The final coordinate transformation required the N-E ORNL axis to be rotated clockwise by $127^{\circ}$, i.e. the $\mathrm{X}$ coordinate axis, plotted in Figure 29.1 is $37^{\circ}$ in a clockwise direction from the ORNL East axis.

The elevation of the borehole measured using the magnetometer is listed in the second column of Table 3. These elevation data were plotted at the bottom of Figure 29(b) for ease in visualizing the plan and profile of the test bore. The comparison between the magnetometer and radio detection device can now be made.

\subsubsection{Comparison Between Magnetometer and Radio Detection Data}

Borehole No. 1 starts at survey point 55, which corresponds to the origin of the $X-Y$ axis. The radio detection and magnetometer data are both equal at the starting point, (Figure 29.1). For the first 35 feet along the $\mathrm{X}$ axes, both sets of data are nearly identical, and indicate that the mole progressively drifts downhill. At 35 feet the $\mathrm{Y}$ offset distance is about 3.6 feet. From 35 to 50 feet (X distance) the radio detection and magnetometer data indicate that the rate of sliding of the mole becomes less and less. The offset downhill of the $\mathrm{X}$ axis is about 4.8 feet for the magnetometer data and 5.5 feet for the radio detection device. From 50 feet to the end of the data collected with the radio detection device $(X=65.3$ feet) both instruments shown similar trends. The mole has stopped sliding downhill and is progressing parallel to the $\mathrm{X}$ axis. 
The comparison between the elevations measured with both devices is plotted in Figure 29.2. In general, the radio detection data shows the same general trend as the magnetometer data. but plots about 12 inches above the magnetometer measurements. Part of the discrepancy is due to the need to correct both sets of data for ground surface variation, i.e. optical survey was not performed directly over each point measured with radio detection or magnetometer. It should be noted that the radio detection device measures depth below the ground surface, while the magnetometer measures depth below a horizontal plane, with a starting elevation at the collar of the borehole. The maximum depth recorded with the radio detection device was 6 feet (X) $60.7 \mathrm{ft})$, and with the magnetometer was about $7.3 \mathrm{feet}(\mathrm{X}=65 \mathrm{ft}$.). The maximum depth measured with the magnetometer compares well with the physical measurements made of the bottom of the rescue pit ( 7 feet).

The comparison between the magnetometer and radio detection data can be considered to be identical for the first 40 feet (X distance). Thereafter, the $\mathrm{Y}$ offset and elevation determined using the radio detection device is about 12 inches from the magnetometer data. In consideration of the low cost of a radio detection system $(\$ 1,500)$ versus magnetometer $(\$ 100,000)$ and ease of use of the radio detection device it would appear that the radio detection system is adequate for providing guidance to the Steer-Rite mole. It is considered adequate to be used for depths of 7 feet or less for any future applications of the Steer-Rite drill at WAG 6.

Now that the relative reliability of the radio detection and magnetometer data has been considered, the ability of the Steer-Rite drill to satisfy the success/failure criteria proposed under Section 3.3 can be examined.

\subsection{DRILLING ACCURACY}

The drilling accuracy is linked to two activities. The first being the ability to detect the position of the mole, with the second related to the steering ability of the mole. When comparing the prescribed flight path (superimposed under Figure 29.1 \& b) to either the radio detection or magnetometer data it becomes evident that the mole was not guided along the prescribed flight path correctly. It is believed that the radio detection device was adequate for locating the mole, but the mole was not able to be steered through the ground with sufficient accuracy. The mole usually drifted downhill of the prescribed location ( $\mathrm{X}$ axis), and was usually much shallower than the prescribed elevation. For most of the flight path bored by the mole, the actual path was at least four or more feet off line and grade. The flight path termination point was about 25 feet downrange of the prescribed location.

With respect to drilling accuracy, the mole's path varied twice the specified tolerance $(+/-24$ inches) from the planned path. The tendency for the mole to drift downhill probably was related to the impact mole penetrating through soft organic clayey soil. The weight component of the mole plus the impact force of the pneumatic hammer were much larger than the resistive force imposed by the steering fins of the mole. This is especially true if the surrounding soil is a weak organic clay, instead of the saprolite which was expected. It would have been better to have started the drilling from a downhill position and drill uphill through the soft organic clay soil.

\subsection{PENETRATION OF WAG 6 SOIL PROFILE}

The Steer-Rite mole was able to self-bore through about $75 \%$ of the prescribed flight path. The portions of the borehole through saprollite was easily penetrated and the drill seems to be able to stay on the required 
course. However, once the soft organic clay deposit was encountered the drill was not able to stay on the correct course and veered downhill by as much as 5 to 6 feet. Furthermore the mole was observed to oscillate back and forth in the bottom of the rescue pit. This would indicate that the impact mole needs to bore through ground with a certain minimum shear strength. The soils shear strength will provide side shear resistance to prevent the mole from going backward as the impact hammer cycles back and forth.

The shallow pit uncover weathered shale at a depth of about seven feet, (elevation 790.5). This is the elevation of the floor of the adjacent trench cluster 277-282-290-293-304. It would therefore appear that in order to directionally drill beneath these trenches the mole would have to bore through some decomposed shale. Based upon the SEG site demonstration the mole lacks sufficient power to effectively penetrate this soil formation.

With respect to criteria 2 it appears that the Steer-Rite drill would have problems with penetrating weak clay deposits, especially steering through them. There would be a need to provide external thrust to the tail of the mole to assure its forward motion. This may be possible by having the mole carry in a piece of flexible casing (HDPE). The casing would also serve the function of preventing soil collapse around the service lines. This would assure that the mole would not inadvertently go into reverse. Lastly, the Steer-Rite mole does not posses enough power to effectively penetrate the other extreme of soil condition at WAG 6, compacted clay shale.

\subsection{WASTE MANAGEMENT}

The mole was easily launched from the surface and pulled the stub casing muffler into place. The stub casing muffler did not provide enough control of the exhaust gases ejected by the mole. This problem could be easily rectified by placing a back flow preventer valve inside the muffler in-between the T-section where the supervac attaches and the exit port for compressed air, see Figure 8. A major success of the Steer-Rite drill is related to not ejecting any soil cuttings from the collar of the borehole. This was one of the major reasons for selecting this drill, and the actual field performance support the "fluidless" aspects of the drilling. Finally, the drill was able to self-bore out of the ground and be retrieved at the surface.

Although a rescue pit had to be excavated to place the drill into forward motion, no soil from the excavation had to be removed from the site.

In general, it appears that the Steer-Rite drill successfully satisfied the waste management requirements established for the demonstration. It is believed that if the drill pulled into place a flexible casing it would have never gone inadvertently into reverse and would have completed the test bore without need for a shallow rescue pit.

\subsection{DEPLOYMENT OF SEAMIST}

The SEAMIST membrane performed flawlessly as a well completion technique. Pulling back a steel "pig" ahead of the SEAMIST membrane work very well, assuring that the membrane would go through an uncased borehole. The deployment of SEAMIST over the 91.7 foot length of borehole lasted 15 minutes. The magnetometer survey proved that the SEAMIST membrane can be used to deploy and retrieve a large sonde. 
The SEAMIST membrane has been kept pressurized since August 1994 using a solar powered air compressor. As of September, 1995, the air compressor has been working very well for a period of 13 months. Only minor maintenance is required (changing of rubber diaphragm on air compressor). The SEAMIST membrane (and cotton absorber)will be pulled from the borehole during September, 1995. The cotton absorber will have been in the ground for approximately one year. 


\section{SUMMARY AND RECOMMENDATIONS}

\subsection{SUMMARY}

General results from the demonstration indicate that the Steer-Rite directional drill could not follow a prescribed flight path. The drill inadvertently went into reverse when it was within 25 feet of completing the horizontal bore. Attempts to put the drill back into forward motion by remote control were unsuccessful.

Although the Steer-Rite tool did not satisfy certain success criteria established at the beginning of the test, it did display the following positive characteristics:

(1). The mole surface launched and was steered along an initial radius of curvature of about forty feet. Typical directional drilling is on the order of a 275-foot radius. For shallow bores the forty-foot radius of curvature represents a significant advantage over conventional rod push systems.

(2). During the first 30 feet of the bore, the mole stayed within acceptable deviations, $(+/-24$ inches of the prescribed flight path). After approximately 30 feet the mole encountered a wet organic layer which would not allow the mole to be effectively steered. This resulted from insufficient side friction from the organic soil layer. The mole tended to veer downhill following the natural contour of the surface slope. Although the mole could not steer at tight radius of curvature through the organic soil it was able to be steered 10 inches back toward the correct flight path (bore length was about 40 feet to correct 10 inches).

(3). The mole generates approximately $50 \mathrm{~g}$ of impact force. During 6 hours of cyclic loading, the tool instrumentation (i.e., dip angle indicator, tool face roll, radio sonde) remained completely functional. Therefore, the moles location and directional heading could always be ascertained.

(4). The reverse mode of the mole is an important feature to maintain. Demonstration at the SEG Bear Creek Valley site was through $80+$ blow count shale. The mole penetrated approximately 24 feet through this formation. Due to time constraints on the use of the site, the dress rehearsal was stopped, and the mole was able to back out 24 feet of the borehole using the reverse mode.

(5). The mole used in the SEG and WAG 6 demonstrations is self-boring; therefore, no drill-assist is necessary at the surface. As a result, safety issues related to overhead power lines are of little consequence for the self-penetrating impact mole.

(6). If the air pressure line had not been turned off near the end of the WAG 6 bore (to obtain stable instrumentation readings), then it is most likely that the mole would have self-bored along the 92 foot path and surfaced. Therefore, there would have been no need to excavate a rescue pit.

The demonstration indicates that the SEAMIST Membrane was successfully emplaced through 92 feet of horizontal borehole drilled by the Steer-Rite mole. Prior to membrane deployment, the reaming cylinder was successfully pulled back with a winch truck. This assured that the 4.5 inch diameter bore was completely open. Thereafter, the SEAMIST membrane was deployed completely through the borehole within fifteen minutes.

During the demonstration the magnetometer sonde was successfully pulled through the entire horizontal borehole. Flight path coordinates were surveyed at about five-foot intervals. The ninety-two feet of survey 
(20 readings) took approximately ten minutes to complete. The magnetometer was successfully retrieved from the horizontal borehole. A data output summary was provided within 30 minutes of completing the borehole survey.

\subsection{RECOMMENDATIONS}

\subsubsection{Steer-Rite Tool Modifications}

The manner in which the Steer-Rite mole is placed into reverse clearly must be re-examined. For the SEG and WAG 6 demonstrations, the air pressure line, which supplies power to the mole, is also the mechanism for putting the mole into reverse. The air supply line must be turned off, and then the air line is pulled back. This process resets the pneumatic valve in the tail of the mole to the reverse position. The four control and supply lines tangled; therefore, adequate tension could not be placed on the air supply line to reverse the drill. Once the mole was rescued and set on forward path, the air pressure line stretched approximately five feet. After this forward movement had occurred, tension in air line was relieved, and the mole bored to the surface.

The reversing operation can occur inadvertently as indicated in the WAG 6 demonstration. Essentially, after eighty feet of boring, excessive friction developed between the sidewalls of the borehole and lines supplying the mole (air, water, electric). Thus, the tension on the air supply line triggered the mole's reversal. This friction could have been instigated by a partial collapse of the organic soil into the borehole or snagging of the air line on a tree limb buried in the organic soil.

Several improvements to the Steer-Rite drill are possible to prevent inadvertent reversing of the drill. The original workplan examined the possibility of encasing all mole service lines with a steel drill rod (NCC class). However, this drill rod is not flexible enough to steer a tight radius of curvature. A second option was to have the mole carry in a flexible HDPE tube which would line the borehole as the mole penetrates the ground. The HDPE was to cover the pull back cable so that a set of thin drill rods (AW) could be threaded through the HDPE and provide thrust to the tail of the mole to push it out of the ground. It is unclear if this thrust would have propelled the mole out of the ground, with the mole stuck in reverse.

Based upon the inadvertent reversing of the mole and great likelihood of reoccurrence it appears that the following mole improvements should be examined:

(1). Have a single outer tube to encase all supply lines to the mole. In this manner the relative position of all supply lines can be fixed inside the flexible tubing. The air pressure line will not be frozen by twisting nor be put under tension by soil collapsing within the borehole.

(2). Improve the method by which the air exhausted by the mole is handled at the surface. A single HDPE tube with a T-section close to the hole collar and an open end, with the cable far away from T-section, may be a solution. Furthermore, surface casing must be rotated to allow the mole to steer through the ground, and prevent twisting of the mole service lines. Rotating the flexible tubing would also reduce the shear friction against the soil and tubing.

Capability of flexible tubing to transmit thrust to the tail of the mole should be examined. Thrust, combined with impact boring, may make it possible to drill directionally through compact clay shale. The maximum depth required is approximately $20-25$ feet, compared to the WAG 6 demonstration depth of seven feet. 
Attaching button bits to the inclined plane of the mole may enhance the cutting and fracturing of compact clay shale. This may allow the mole to penetrate the ground more effectively.

The geiger counter should be incorporated into the drilling system. GM tool and cable must be hardened to resist excessive forces (i.e., on the order of $50 \mathrm{~g}$ ) imposed during impact boring.

\subsubsection{Applicability and Further Development of Steer-Rite Mole}

Results from the WAG 6 demonstration indicate that the existing Steer-Rite mole is applicable for shallow bores through overburden ( $7-10 \mathrm{ft}$. maximum depth) over a distance of approximately 100 feet. Inadvertent reversing of the mole could be eliminated as discussed in Section 5.2.1. Current applications for the mole are utility installation (4.5 inch diameter) within the ORNL complex and/or installation of the SEAMIST system for site characterization of the vadose zone.

The existing Steer-Rite FDD system is inadequate for drilling beneath WAG 6 trenches, and cannot be relied upon for time critical work. Development of an FDD system to meet these needs would require approximately $\$ 400,000$ and one year to complete. The uniqueness of this undertaking creates significant uncertainty in this estimated cost and schedule; therefore, these figures should be viewed as order of magnitude estimates. The development process would be a co-operative effort with drilling industry experts. This process would include a world-wide technology search, specification development, design, fabrication, and testing. All phases would be highly interactive with ER management.

\subsubsection{Applicability and Further Development of SEAMIST for ER Applications}

The SEAMIST membrane, pull back system, and pulling of a sonde through the SEAMIST membrane have been successfully demonstrated for vadose zone application. The next level of testing would be retrieval of an emplaced SEAMIST membrane, while simultaneously deploying a second membrane. This membrane shuttling would allow a horizontal borehole to be used again and again for various activities (sampling, environmental restoration, etc). 


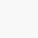


APPENDIX 



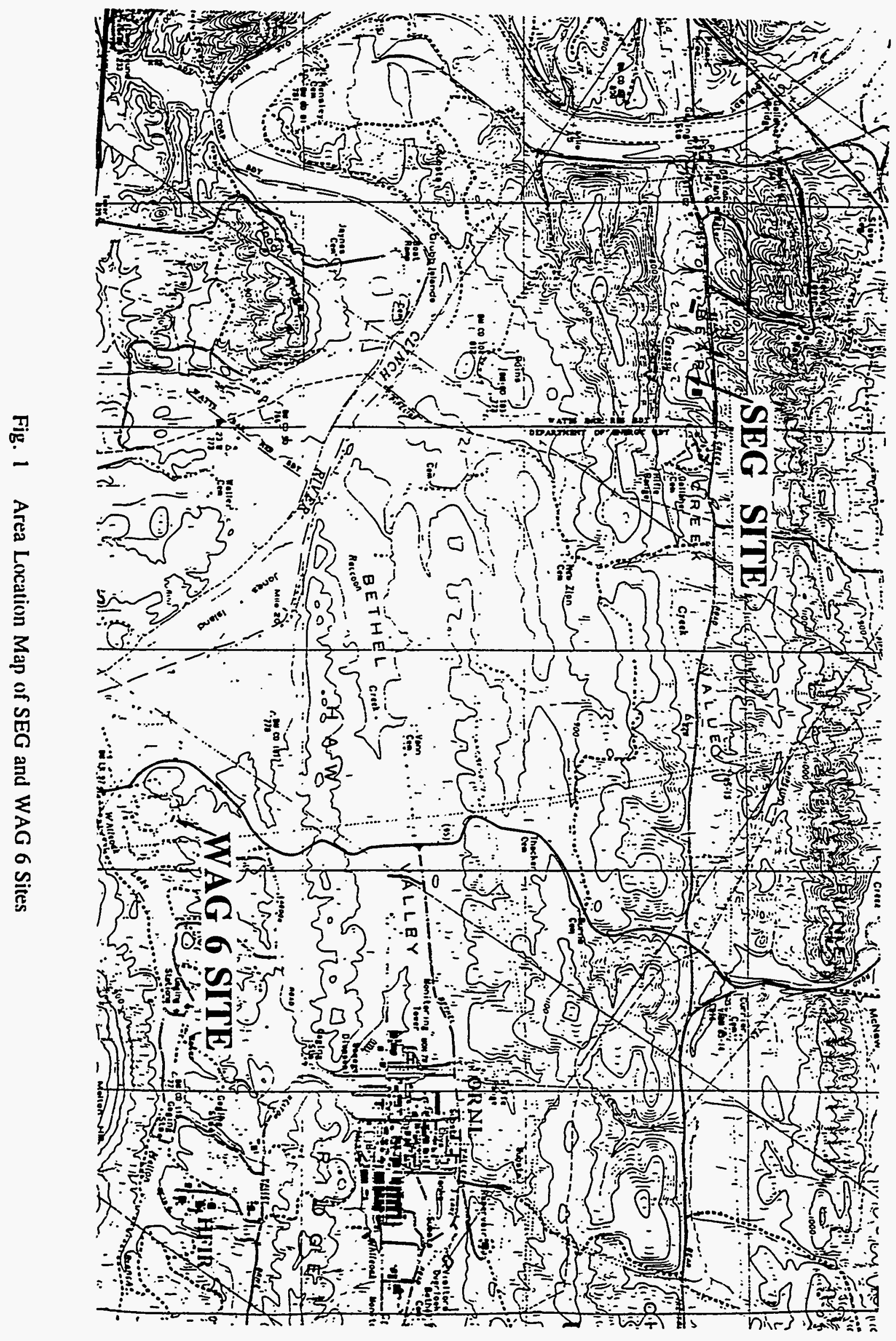




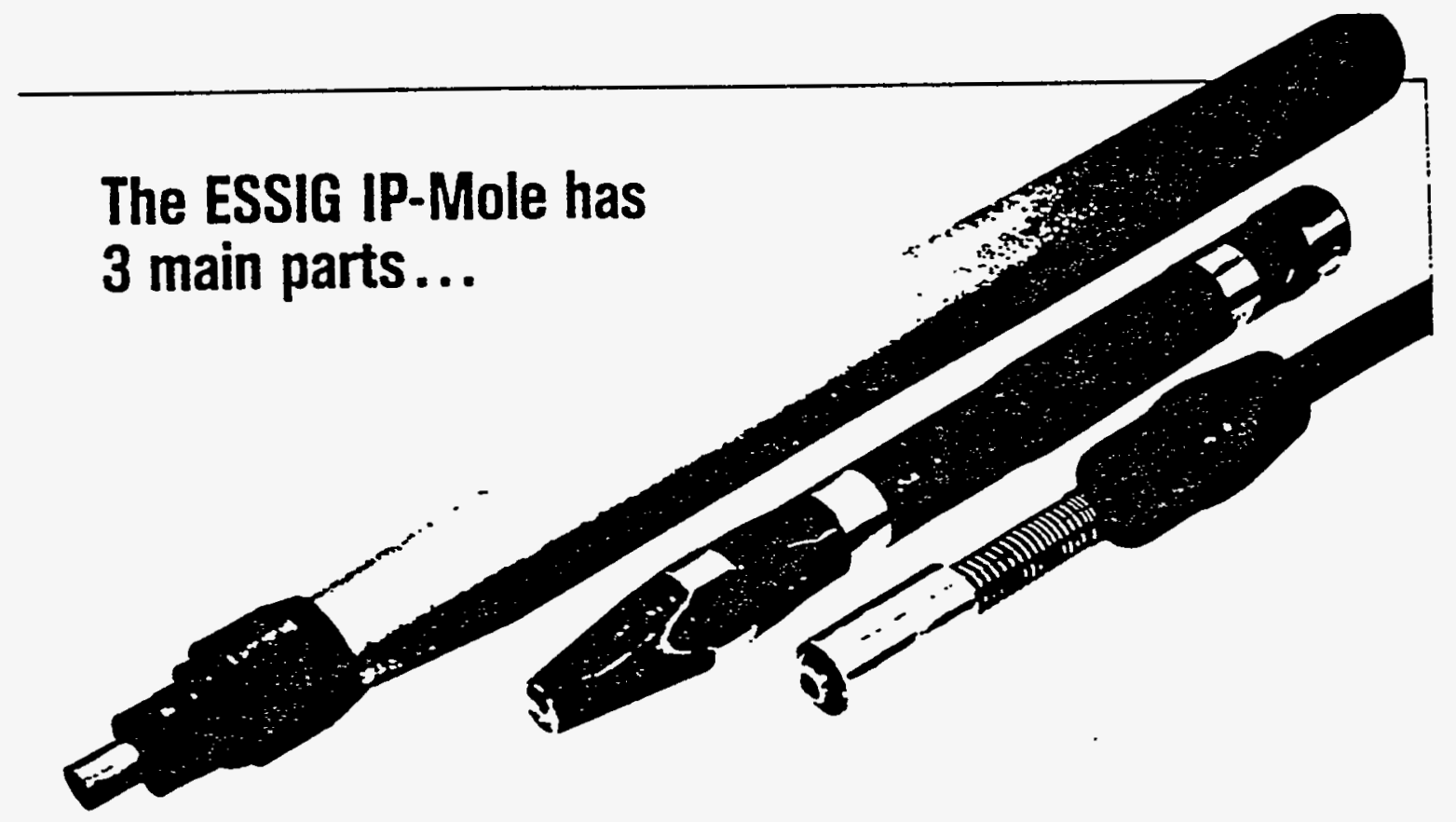

Fig. 2 

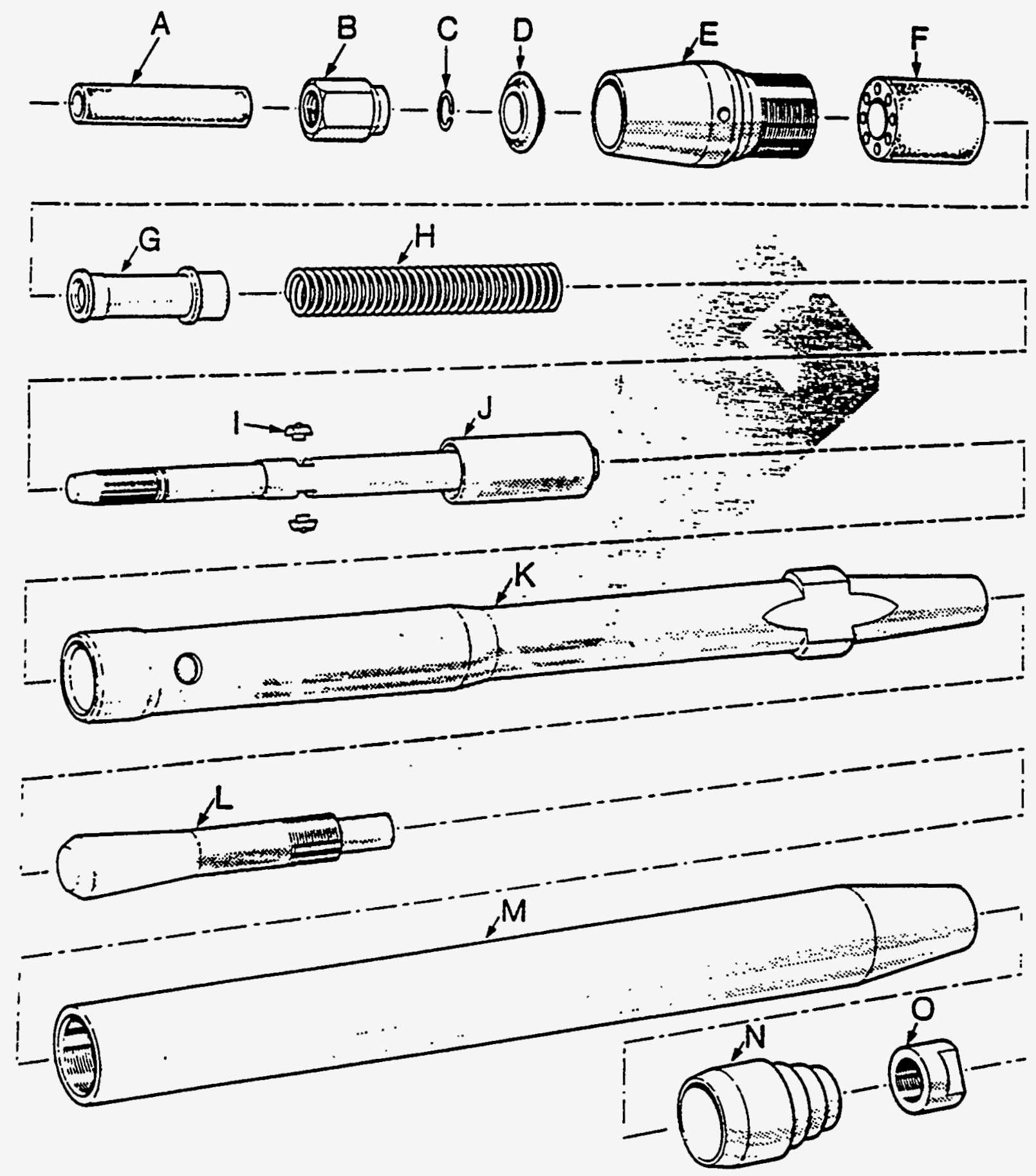
A TAIL HOSE
E BACK END NUT
I COLLETS
B TAIL HOSE NUT
F SHOCK ABSORBER
J CONTROL VALVE
C CIRCLIP
G COLLET SLEEVE
K PISTON
M BODY CASING (NOT TO SCALE)
D fLAP VALVE
H SPRING
L ANVIL
N CUTTING HEAD
O HEAD LOCKING

Fig. 3 Schematic Blow-up of Essig Mole Internal Parts 


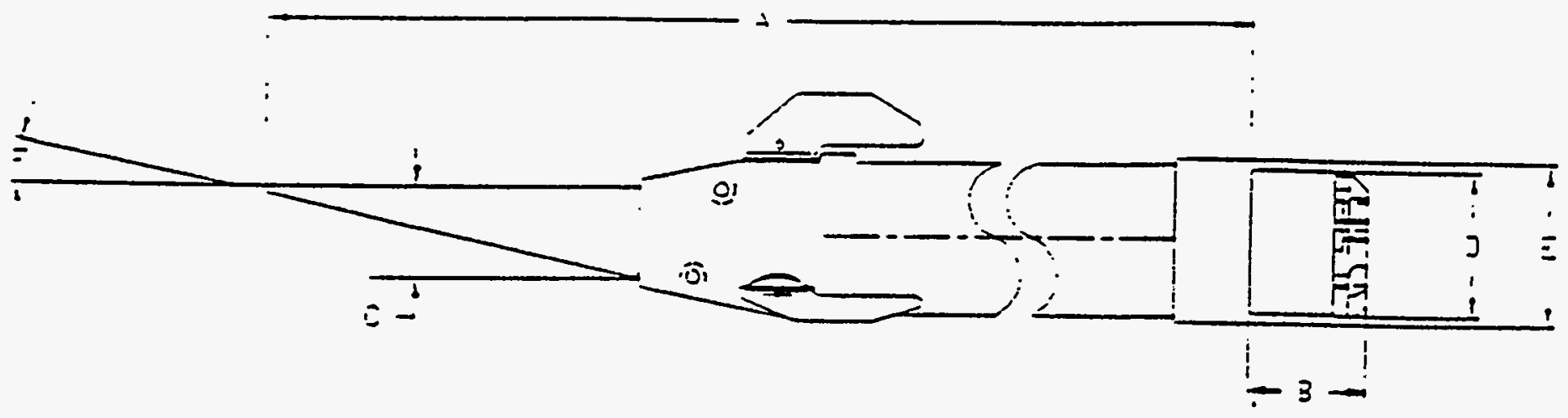

\begin{tabular}{|l|r|}
\hline Power Unit & IP95/375 \\
\hline Tool Diameter & $33 / 4$ \\
\hline A. Pathfinder Length & 75.0 \\
\hline B. Patriot Length & 2.62 \\
\hline C. $\quad$ Anvil Diameter & 2.38 \\
\hline D. Patriot Diameter & 4.50 \\
\hline E. Pathfinder Diameter & 4.62 \\
\hline F. Steering Face Angle & $12^{\circ}$ \\
\hline G. Weight & $65 \mathrm{lb}$ \\
\hline
\end{tabular}

Fig. 4 


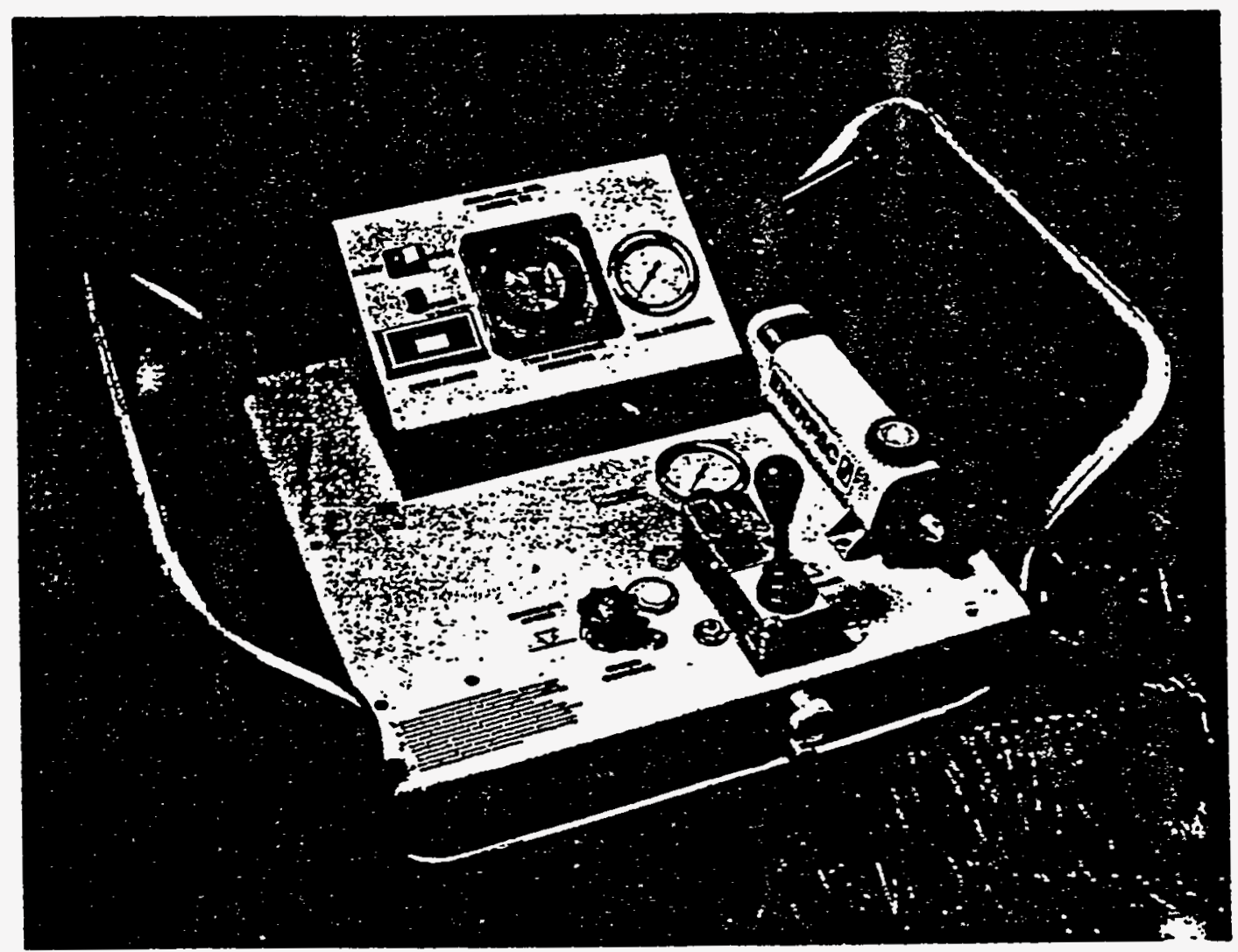

Fig. 5 General View of Command Module Used to Acquire Dip and Roll of Steer Rite Tool; and to Pressurize Steering Fins 


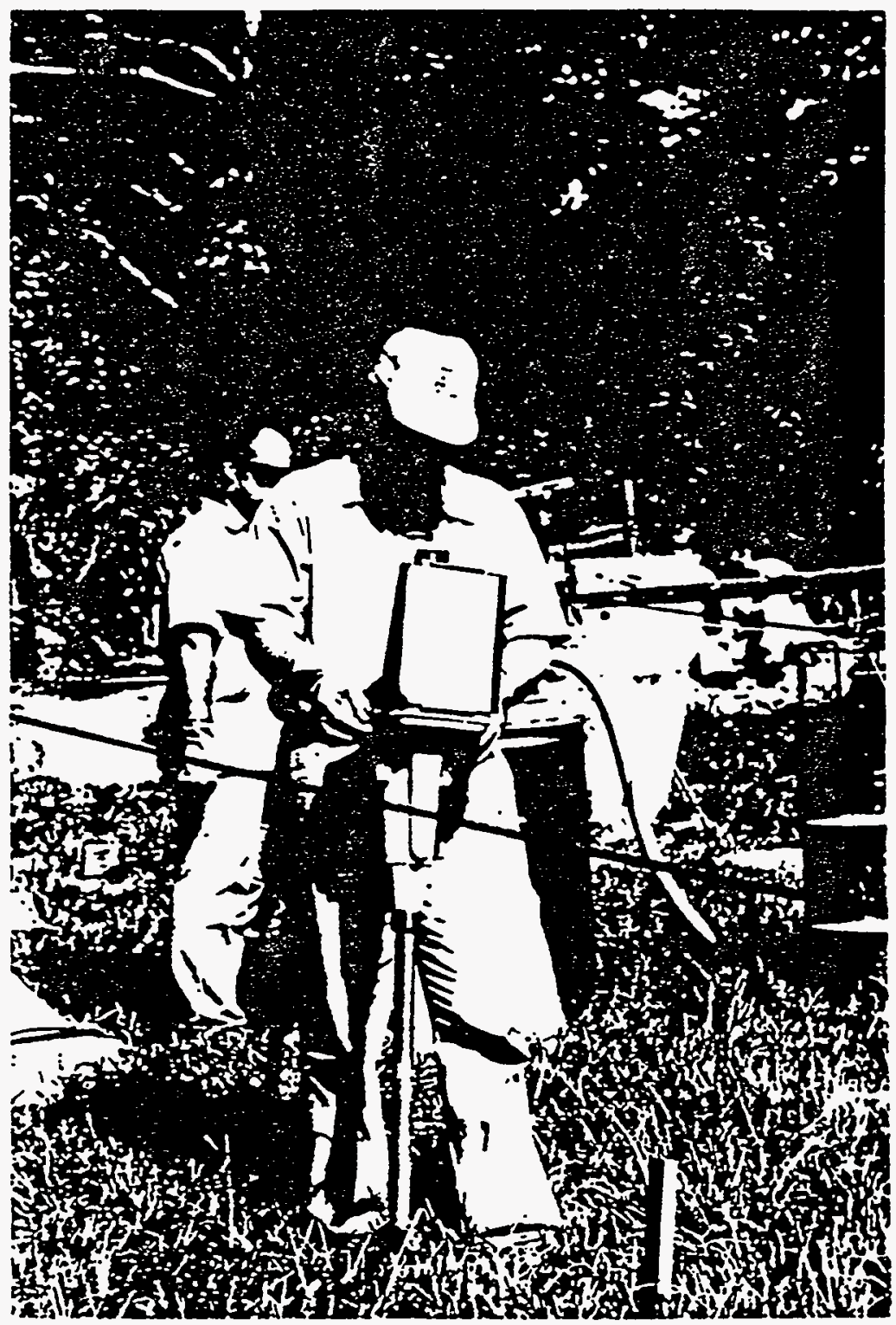

Fig. 6 Photograph of Radio Detection Device Being Used at WAG 6 


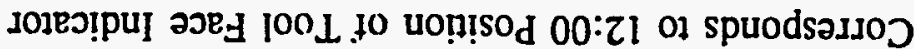

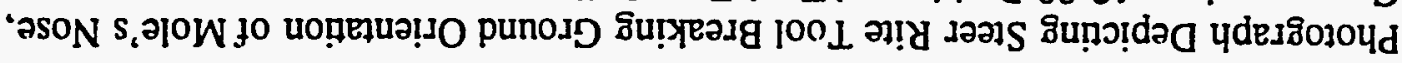

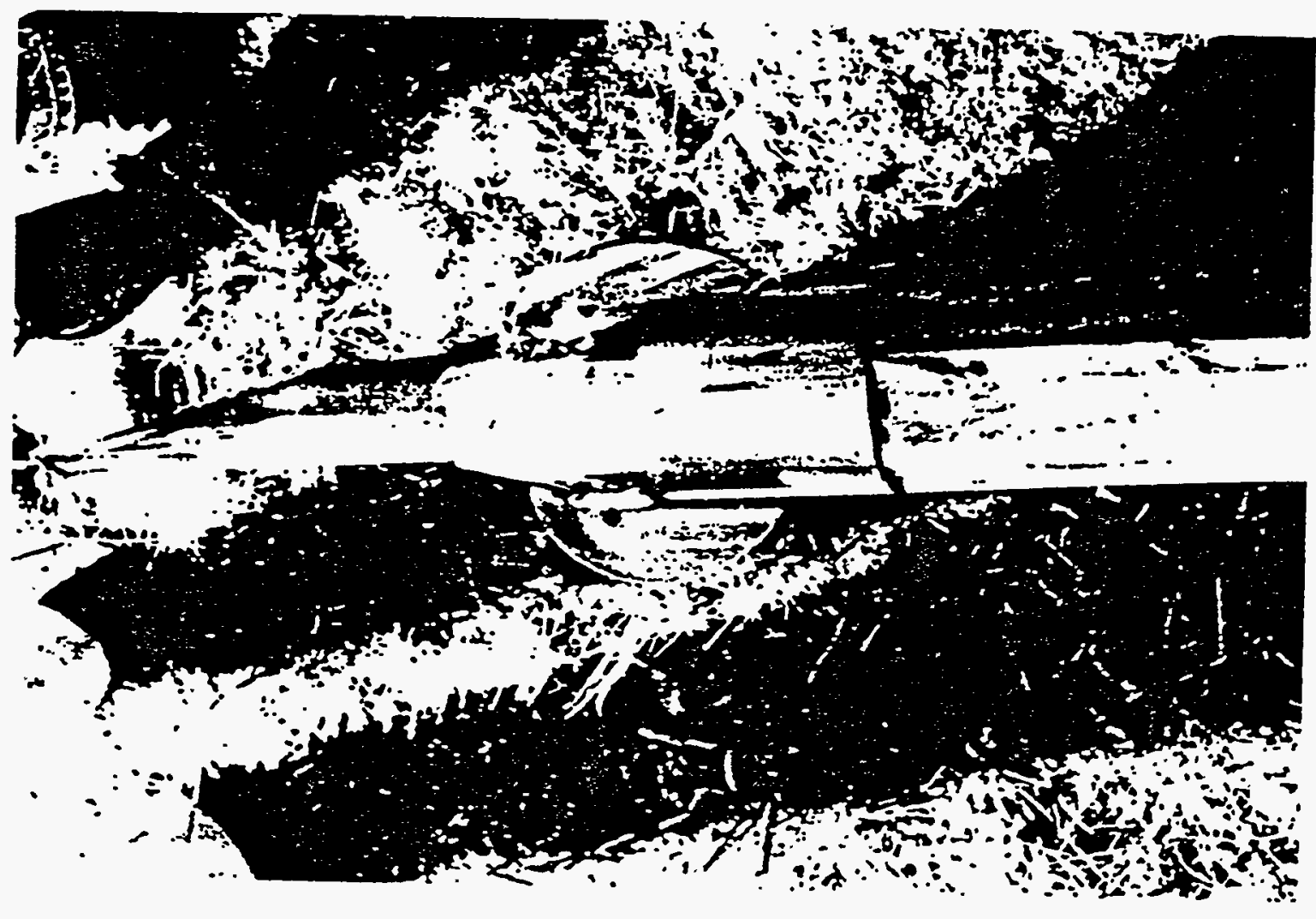




\section{NOTE: DRILL 2"ø HOLES IN ALL CAPS \\ INSTALL SPLIT RUBBER STOPPERS}

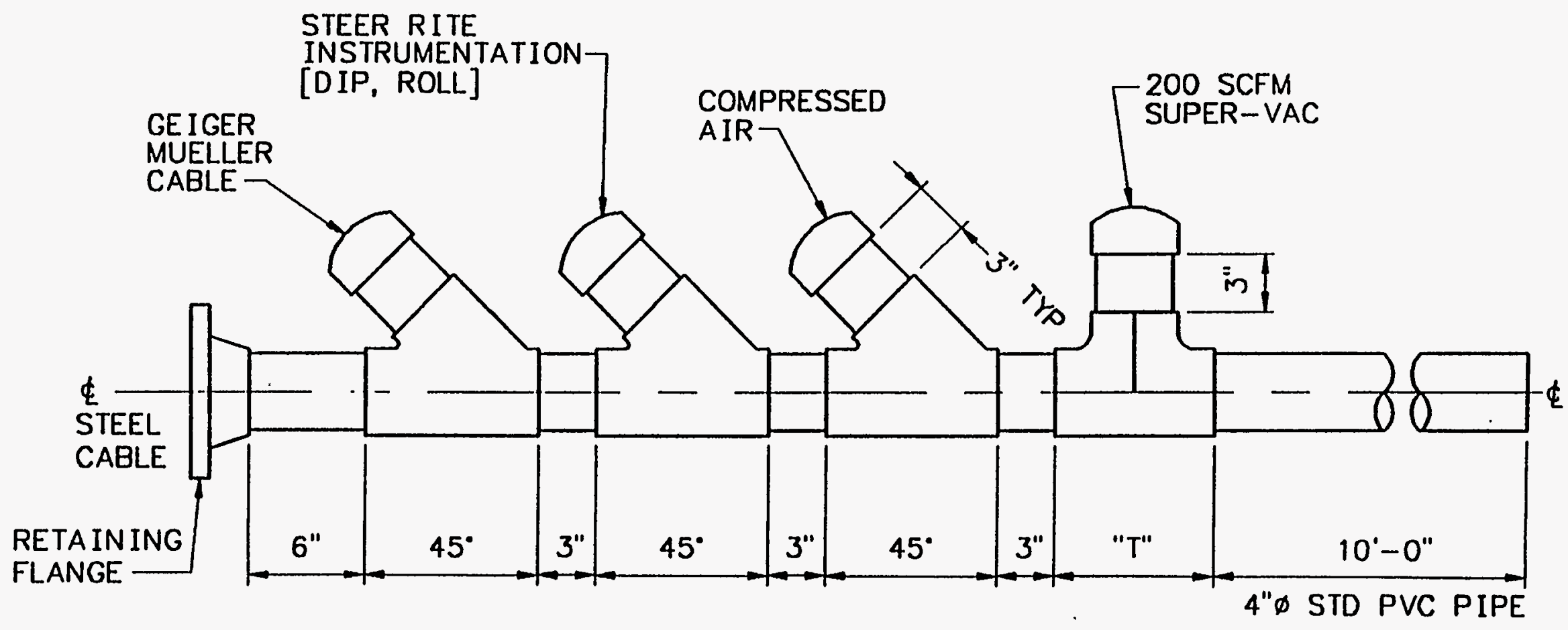

Fig. 8 Mechanical Drawing Used to Fabricate the Stub Casing Muffler for Controlled Venting of Exhaust Gas Ejected by Steer Rite Mole 


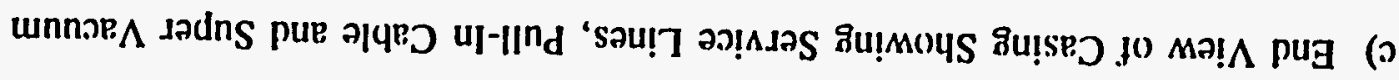

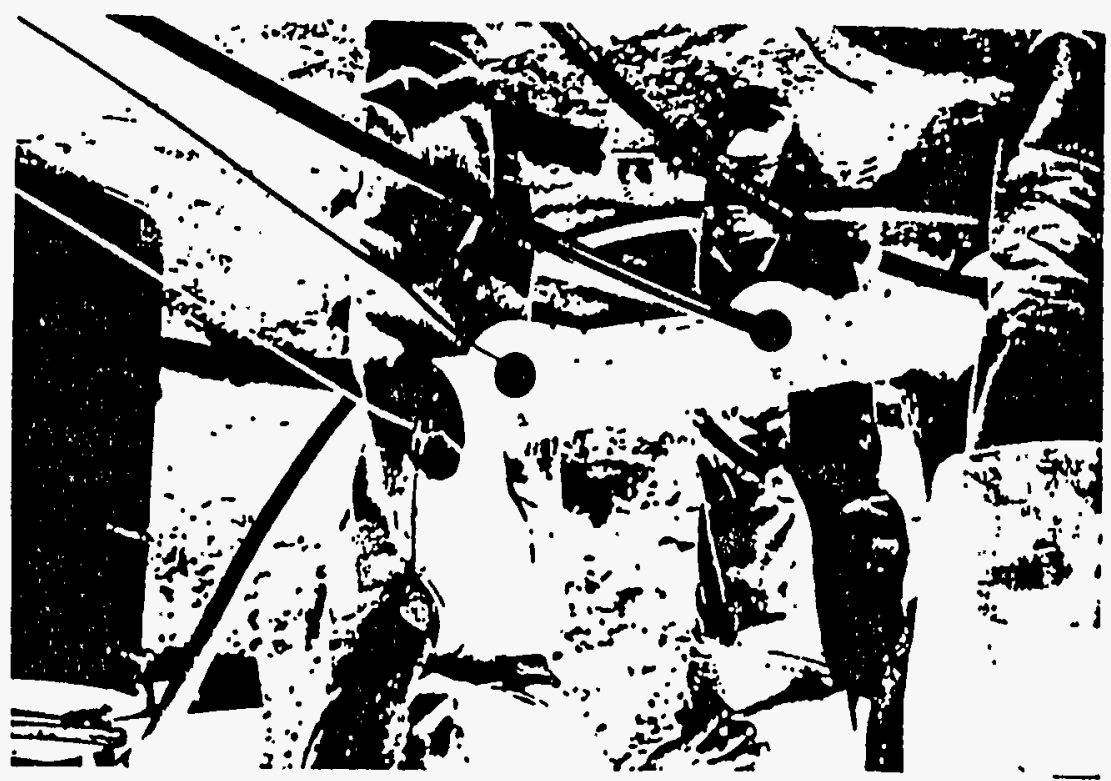

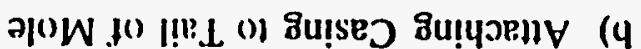

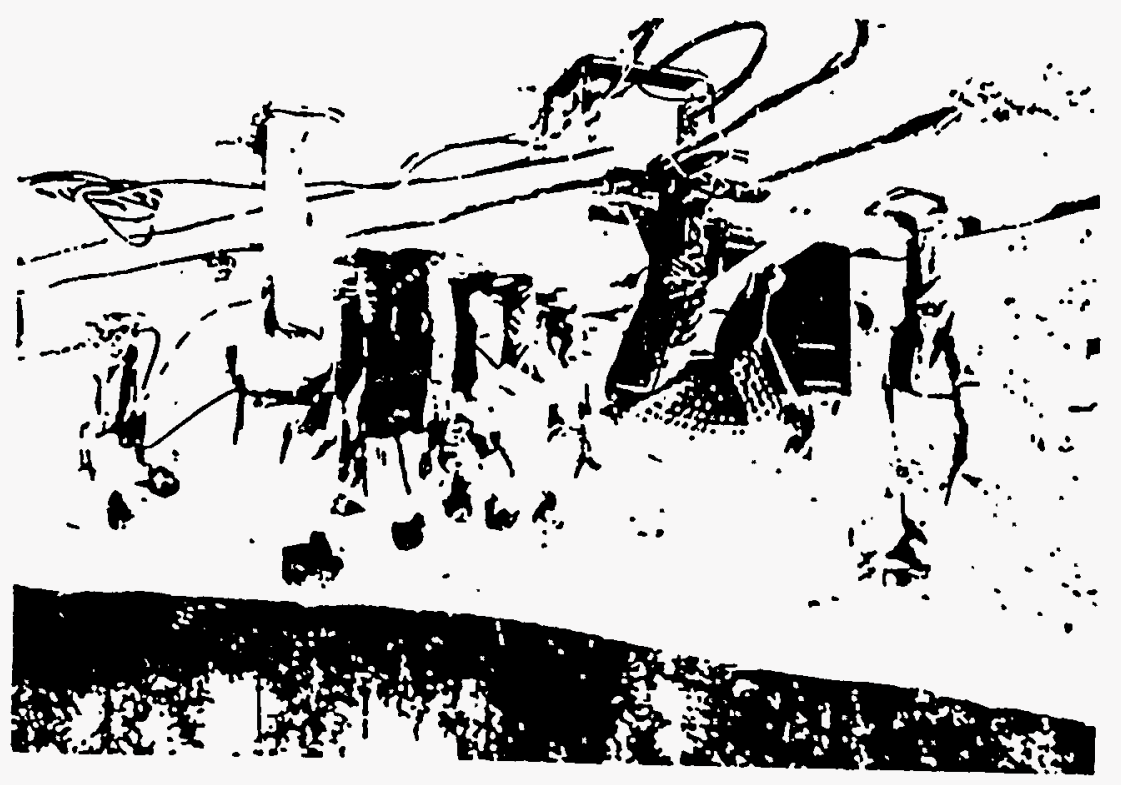

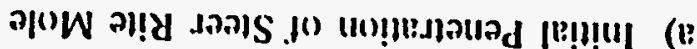

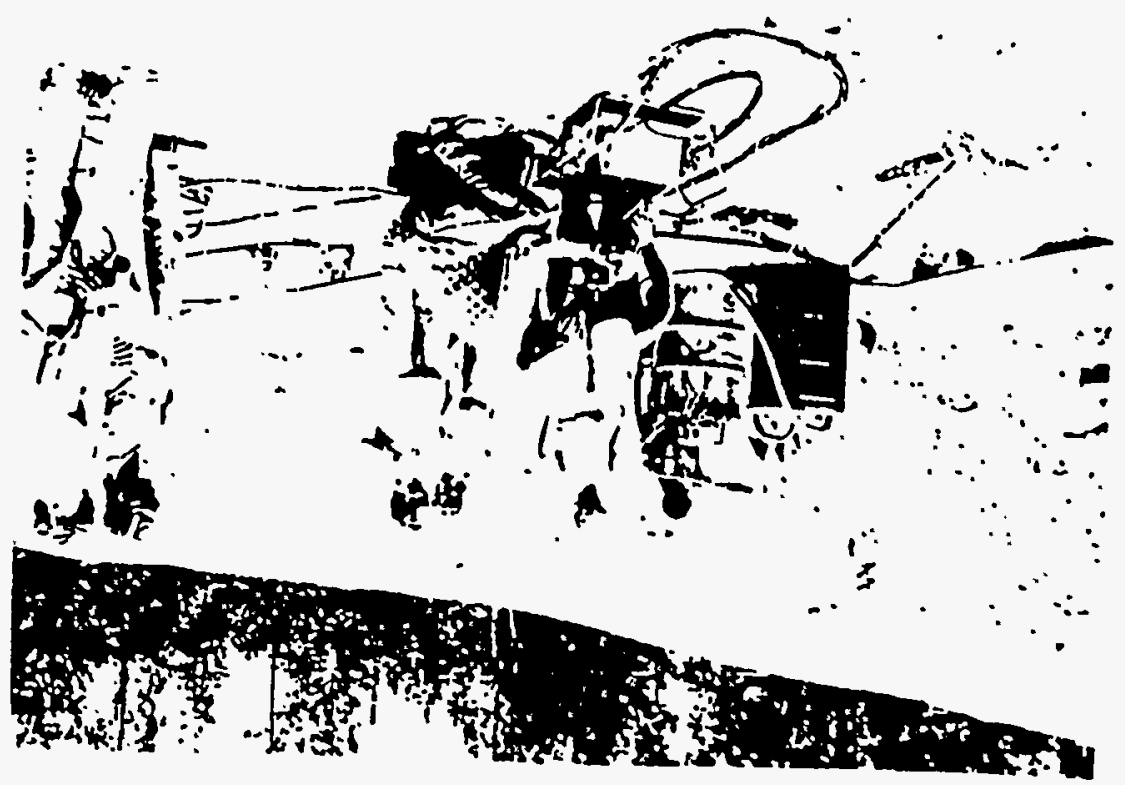




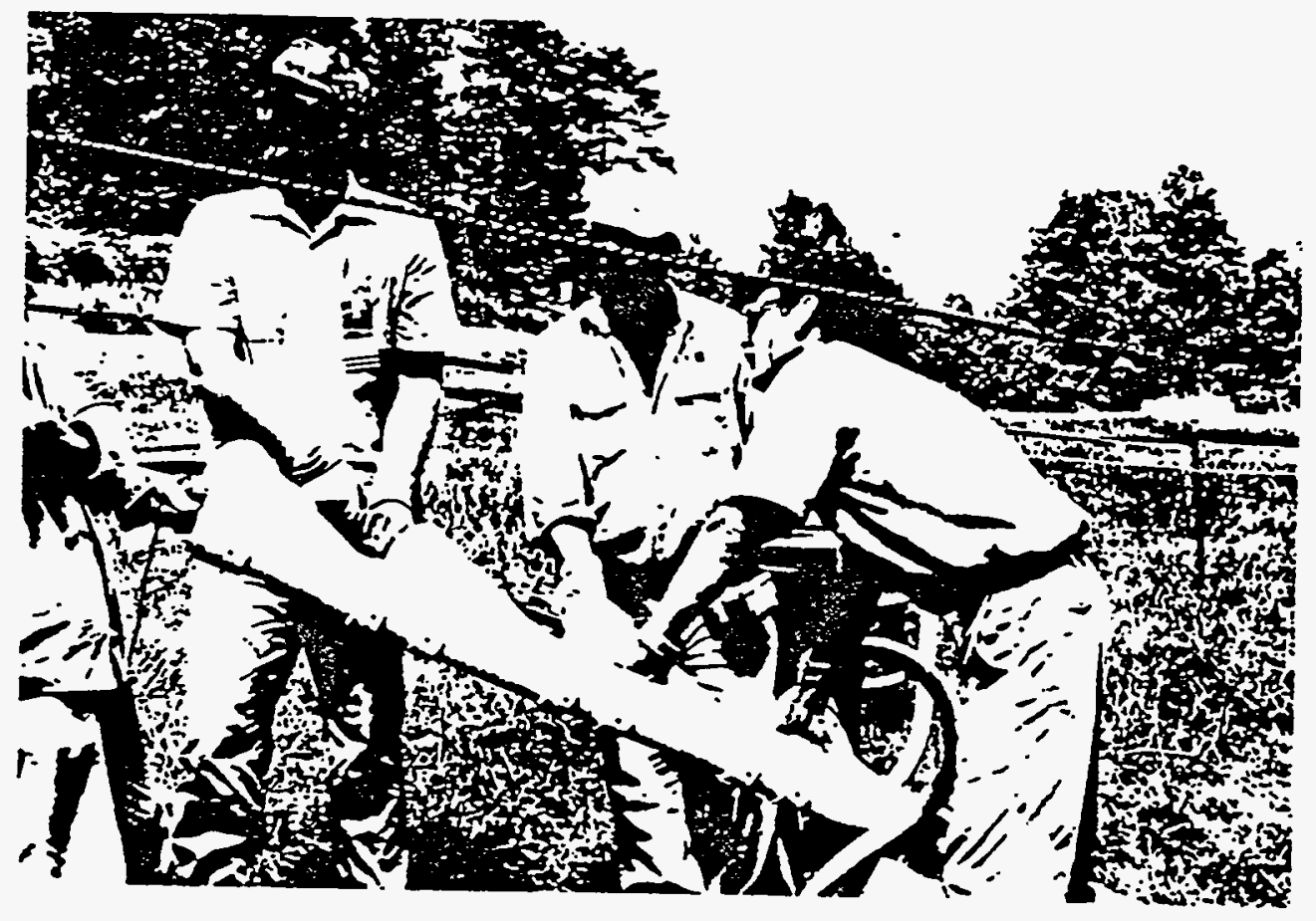

a)

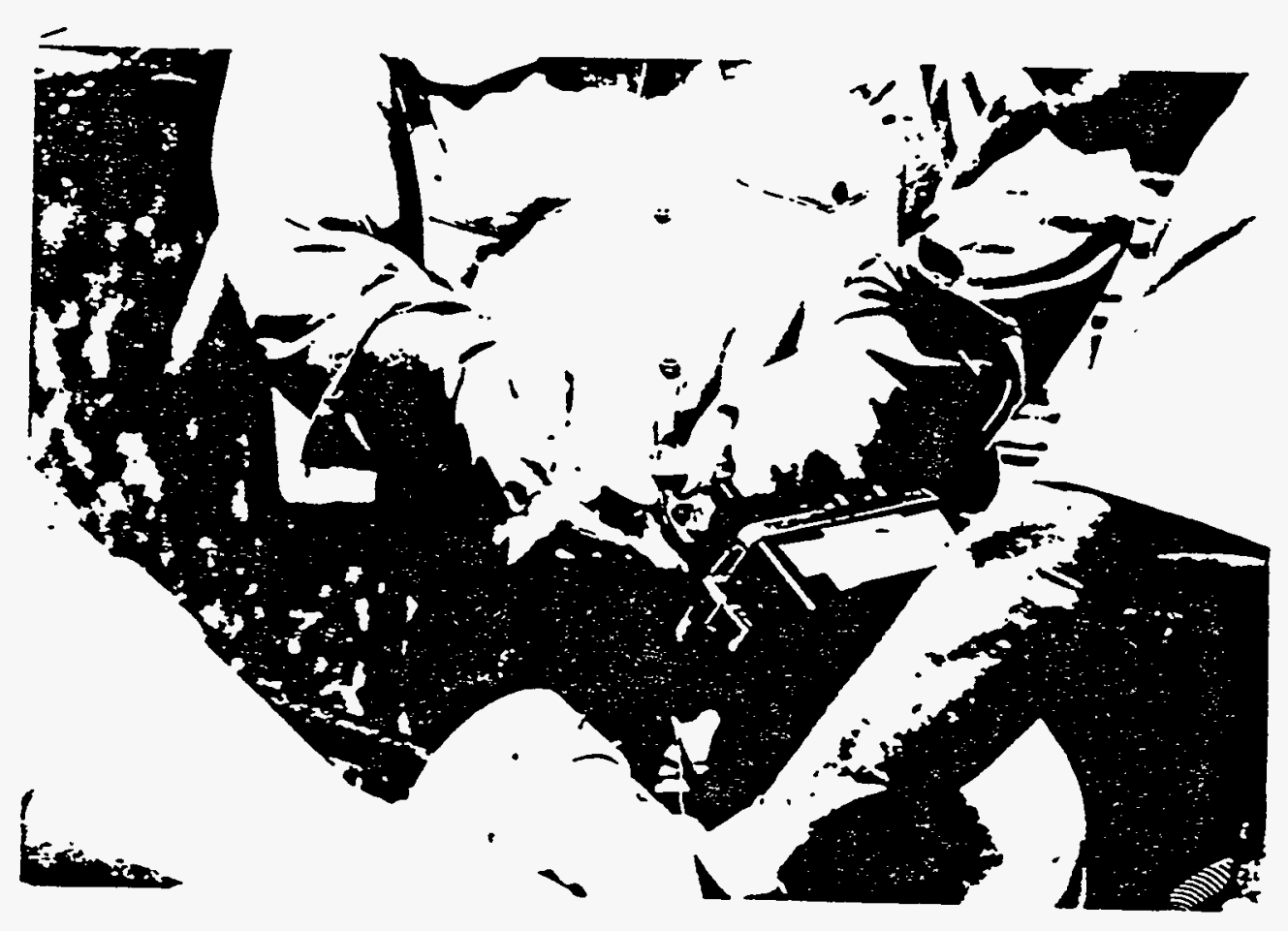

b)

Fig. 10 Gross Gamma Swipe Sampling of Exhaust From Stub Casing Muffler 

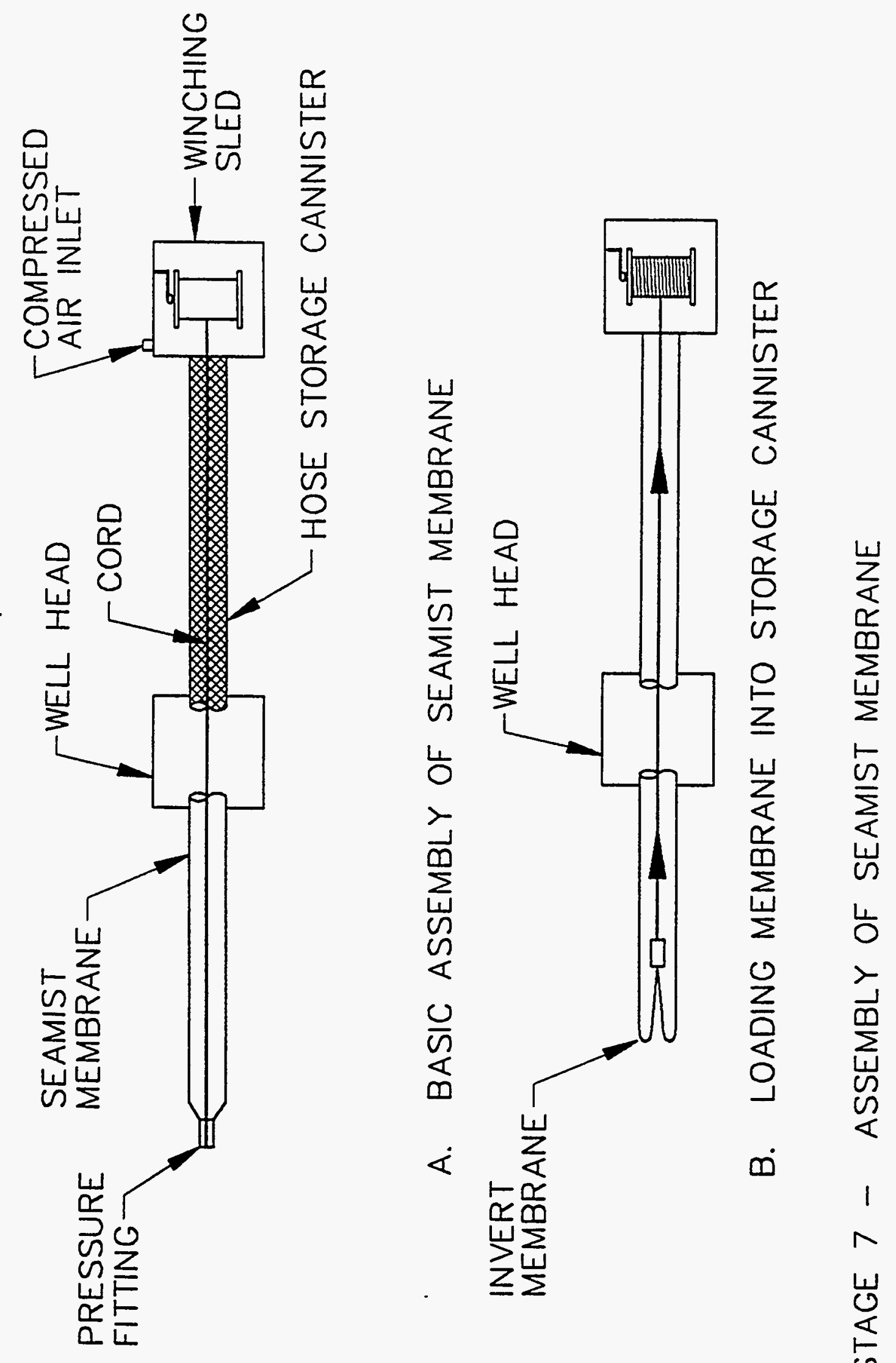

$\dot{\oplus}$
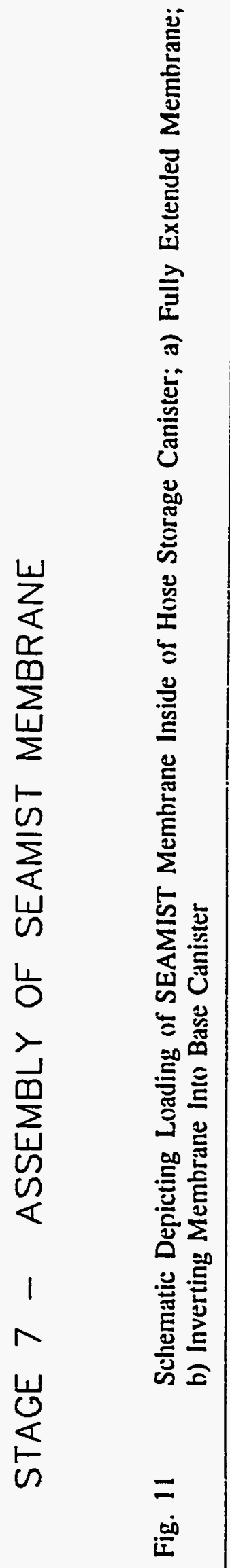


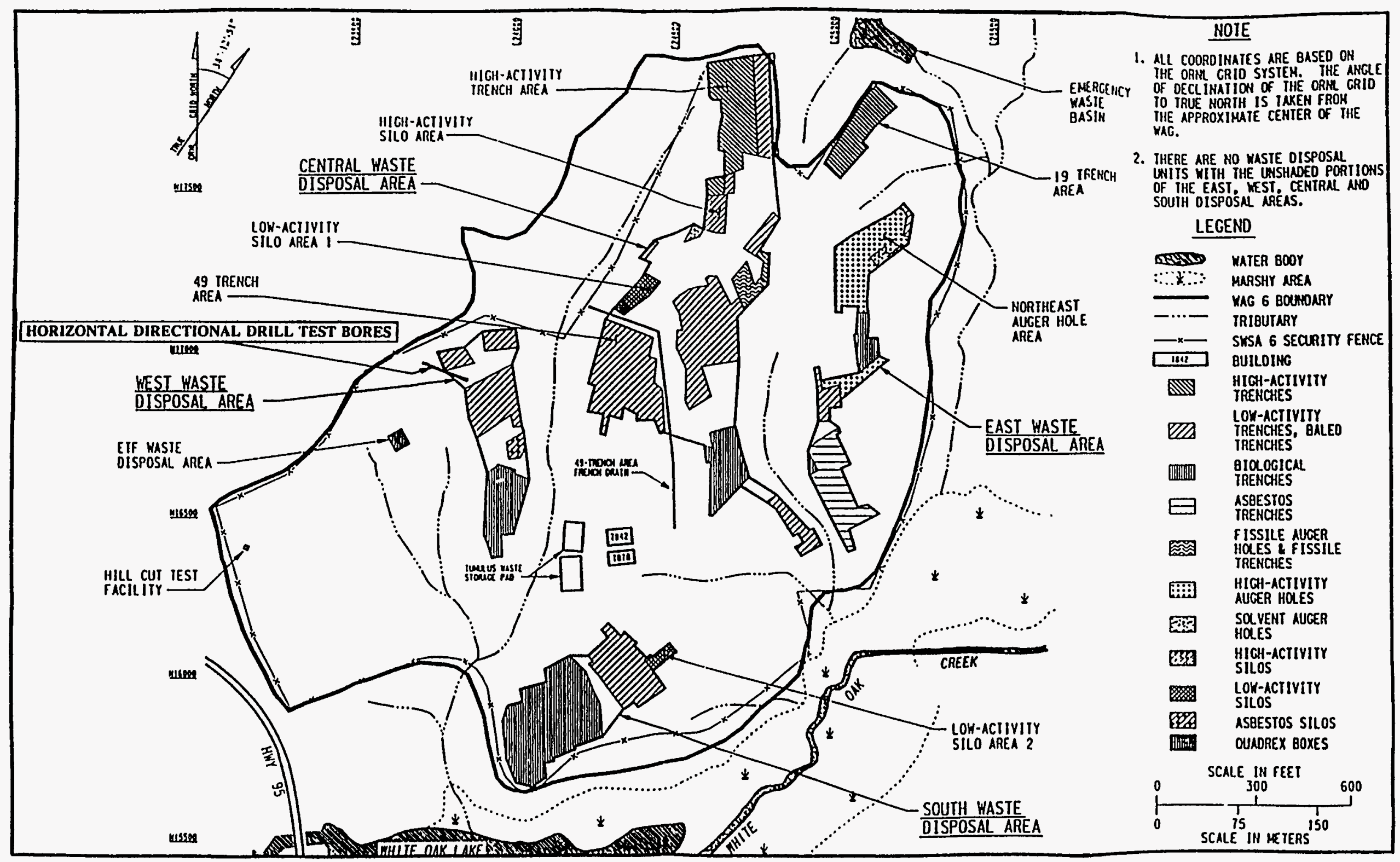

Fig. 13 Site Location MAP of WAG 6 Site 


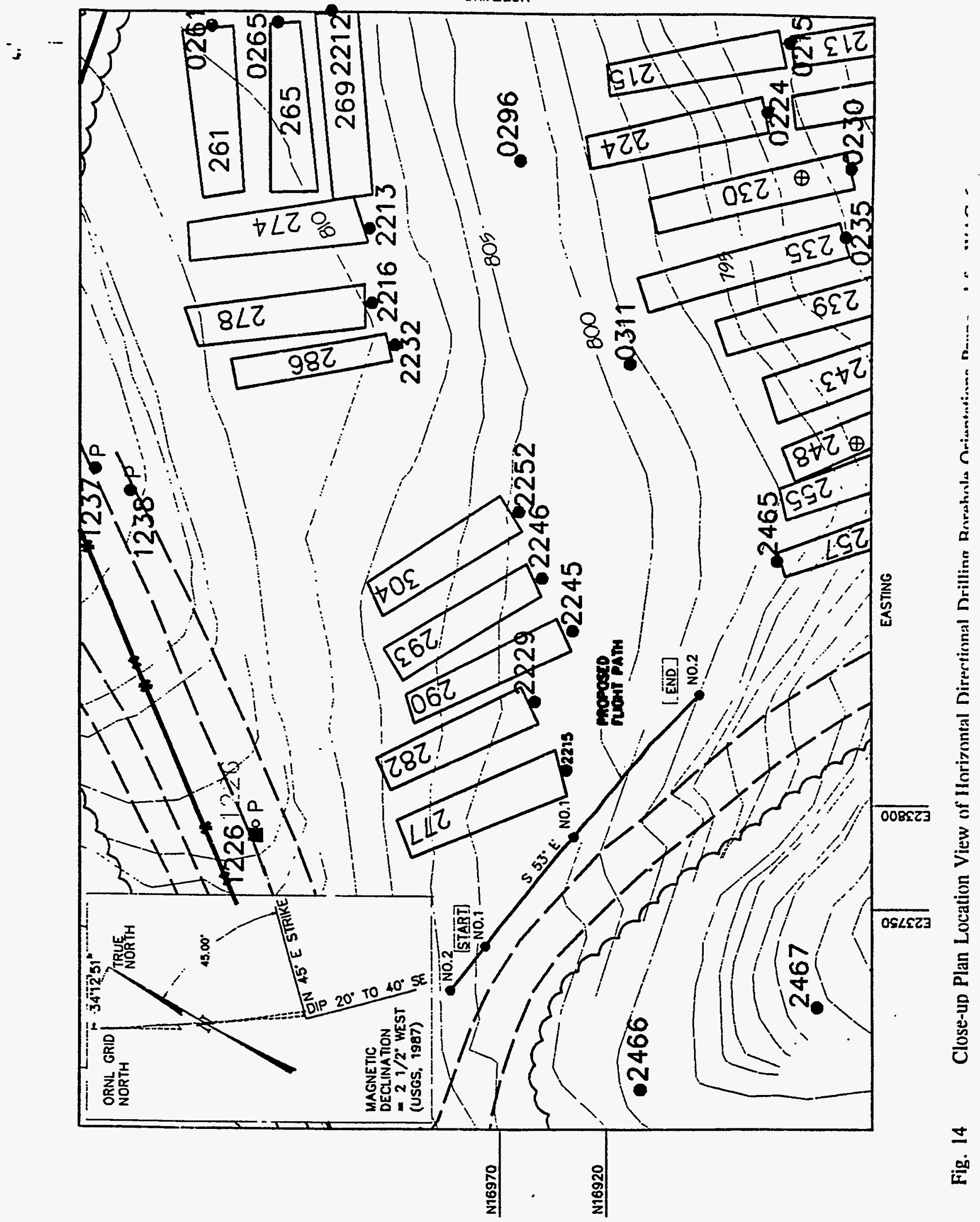



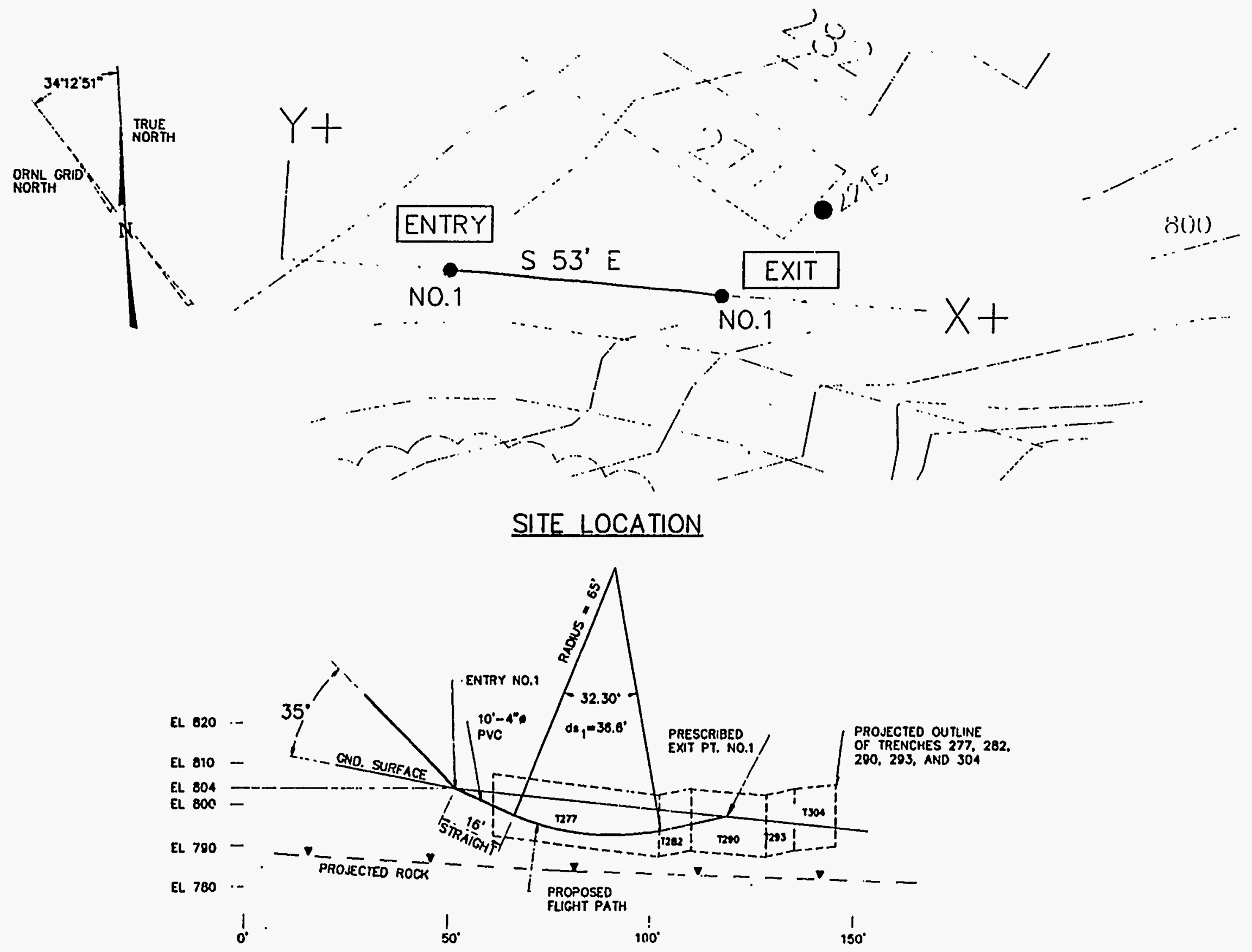

Fig. 15 Orientation and Elevation View of Specified Flight Path for Directional Test Bore No. 1; Installed at WAG 6 


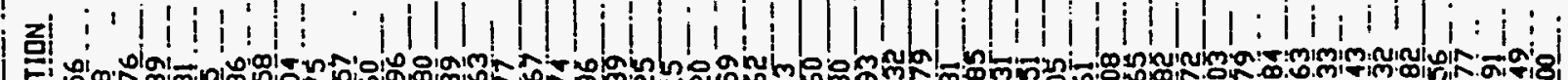

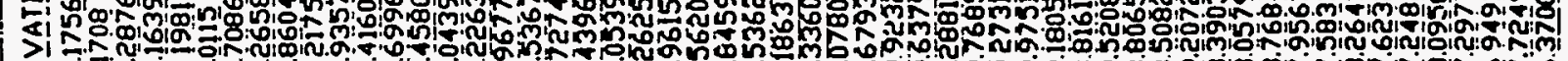
w

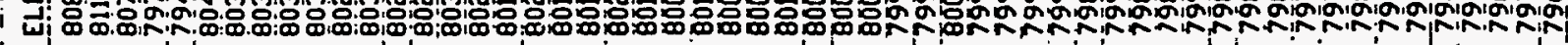

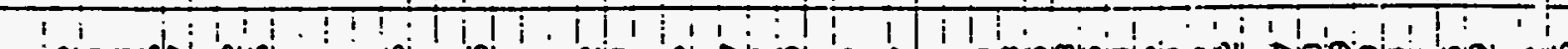

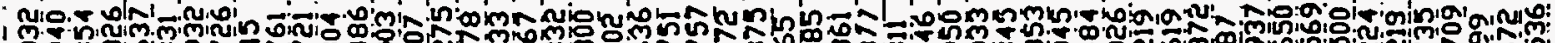

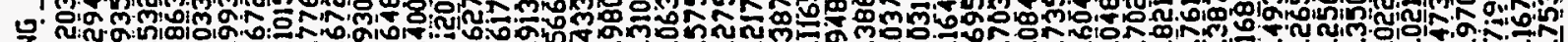

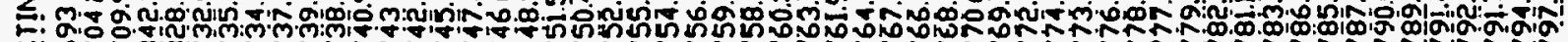
- 4: W. R.

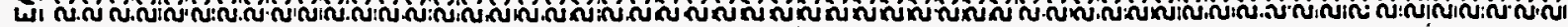

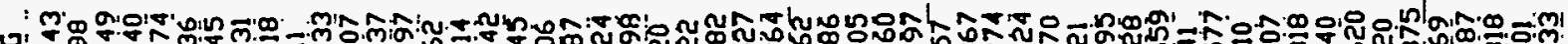

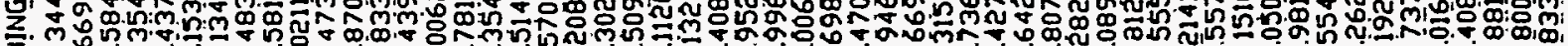
I: Lొผ

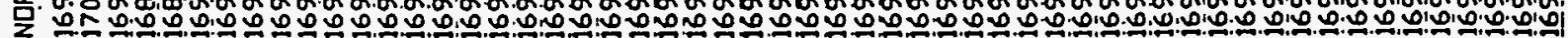

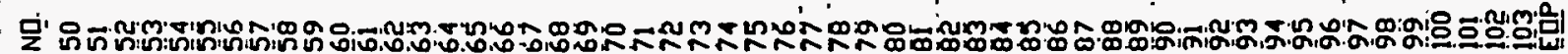

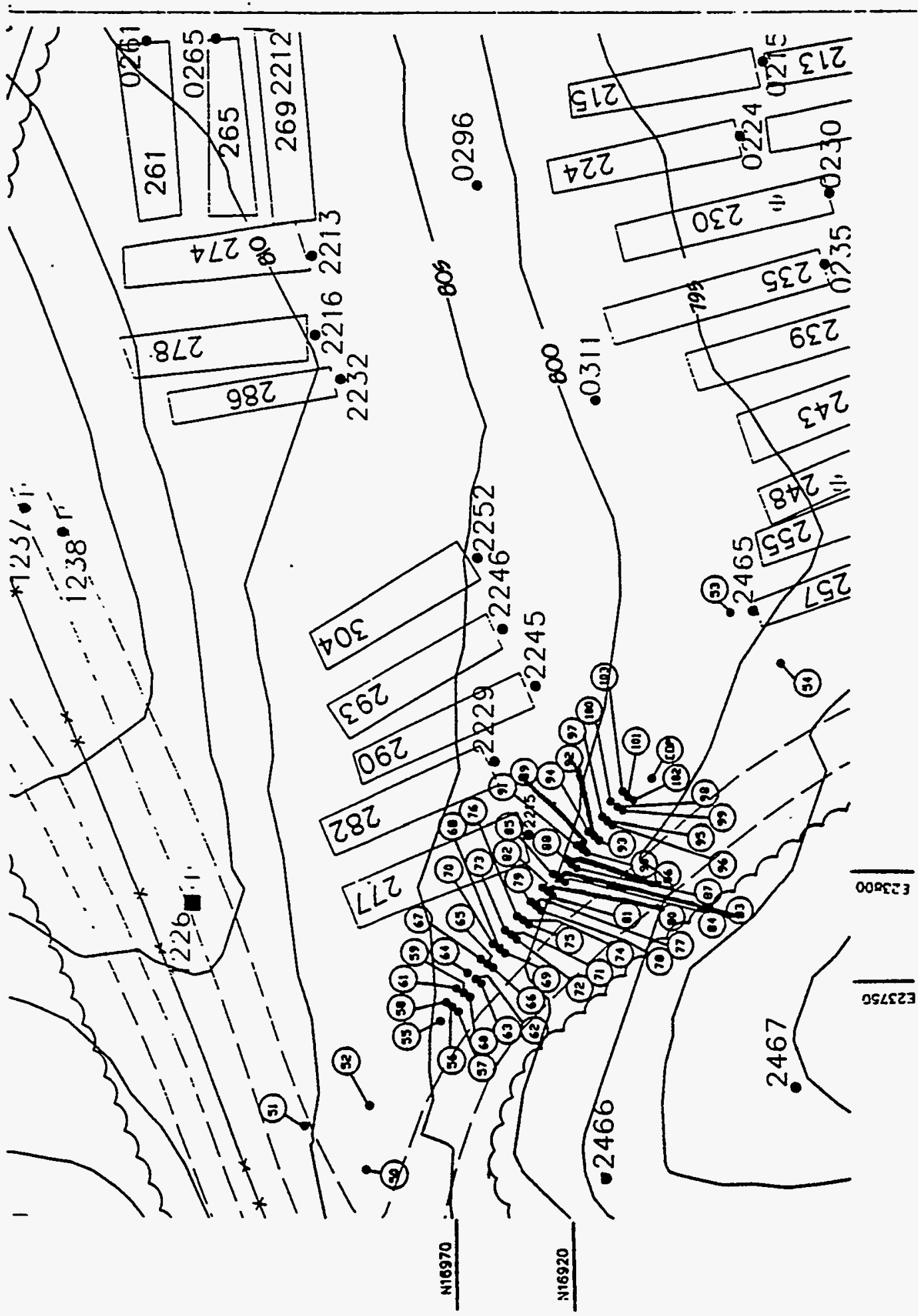




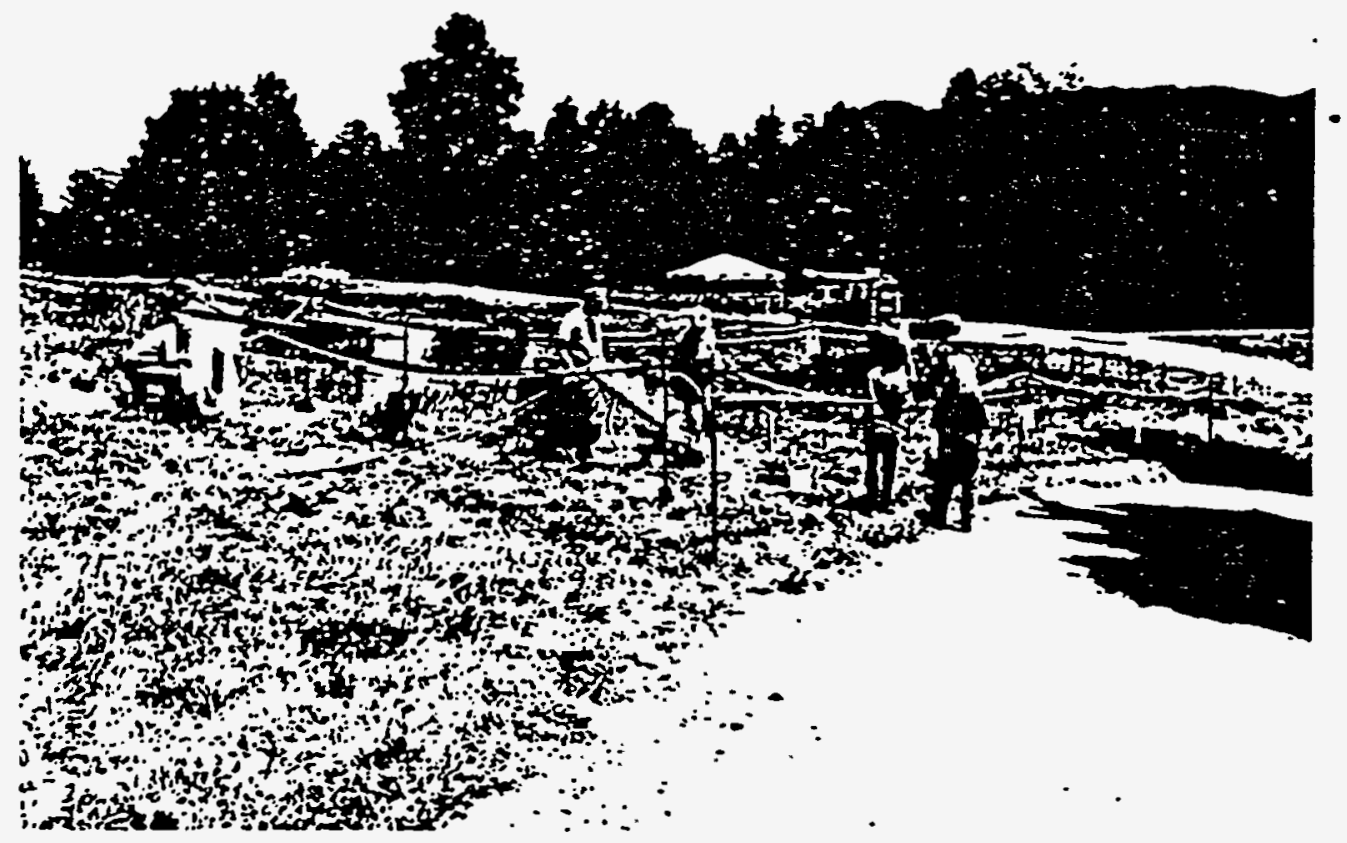

Fig. 17 General View of Test Site Depicting Exclusion Zone. CRZ, and Support Area at WAG 6

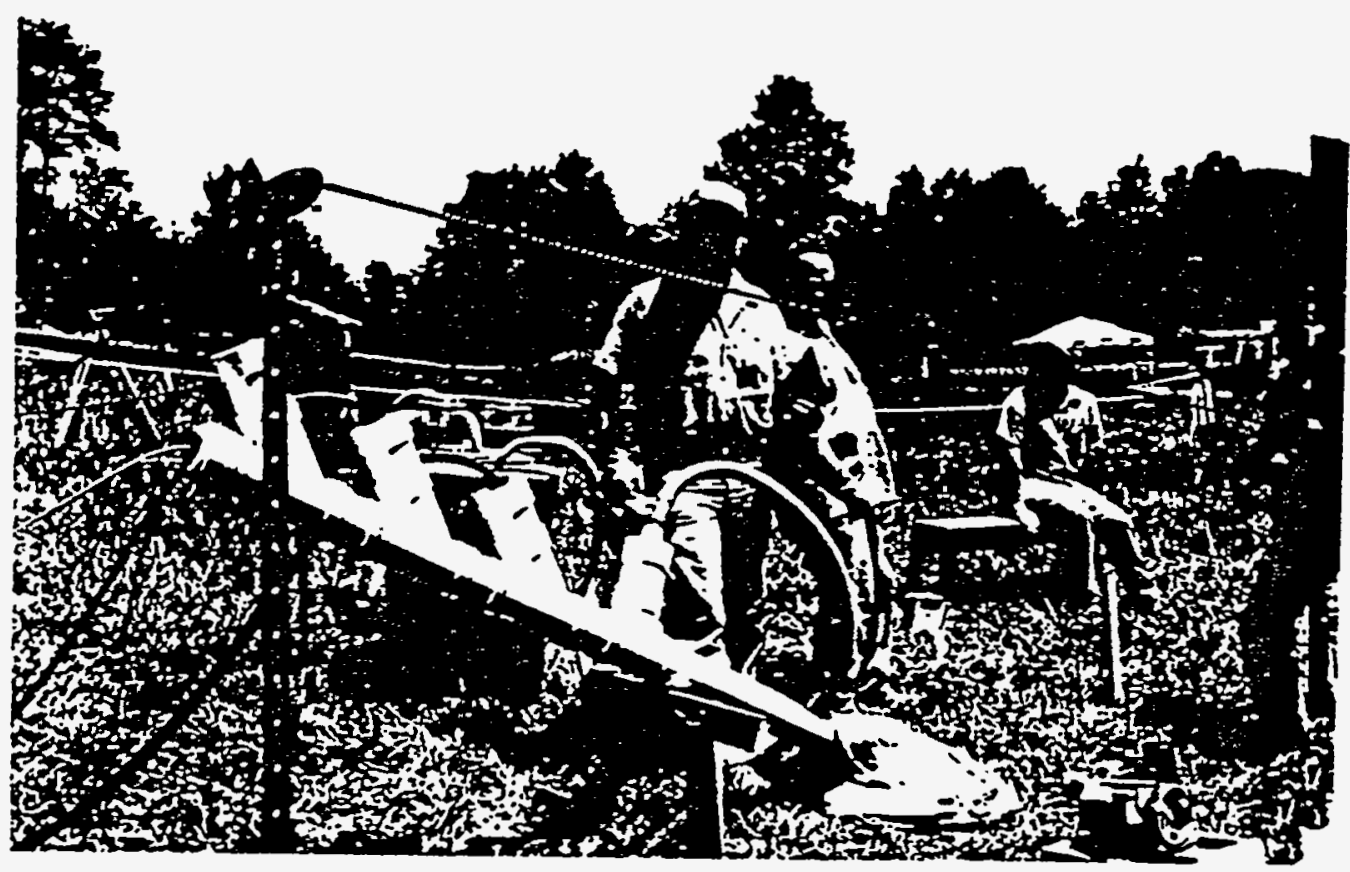

Fig. 18 Photograph Illustrating Arrangement of Stub Casing Muffler, Air Sampling Instrument. Supervac, and Radiation Monitoring Instrument 


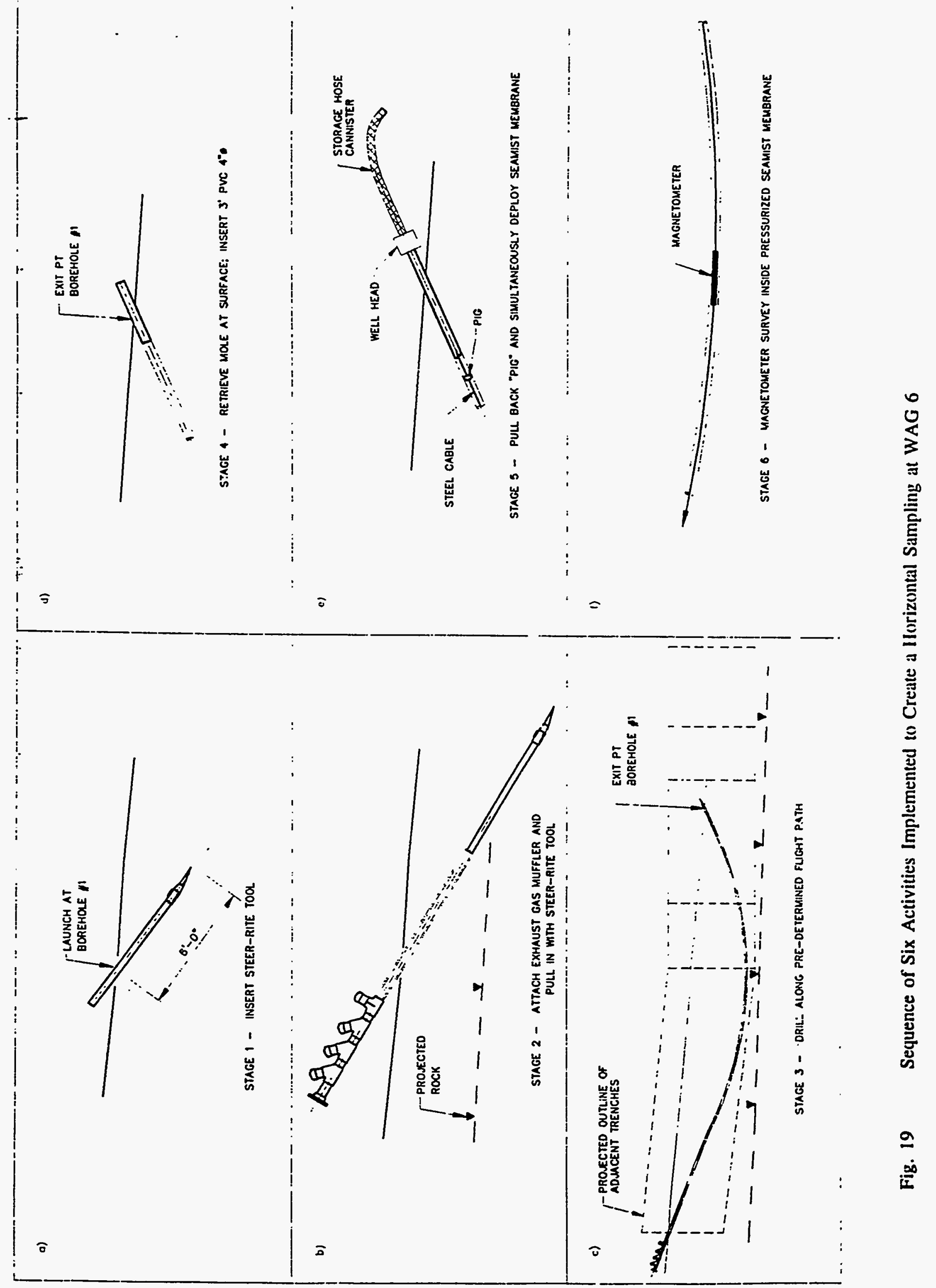



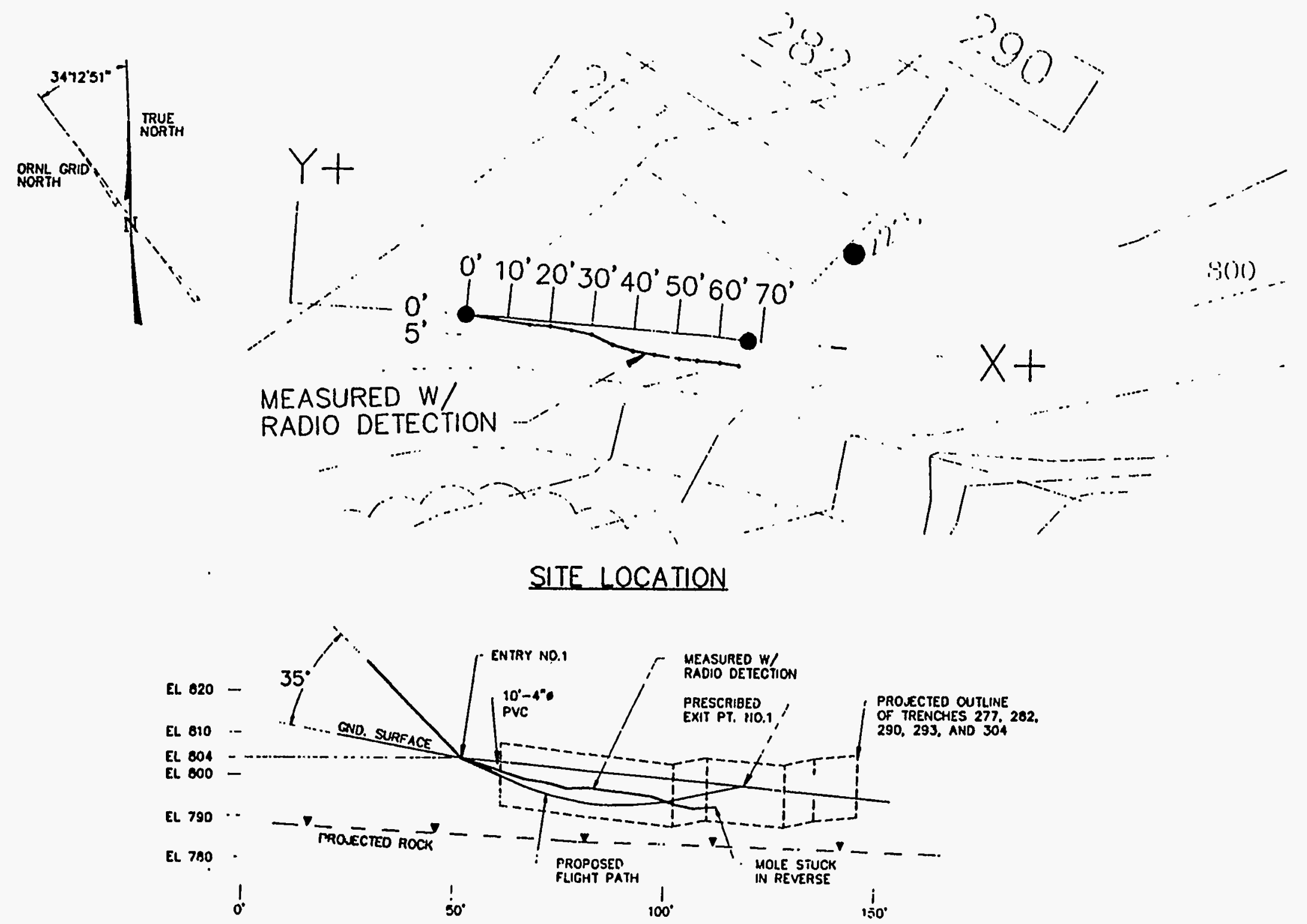

Fig. 20 Proposed Flight Path Versus Measured Using Radio-Detection Device 


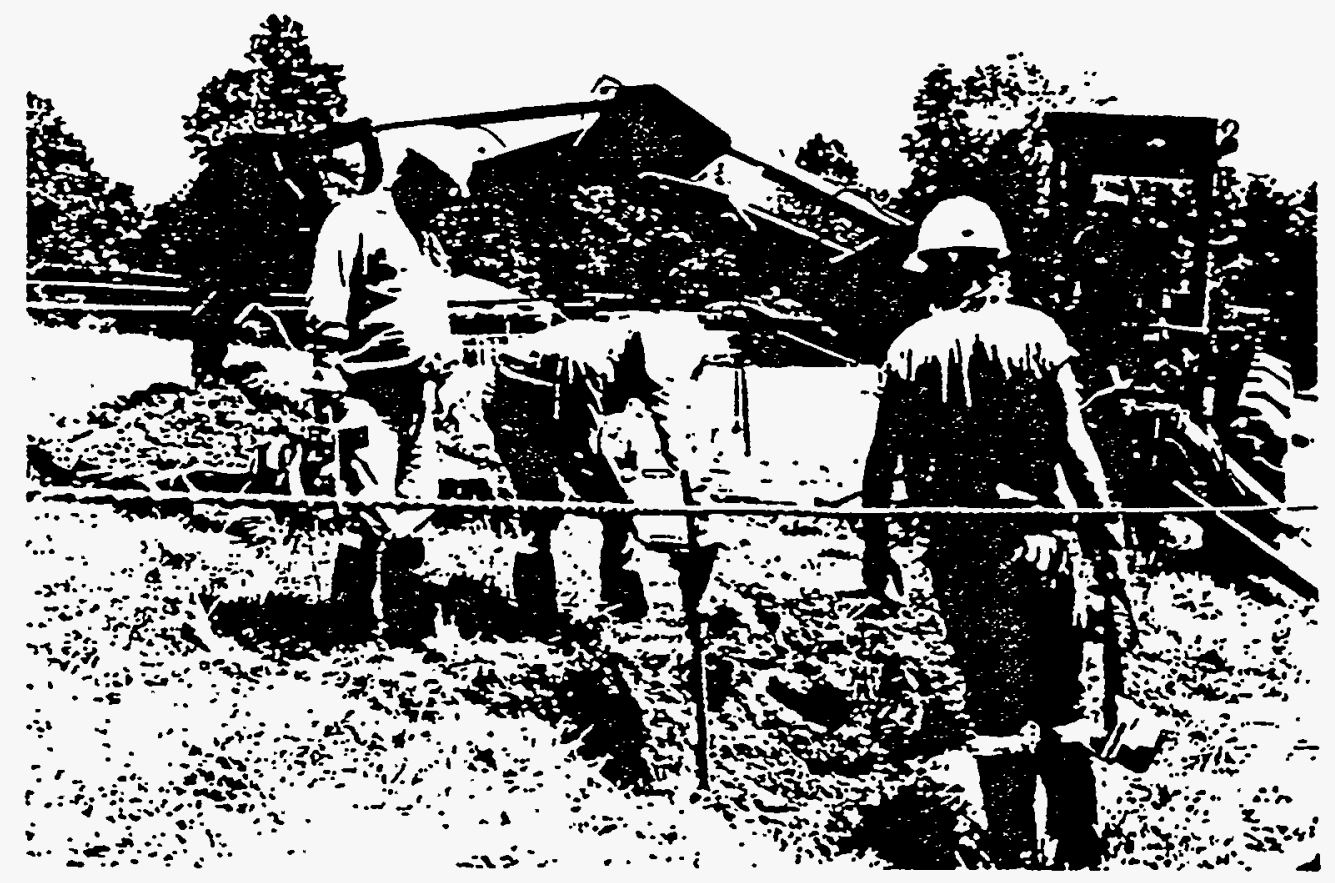

Fig. 21 Excavation of Pit to Rescue Steer Rite Mole 


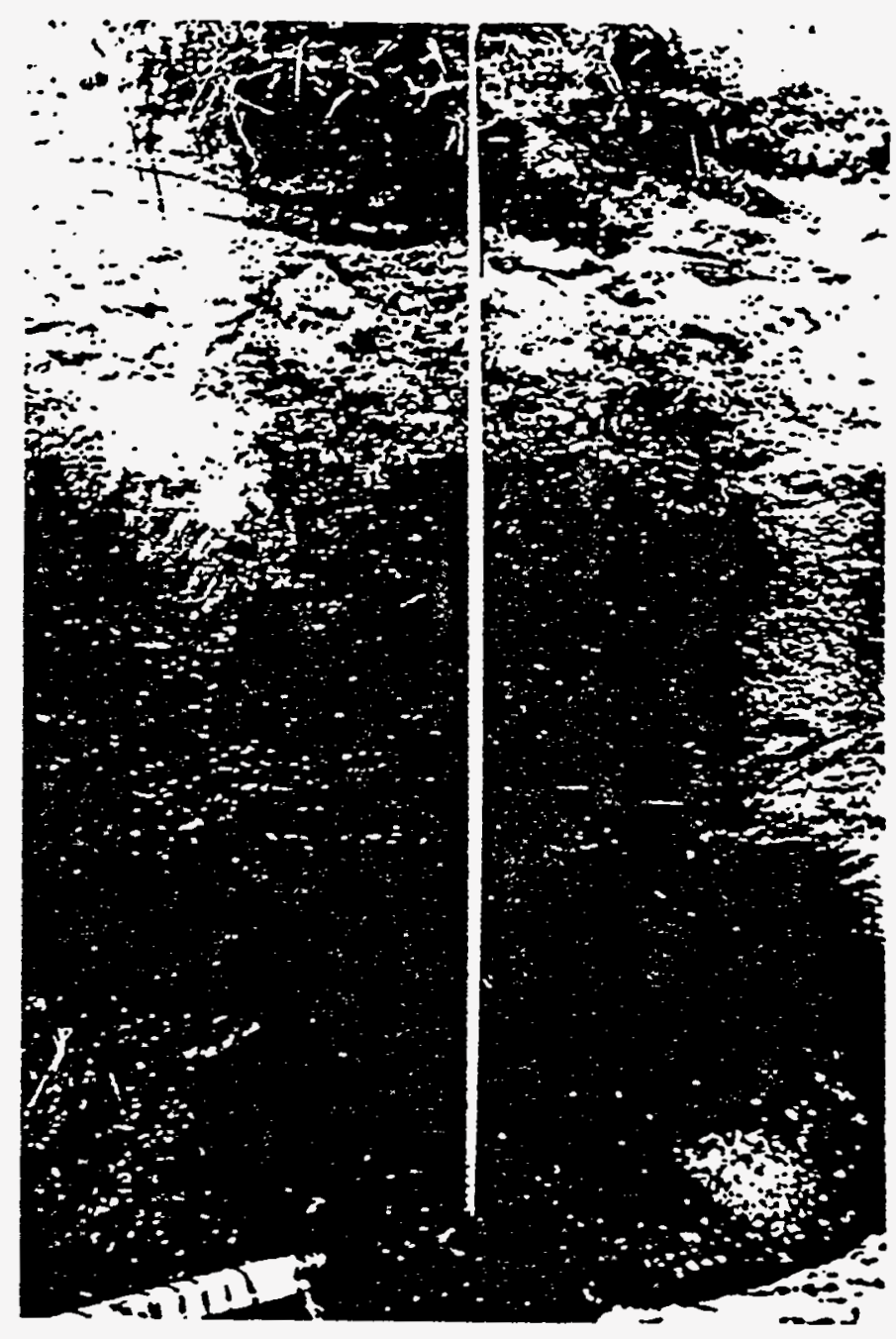

Fig. 22 Soil Stratigraphy Uncovered During Pit Excavation (Note: Soft Organic Clay Layer at Bottom of Pit) 


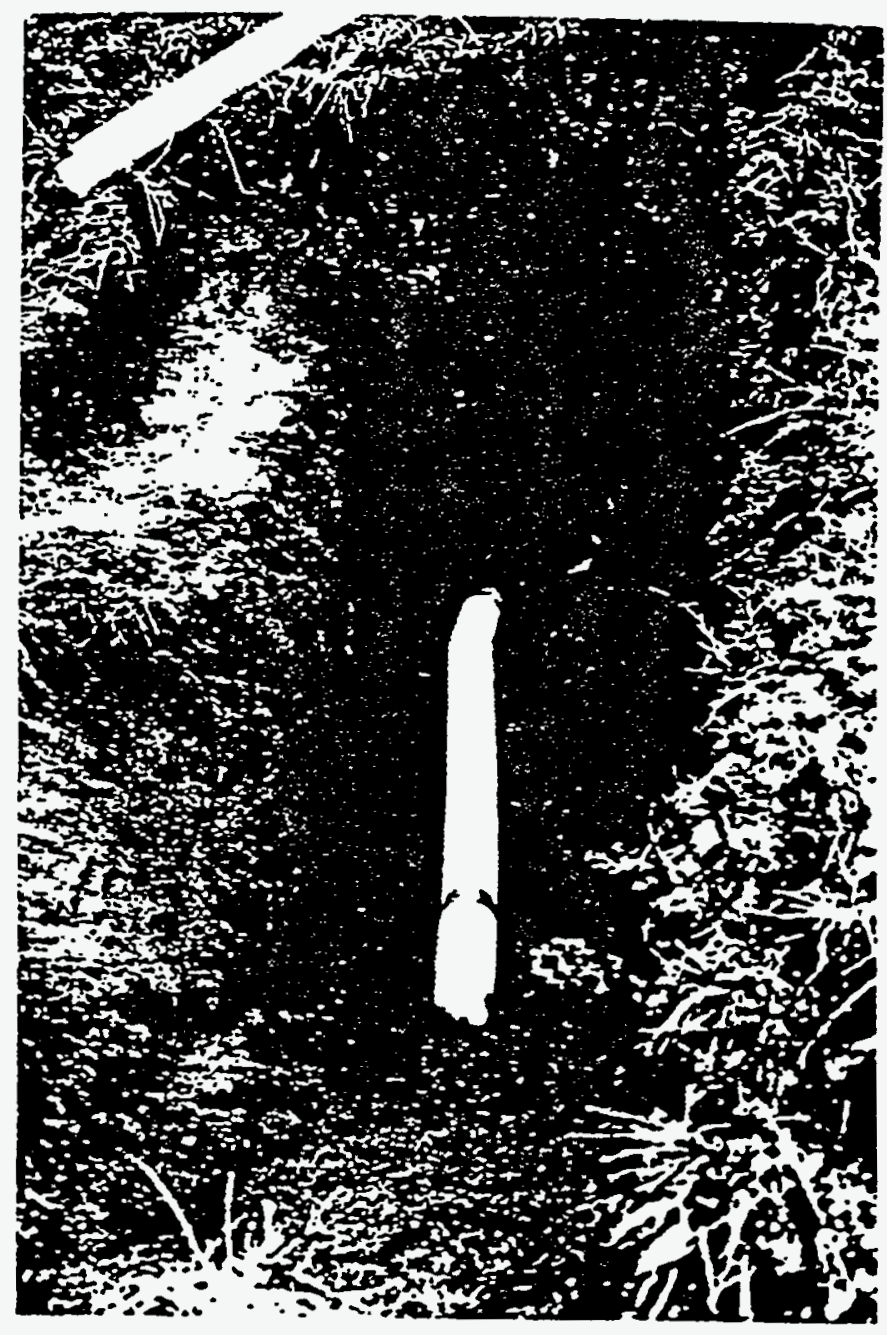

Fig. 23 SEAMIST Membrane Covered with Cotton Absorber, View from Open Pit Used to Rescue Steer Rite Drill 


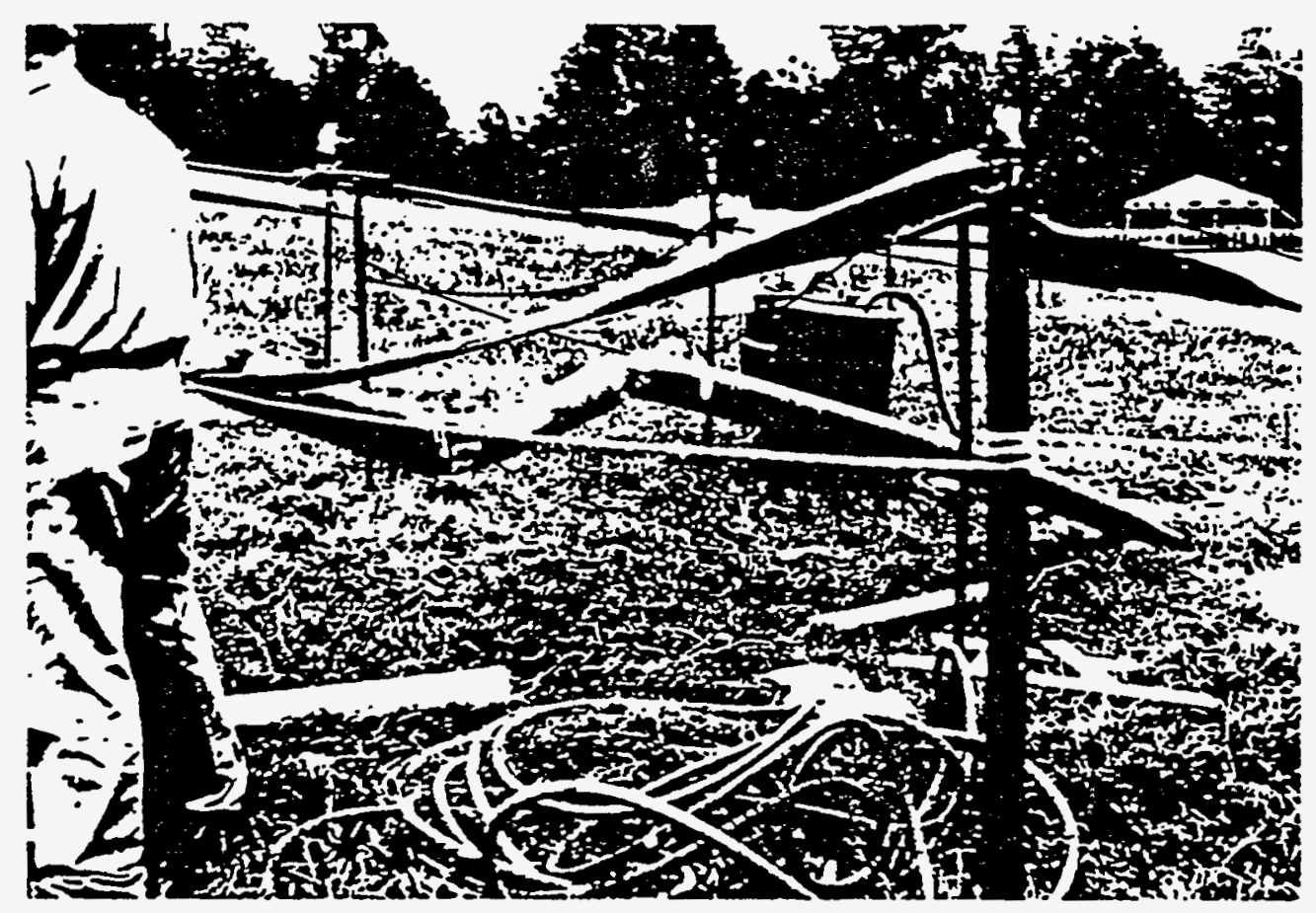

Fig. 24 SEAMIST Membrane Cinched-Off to Allow Magnetometer Placement Inside Depressurized Portion of Membrane

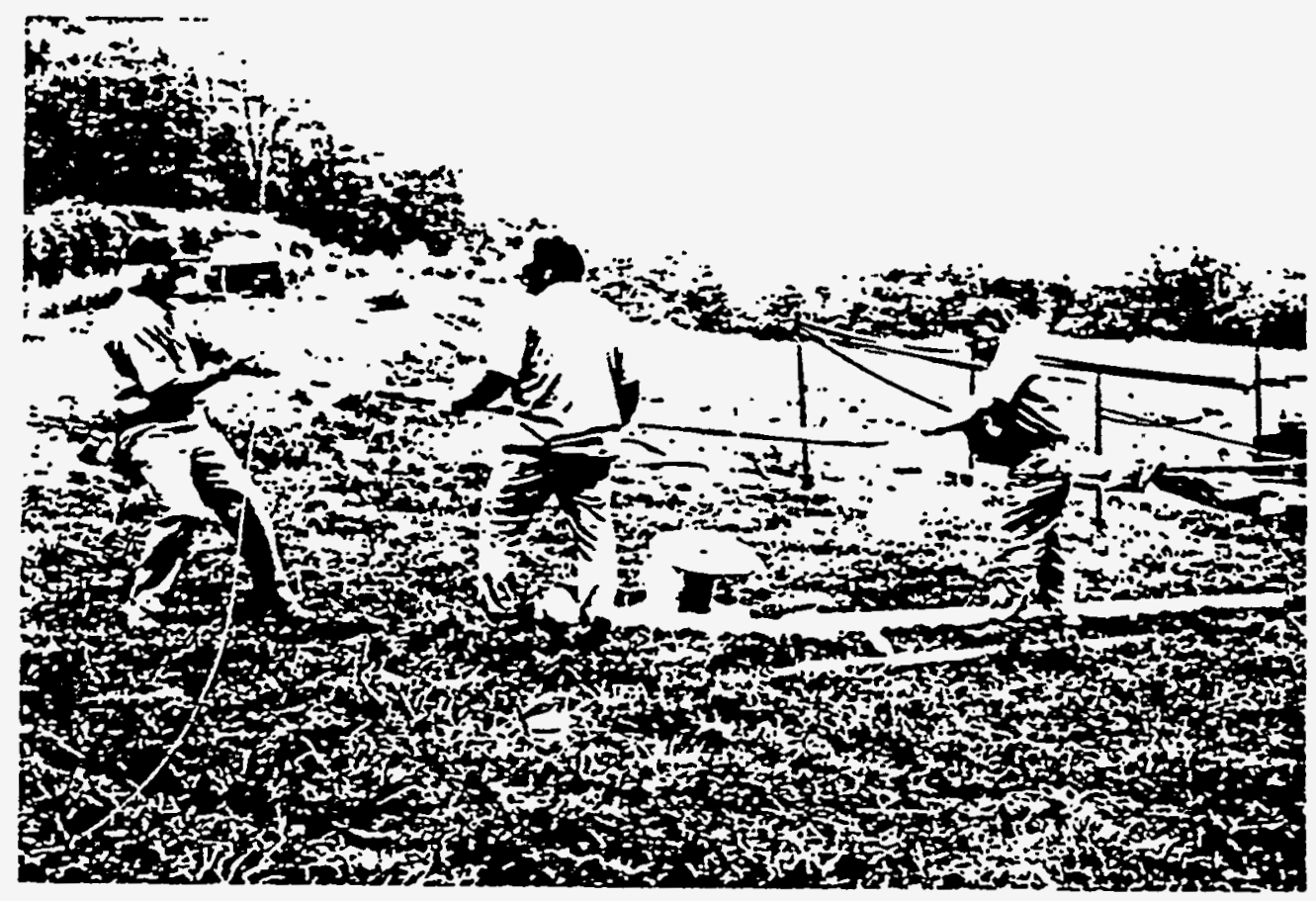

Fig. 25 Magnetometer Prepared for Placement Inside SEAMIST Membrane 


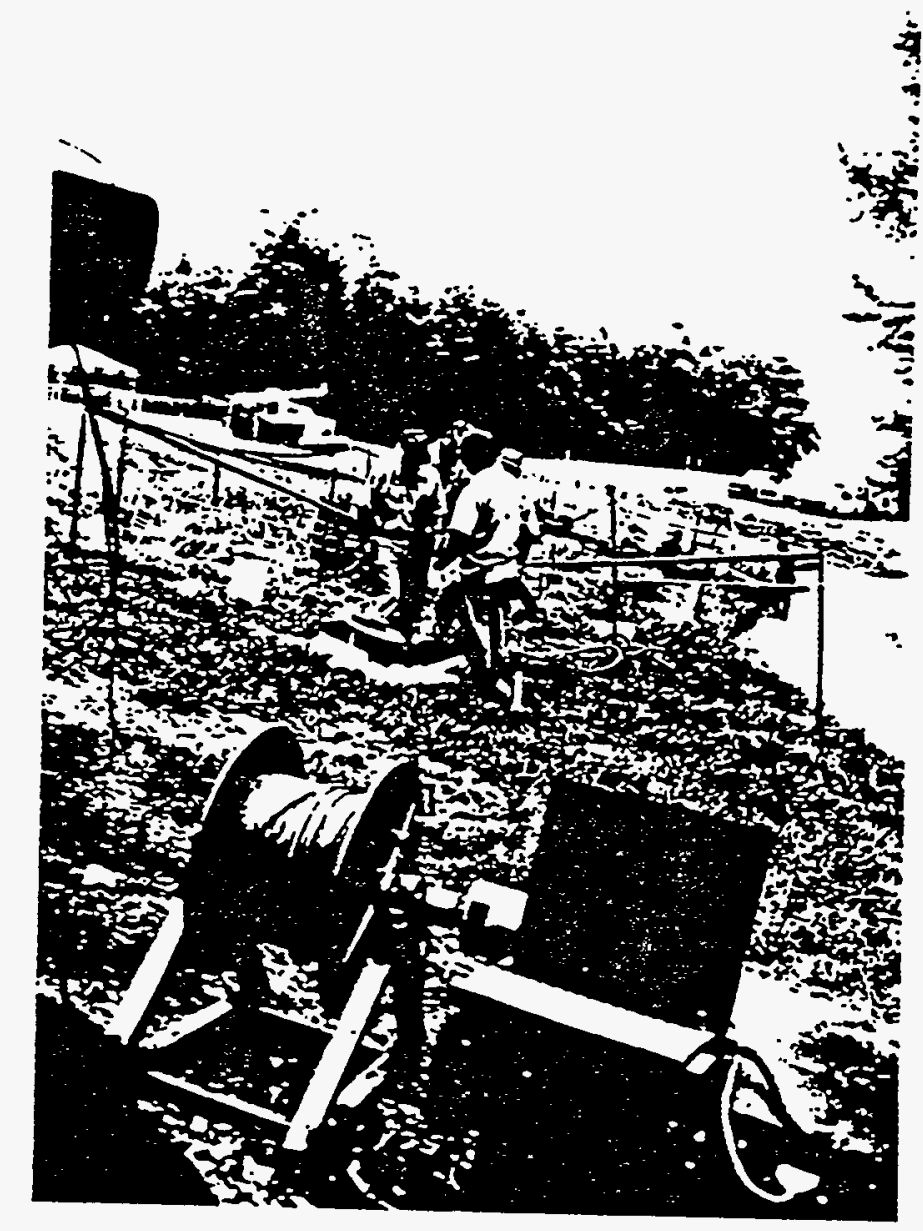

Fig. 26

General View of Equipment Used for Magnetometer Survey 


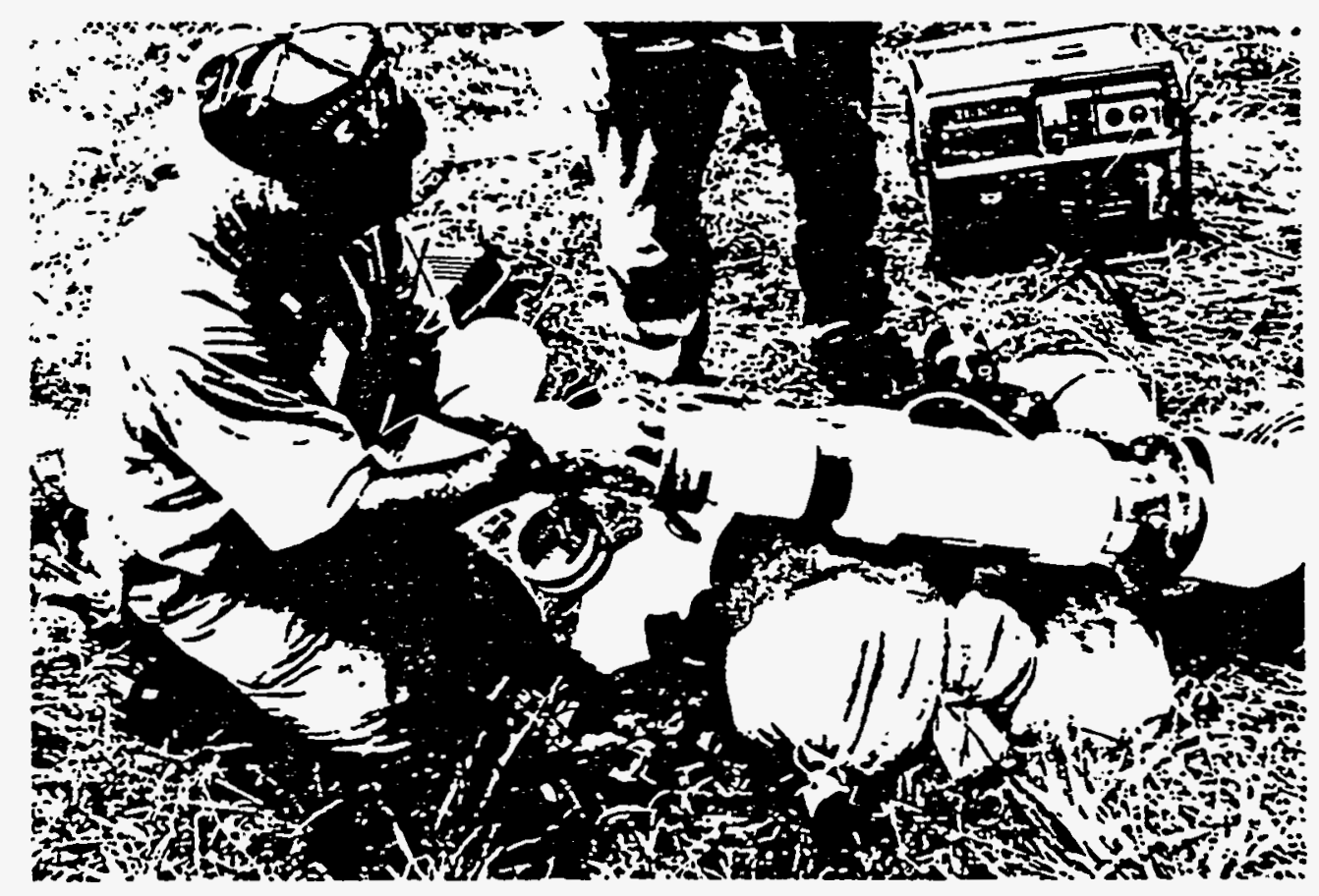

Fig. 27 Close-up Photograph of Sealing SEAMIST Membrane Wellhead 


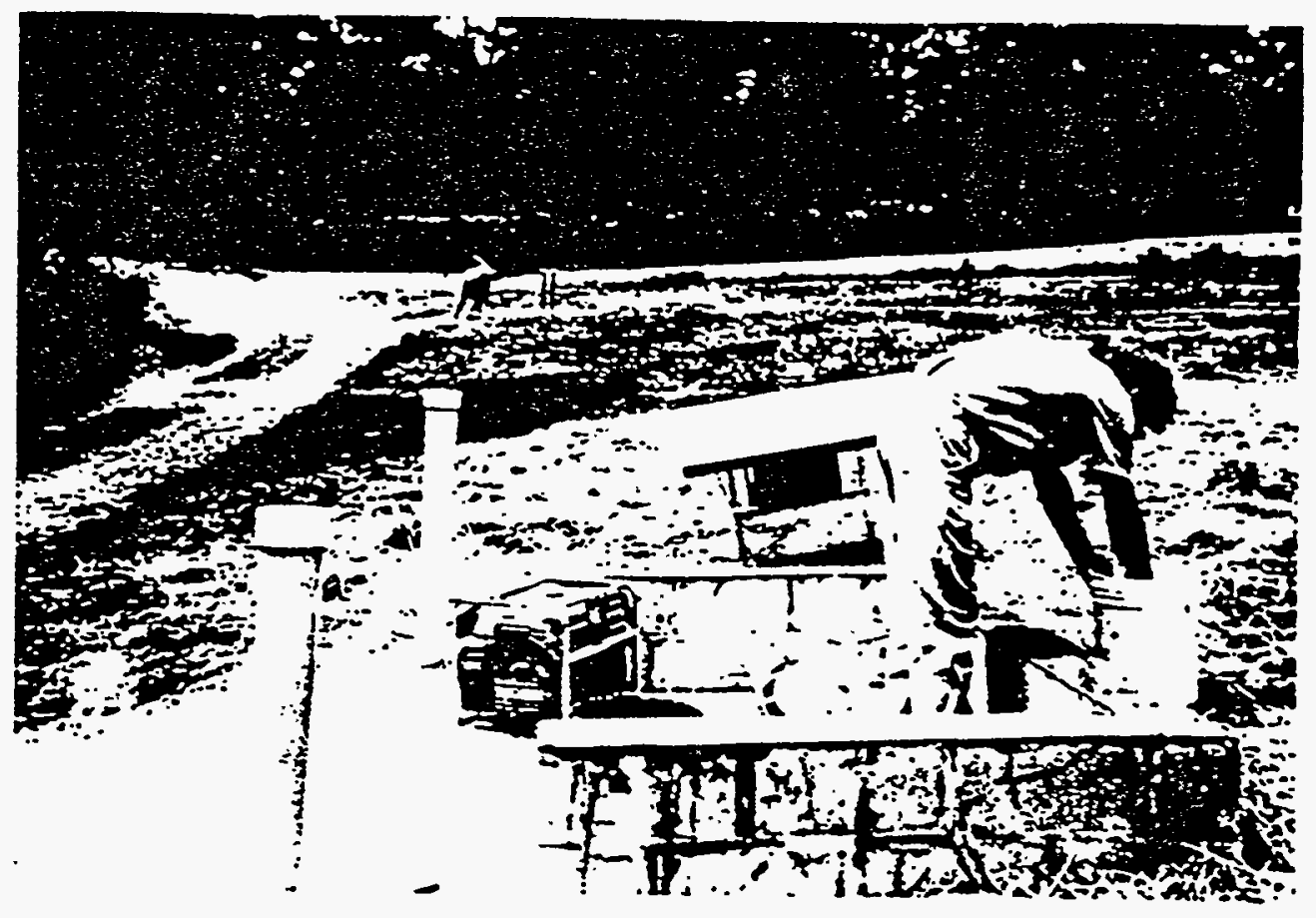

a)

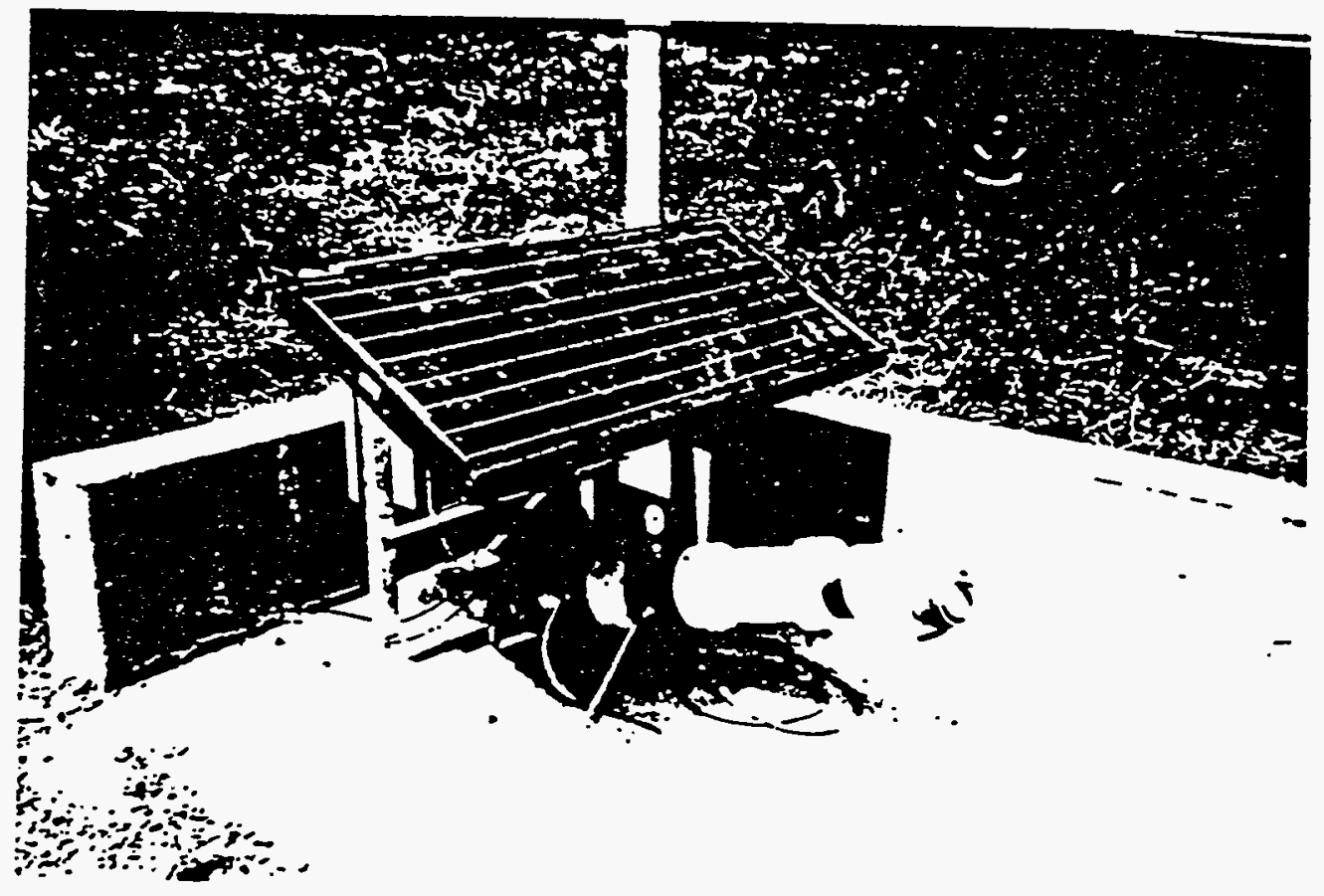

b)

Fig. 28 Wellhead Completion for Horizontal Bore No. 1

a) General View b) Close-up of Solar Powered Air Compressor to Keep SEAMIST Membrane Intlated 

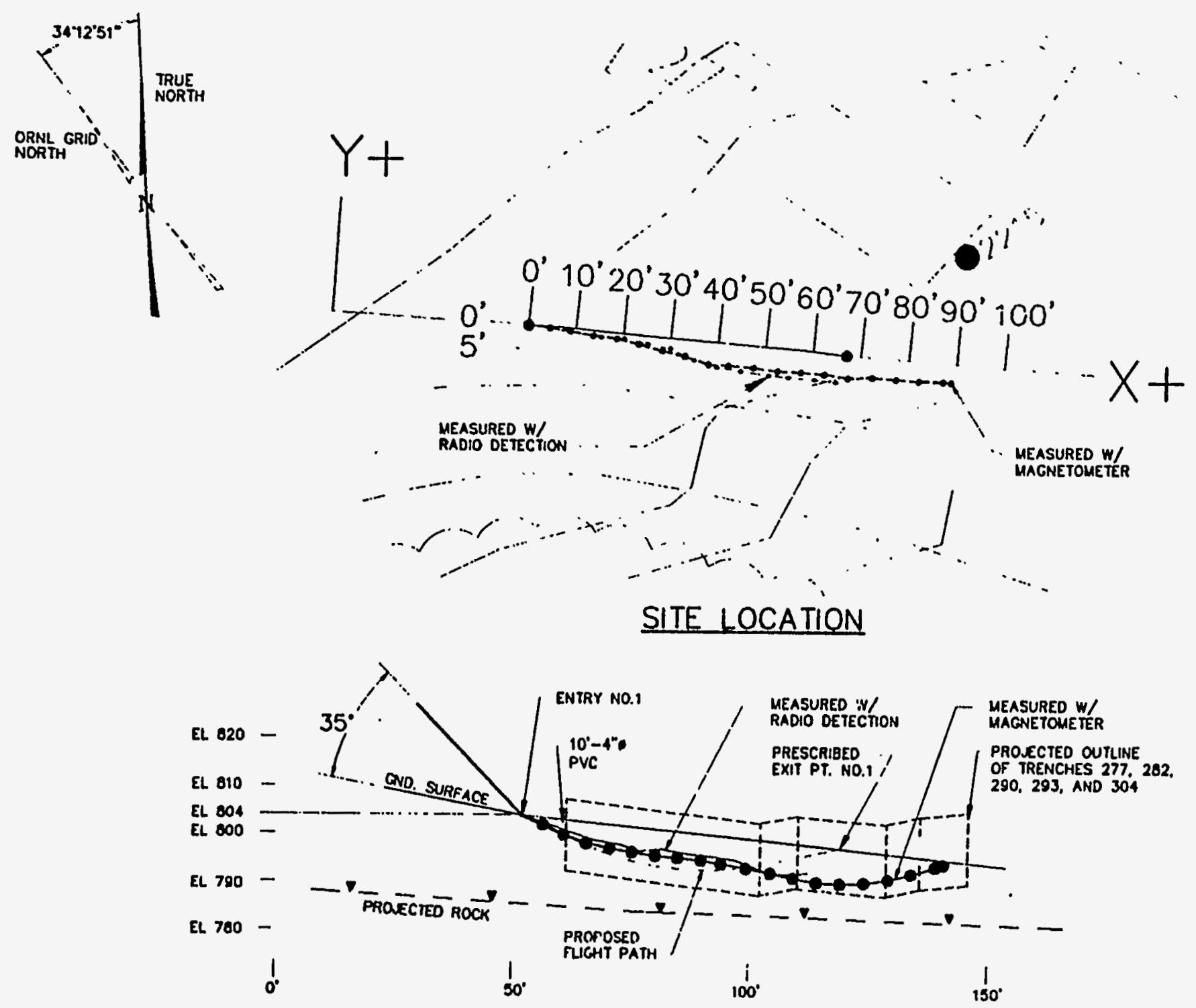

Fig. 29 Comparison Among Magnetometer and Radio Detection Surveys Versus Flight Path Prescribed for Borehole No. 1 at WAG 6 
Table 1. Inventory of WAG 6 Trenches: 277-282-290-304

a) Waste Composition and Container Types

Waste Composition

Container Types

Trench \#277

Dirt, filters, wood, steel, and other metals.

Cardboard boxes, stainless steel \& steel drums, wooden boxes, plastic

\section{Trench \#282}

Concrete blocks, steel plates, oils, resins, dirt.

Fiber drums, steel drums, wooden boxes, compactable \& non-compactable dumpsters, wooden boxes, gas cylinders.

Trench $\# 290$

Metal duct work, pipes, dirt, glass.

Wooden boxes, dumpsters.

Trench \#293

Dirt, piping, beryllium, oil, toluene, vermiculite, used filters, plastic, lumber.

G.I. cans, dumpsters, plastic, iron drums, cardboard boxes, oil drums.

Trench \#304

Concrete, a furnace, shop equipment, oil, floor tile.

Plywood boxes, fiber drums, wooden boxes, cardboard boxes. 
Table 1) Inventory of Wag 6 Trenches: 277-282-290-293-304

b) Isotope Content (curies)

\begin{tabular}{|c|c|c|c|c|c|c|c|}
\hline & & WAG Tre & nehes -150 & tope Contents & (curies) & & \\
\hline & & & & & & & \\
\hline & & & & Trench $F$ & & & \\
\hline & Isotope & 277 & 282 & 290 & 293 & 304 & TOTAL \\
\hline & Unidentified & 1.03703 & 11.089011 & 0.10853 & 0.16933 & 0.108804 & 12.512705 \\
\hline & IMFP & 0.00001 & & & 2.61 & 3.55 & 6.15001 \\
\hline & Am-241 & & & 0.000009 & 0.000522 & & 0.000531 \\
\hline & $A \ln -243$ & & & & & 0.00004 & 0.00004 \\
\hline & $B a-133$ & & 0.0005 & & & & 0.0005 \\
\hline & $B a-140$ & & 0.000001 & & & & 0.000001 \\
\hline & $C .14$ & 0.001 & & & & 0.001 & 0.002 \\
\hline & $\mathrm{Cm} \cdot 244$ & 0.0001 & 0.00011 & & 0.004122 & 0.00064 & $=0.004972$ \\
\hline & Cr-252 & & & & 0.0001 & & 0.0001 \\
\hline & 60.57 & 0.0001 & & & & & 0.0001 \\
\hline & Co-60 & 0.0001 & 0.011011 & 0.5001 & 0.1503 & 0.000254 & 0.0617041 \\
\hline & $C 5.137$ & 0.111 & 4.50151 & 1.00013 & 2.21494 & 7.01027 & 14.83685 \\
\hline & Cu-64 & 0.0001 & & & & & 0.0001 \\
\hline & Ey-154 & & & & 0.0001 & & 0.0001 \\
\hline & Fe-55 & 0.00011 & & & & & 0.0001 \\
\hline & $\mathrm{H}-3$ & & & & 7.500025 & 273.52 & 281.020025 \\
\hline & $\mid 1.131$ & & & 0.00002 & 0.091 & 0.11 & 0.19102 \\
\hline & $11 .-192$ & 0.01 & & & & & 0.01 \\
\hline & $\bar{K} r-\overline{85}$ & & 0.001 & & & & 0.001 \\
\hline & Mn-54 & 0.00011 & & & & & 0.0001 \\
\hline & $\sqrt{\mathrm{Na}-22}$ & 0.0001 & & & & & 0.0001 \\
\hline & Ni-63 & & & & & 0.000002 & 0.000002 \\
\hline & P.32 & & 0.000003 & & & 0.000001 & 0.000004 \\
\hline & Pu-238 & 0.000011 & & & & & 0.000011 \\
\hline & $P_{U}=239$ & & & & 0.00001 & 0.002801 & 0.002811 \\
\hline & Rिa.226 & & & & 0.0003 & & 0.0003 \\
\hline & $5 \mathrm{Sm}=\overline{15 !}$ & & 2 & & & & .2] \\
\hline & $S n-121 \bar{M}$ & & 2 & & & & 4 \\
\hline & Sr. 85 & & 0.000003 & & & 0.000005 & 0.000003 \\
\hline & Sr-90 & 0.0101 & -400101 & 1.0001 & 0.071941 & 7.001005 & 13.084155 \\
\hline & Ta.132 & 0.0001 & & & & & 0.0001 \\
\hline & TC-95M & & 0.000003 & & & & 0.000003 \\
\hline & Tि.99 & & 0.001 & & 0.016901 & 1.00101 & $1.0: 3911$ \\
\hline & Th-232] & 0.000015 & & 0.000001 & 0.000012 & 0.00001 & 0.000039 \\
\hline & 4.233 & 0.00013 & $0.00010 i$ & & 0.0001 & 0.000105 & 0.000430 \\
\hline & u. 235 & 0.001 & & 0.000013 & 0.000002 & & 0.001015 \\
\hline & U-233 & 0.00001 & 0.000002 & $0.000 \leqslant 22$ & 0000023 & 0.000135 & 0.001093 \\
\hline & $M-181$ & 0.0001 & & & & & 0.0001 \\
\hline & $2=0.63$ & 0.0001 & & & & & $0.000 \mathrm{i}$ \\
\hline & TEr-su & & 15 & & & & 15 \\
\hline & TTOTAL & 9.17 & 25.11 & 2.61 & 18.82 & 292.30 & 340.00 \\
\hline
\end{tabular}


Table 1) Inventory of Wag 6 Trenches: 277-282-290-293-304

c) Coordinate Location of Trench Corners

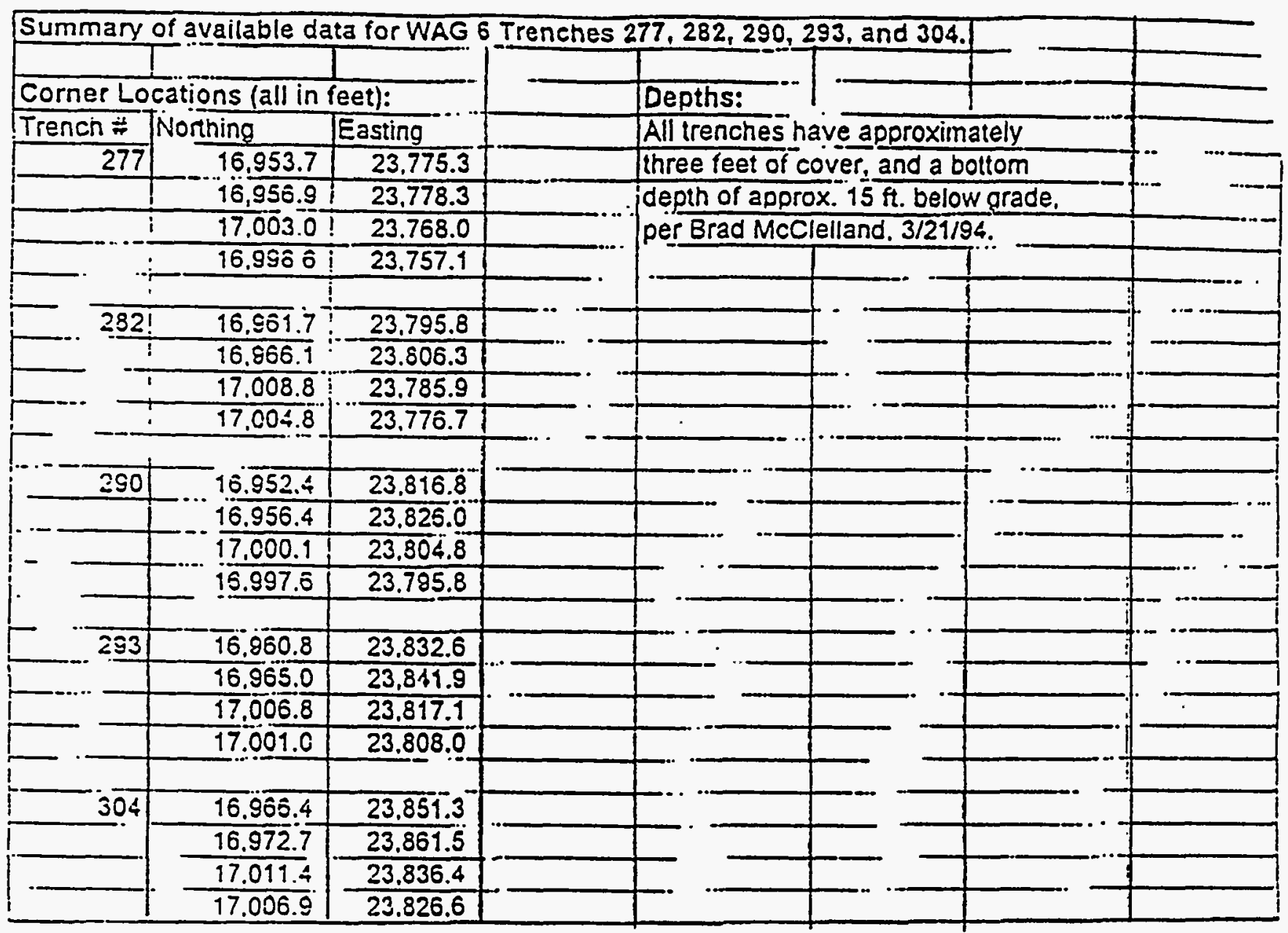


TABLE 2

Test Data Measured During the Steer Rite

Horizontal Directional Test Bore at WAG 6, ORNL

\begin{tabular}{|c|c|c|c|c|c|c|c|c|c|}
\hline 1 & 2 & 3 & 4 & 5 & 6 & 7 & 8 & 9 & \\
\hline TMME & $\begin{array}{c}\text { TOOL FACE } \\
\text { POINTER } \\
\text { (clock position) }\end{array}$ & $\begin{array}{c}\text { VANE } \\
\text { PRESS } \\
\text { (psi) } \\
\end{array}$ & $\begin{array}{c}\text { BOREHOLE } \\
\text { LENGTH } \\
\text { (ft) }\end{array}$ & $\begin{array}{c}\text { MEASURED } \\
\text { ANGLE } \\
\text { (degrees) } \\
\end{array}$ & $\begin{array}{l}\text { GROUND } \\
\text { SURFACE } \\
\text { ELEV. (ft) } \\
\end{array}$ & $\begin{array}{c}\text { X-DIST } \\
\text { (ft) }\end{array}$ & $\begin{array}{c}\text { Y-DIST } \\
\text { (ft) }\end{array}$ & $\begin{array}{l}\text { SONDE } \\
\text { DEPTH } \\
\text { (ft) }\end{array}$ & COMMENT \\
\hline $\begin{array}{c}(8 / 17 / 94) \\
9: 15\end{array}$ & $12: 00$ & 0 & 6.0 & -29.0 & 804.0 & & & & $\begin{array}{l}\text { Start test; Sunny and hot }\left(90^{\circ} \text { s) }\right. \\
\text { Stake No. } 55 \text {; Launch Angle }=35^{\circ}\end{array}$ \\
\hline $9: 25$ & & & & & & & & & Install PVC casing @ hole collar \\
\hline $9: 32$ & & & & & & & & & Start; began correction of roll \\
\hline \multirow[t]{2}{*}{$9: 35$} & & & & & & & & & Stopped to adjust cable and mark hose \\
\hline & & & & & & 5.0 & 0 & & Sonde reading (5'; stake no. 56)* \\
\hline $9: 45$ & $12: 00$ & 0 & 12.5 & -20.6 & & & & & \\
\hline $9: 55$ & $12: 00$ & 0 & 14.0 & -13.4 & & & & & $\begin{array}{l}\begin{array}{l}\text { Pressurize vanes @ 10:00 to make mole } \\
\text { drill deeper }\end{array} \\
\end{array}$ \\
\hline 10:05 & 9:00 & 1000 & 16.0 & -11.3 & & & & & \\
\hline \multicolumn{10}{|l|}{$10: 20$} \\
\hline $10: 25$ & & & 18.0 & -7.9 & & & & & \\
\hline $10: 30$ & & & & & 803.2 & 9.9 & -0.3 & & Sonde reading (10'; stake no. 59)* \\
\hline $10: 37$ & $6: 00$ & 2000 & 20.0 & -8.3 & & & & & \\
\hline $10: 53$ & $3: 00$ & 0 & 22.0 & -8.4 & & & & & \\
\hline $11: 00$ & $3: 00$ & 2000 & 23.0 & -8.2 & & & & & \\
\hline $\begin{array}{l}11: 30- \\
12: 30 \\
\end{array}$ & & & & & 802.6 & 15.3 & -1.1 & 3.7 & Sonde reading (15'; stake no. 62) \\
\hline $12: 50$ & & & 27.0 & & 802.1 & 20.2 & -1.0 & 4 & Sonde reading (20'; stake no. 65$)$ \\
\hline $13: 05$ & $11: 30$ & 2200 & 30.0 & -7.4 & & & & & \\
\hline 13:07 & $9: 00$ & 2100 & 32.0 & -7.3 & & & & & \\
\hline $13: 10$ & $7: 30$ & 0 & & & 801.6 & 25.2 & -1.6 & 4.9 & $\begin{array}{l}\text { Sonde reading (25'; stake no. } 68 \text { ) } \\
\text { Release pressure }\end{array}$ \\
\hline 13:15 & $6: 30$ & 0 & 36.0 & -4.7 & & & & & \\
\hline 13:18 & $6: 30$ & 0 & 38.0 & -7.9 & & & & & \\
\hline
\end{tabular}

Note: See last page of table for column explanations

* Nominal X-direction location and stake number; See Figure 16 for coordinate definitions 
TABLE 2 (Con't)

Test Data Measured During the Steer Rite Horizontal Directional Test Bore at WAG 6, ORNL

\begin{tabular}{|c|c|c|c|c|c|c|c|c|c|}
\hline 1 & 2 & 3 & 4 & 5 & 6 & 7 & 8 & 9 & \\
\hline TIME & $\begin{array}{l}\text { TOOL FACE } \\
\text { POINTER } \\
\text { (clock position) }\end{array}$ & $\begin{array}{l}\text { VANE } \\
\text { PRESS } \\
\text { (psi) }\end{array}$ & $\begin{array}{l}\text { BOREHOLE } \\
\text { LENGTH } \\
\text { (ft) }\end{array}$ & $\begin{array}{l}\text { MEASURED } \\
\text { ANGLE } \\
\text { (degrees) }\end{array}$ & $\begin{array}{l}\text { GROUND } \\
\text { SURFACE } \\
\text { ELEV. (ft) }\end{array}$ & $\begin{array}{c}\text { X-DIST } \\
\text { (ft) }\end{array}$ & $\begin{array}{c}\text { Y-DIST } \\
(\mathrm{ft}) \\
\end{array}$ & $\begin{array}{l}\text { SONDE } \\
\text { DEPTH } \\
\text { (fi) }\end{array}$ & COMMENT \\
\hline 13:19 & & & & & 801.0 & 30.0 & -2.2 & 4.0 & Sonde reading ( 30 '; stake no. 71$)$ \\
\hline $13: 25$ & $7: 00$ & 0 & 40.0 & -10.0 & & & & & \\
\hline $13: 27$ & $7: 00$ & 0 & 42.0 & -11.4 & & & & & \\
\hline $13: 30$ & $7: 30$ & 0 & 43.0 & -12.9 & 800.5 & 35.2 & -3.0 & 4.3 & Sonde reading ( $35^{\prime}$; stake no. 74 ) \\
\hline $13: 35$ & $7: 45$ & 0 & 44.0 & -10.8 & & & & & $\begin{array}{l}\text { From 1:05 to } 1: 35 \text { mole is pointed } \\
\text { downward to gain depth }\end{array}$ \\
\hline 13.38 & $8: 00$ & 1800 & 46.0 & -10 & & & & & \\
\hline 13:48 & $5: 30$ & 2300 & 48.0 & -11.8 & & & & & \\
\hline $13: 50$ & & & & & 799.9 & 40.0 & -4.2 & 4.2 & Sonde reading (40'; stake no. 77 ) \\
\hline $13: 54$ & $1: 00$ & 2260 & 50.0 & -10.1 & & & & & \\
\hline $13: 55$ & $9: 30$ & 2200 & 52.0 & -9.0 & & & & & $\begin{array}{l}\text { Release vanes - go slow } \\
1: 38 \text { to } 1: 55 \text { make mole dive @ } 10 \\
\text { degrees }\end{array}$ \\
\hline $14: 00$ & $8: 00$ & 0 & 53.0 & -10.3 & & & & & Begin left turn \\
\hline 14:04 & & & & & 799.2 & 45.1 & -5.2 & 4.3 & Sonde reading ( $45^{\prime} ;$ stake no. 80 ) \\
\hline 14:11 & $7: 00$ & 0 & 54.0 & -10.8 & & & & & \\
\hline $14: 15$ & $7: 15$ & 0 & 56.0 & -13 & & & & & \\
\hline $14: 18$ & $7: 30$ & 0 & 58.0 & -13.8 & & & & & Start backup to $56.5^{\circ}$ \\
\hline $14: 35$ & $12: 00$ & 0 & 56.5 & -12.3 & 798.6 & 51.0 & -5.5 & & $\begin{array}{l}\text { Sonde reading ( } 50^{\prime} \text {; stake no. } 83 \text { ) } \\
\text { Back up \& stant up slowly }\end{array}$ \\
\hline $14: 41$ & $11: 30$ & 0 & 60.0 & -10.3 & & & & & \\
\hline $14: 44$ & $12: 00$ & 0 & 62.0 & -8.9 & & & & & \\
\hline $14: 45$ & $12: 00$ & 0 & 63.0 & -8.3 & 798.3 & 55.2 & -5.9 & 5.6 & Sonde reading ( $55^{\prime}$; stake no. 86 ) \\
\hline $14: 56$ & $10: 20$ & 0 & 64.0 & -9.2 & & & & & \\
\hline $15: 00$ & $10: 20$ & 1000 & 63.0 & & & & & & $\begin{array}{l}\text { Start to reverse mole; steering fins } \\
\text { partially locked }\end{array}$ \\
\hline
\end{tabular}


TABLE 2 (Con't)

Test Data Measured During the Steer Rite Horizontal Directional Test Bore at WAG 6, ORNL

\begin{tabular}{|c|c|c|c|c|c|c|c|c|c|}
\hline 1 & 2 & 3 & 4 & 5 & 6 & 7 & 8 & 9 & \\
\hline TIME & $\begin{array}{l}\text { TOOL FACE } \\
\text { POINTER } \\
\text { (clock position) }\end{array}$ & $\begin{array}{l}\text { VANE } \\
\text { PRESS } \\
\text { (psi) } \\
\end{array}$ & $\begin{array}{l}\text { BOREHOLE } \\
\text { LENGTH } \\
\text { (ft) } \\
\end{array}$ & $\begin{array}{c}\text { MEASURED } \\
\text { ANGLE } \\
\text { (degrees) } \\
\end{array}$ & $\begin{array}{l}\text { GROUND } \\
\text { SURFACE } \\
\text { ELEV. (ft) } \\
\end{array}$ & $\begin{array}{c}\text { X-DIST } \\
\text { (ft) } \\
\end{array}$ & $\begin{array}{l}\text { Y-DIST } \\
\text { (ft) } \\
\end{array}$ & $\begin{array}{c}\text { SONDE } \\
\text { DEPTH } \\
\text { (ft) } \\
\end{array}$ & COMMENT \\
\hline $15: 08$ & $10: 20$ & 0 & 64.0 & & & & & & Go forward; reverse mole \\
\hline $15: 13$ & $12: 00$ & 1000 & 63.0 & & & & & & $\begin{array}{l}\text { Fins unlock and mole rotates to } \\
\text { 12:00 position } \\
\end{array}$ \\
\hline 15:14 & $12: 00$ & 0 & 64.5 & -6.5 & & & & & \\
\hline $15: 20$ & $11: 00$ & 0 & 66.0 & -3.9 & & & & & Throttle back air compressor \\
\hline $15: 35$ & $11: 00$ & 0 & 68.0 & -0.7 & 797.9 & 60.7 & -6.0 & 6.0 & Sonde reading (60'; stake no. 89$)$ \\
\hline $15: 42$ & 11:00 & 0 & 70.0 & +1.4 & & & & & Mole begins climbing \\
\hline $15: 50$ & $10: 45$ & 0 & 72.0 & +3.2 & & & & & \\
\hline $15: 53$ & $10: 30$ & 0 & 73.0 & +5.4 & & & & & \\
\hline $16: 00$ & $1: 00$ & 1000 & 72 & & & & & & $\begin{array}{l}\text { Backup } 12^{n} \text { to orient drill into } 1: 00 \\
\text { position }\end{array}$ \\
\hline $16: 07$ & $1: 00$ & 0 & 74.0 & +8.4 & & & & 5.9 & Sonde reading \\
\hline $16: 15$ & $1: 00$ & 2000 & 76.0 & +13 & & & & & Back mole into 13 degree climb \\
\hline $16: 20$ & $12: 30$ & 0 & 78.0 & +14.6 & 797.6 & 65.3 & -5.9 & 5.4 & Sonde reading (65'; stake no. 92) \\
\hline $16: 25$ & $12: 15$ & 0 & 80.0 & +17.1 & & & & & \\
\hline
\end{tabular}

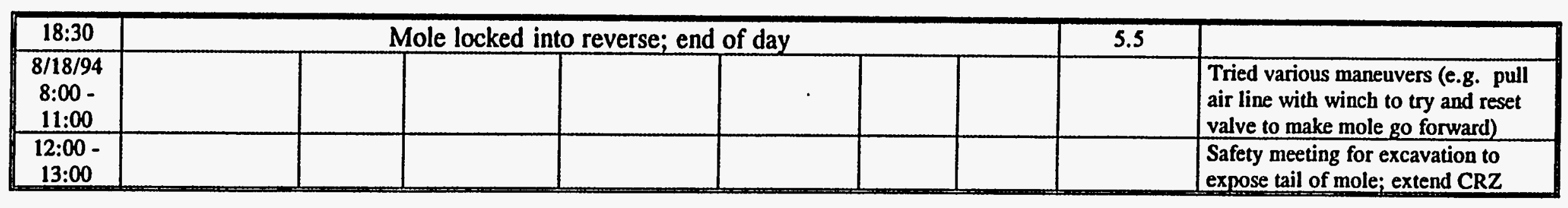


TABLE 2 (Con't)

Test Data Measured During the Steer Rite

Horizontal Directional Test Bore at WAG 6, ORNL

\begin{tabular}{|c|c|c|c|c|c|c|c|c|c|}
\hline 1 & 2 & 3 & 4 & 5 & 6 & 7 & 8 & 9 & \\
\hline TIME & $\begin{array}{l}\text { TOOL FACE } \\
\text { POINTER } \\
\text { (clock position) }\end{array}$ & $\begin{array}{c}\text { VANE } \\
\text { PRESS } \\
\text { (psi) }\end{array}$ & $\begin{array}{l}\text { BOREHOLE } \\
\text { LENGTH } \\
\text { (ft) }\end{array}$ & $\begin{array}{l}\text { MEASURED } \\
\text { ANGLE } \\
\text { (degrees) } \\
\end{array}$ & $\begin{array}{l}\text { GROUND } \\
\text { SURFACE } \\
\text { ELEV. (ft) }\end{array}$ & $\begin{array}{l}\text { X-DIST } \\
\text { (ft) }\end{array}$ & $\begin{array}{c}\text { Y-DIST } \\
\text { (ft) } \\
\end{array}$ & $\begin{array}{l}\text { SONDE } \\
\text { DEPTH } \\
\text { (ft) }\end{array}$ & COMMENT \\
\hline $\begin{array}{l}13: 00- \\
16: 30\end{array}$ & & & & & & & & & $\begin{array}{l}\text { Excavate pit at tail of mole; Pit } 6^{\circ} \\
\text { wide } \times 8^{\circ} \text { long } \times 6^{\prime} \text { deep }\end{array}$ \\
\hline $\begin{array}{l}16: 30- \\
17: 10\end{array}$ & & & & & & & & & $\begin{array}{l}\text { Remove soil from around tail of } \\
\text { mole, loosen air line, reset valve, } \\
\text { propel mole forward }\end{array}$ \\
\hline $\begin{array}{l}17: 10- \\
17: 15\end{array}$ & & & & & & & & & $\begin{array}{l}\text { Depth to top of mole (tape measure) } \\
=7 \mathrm{ft}\end{array}$ \\
\hline
\end{tabular}

\section{COLUMN EXPLANATIONS:}

1 Time at which reading or measurement occurred

2 The Tool Face Pointer indicates the position in which the mole steers if the vanes are depressurized (i.e., vane pressure $=0$ ). The following diagram indicates the tool face orientation relative to the clock position.

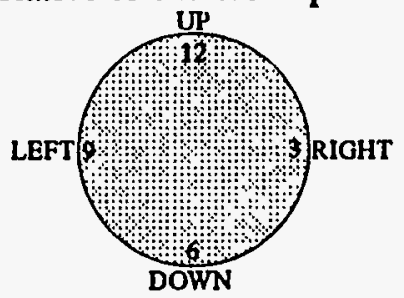

The application or release of Vane Pressure activates or deactivates the steering fins. When Vane Pressure is zero the steering shroud does not rotate and the drill steers according to the current clock position. When the Vane Pressure is greater than zero, the steering shroud rotates continuously producing a net-zero reactive torque and thereby producing a wobbly, but approximately straight, path.
4 The Borehole Length is the distance from the ground penetration point of the borehole to the tip of the drill. Drill length $=6.8 \mathrm{ft}$.

5 The Measured Angle is the angle in the $\mathrm{X}-\mathrm{Z}$ plane that the drill makes with the horizontal.

6 The Ground Surface Elevation, at the sonde location which is in the tail of the drill. See Figure 16 for coordinate definitions.

$7 \& 8$ The $\mathrm{X}$ and $\mathrm{Y}$ Distances refer to the location of the sonde readings relative to the origin at Stake No. 55. See Figure 16 for plan location of stakes.

9 The Sonde Depth refers to the Radio Detection reading which indicates the depth of the tail of the drill relative to the ground surface elevation. 
Table 3

Summary Report from Magnetometer Survey

Inrun Survey by Minimum Curvature

\begin{tabular}{|c|c|c|c|c|c|c|c|c|c|}
\hline AS. & IRUE & VERT. & $\mathbb{R}$ & IHCL & BEARING & coor & ATES & 56 & D-LEG STATIOH OISP \\
\hline OEPTH & ELEY & SECT. & CLOS. & & AZIMUTK & LATIIUDE & OEPARTURE & 1100 & ICL OISP. DIRECTIOH \\
\hline 0.0 & 804.01 & 0.00 & 0.000 & 66.85 & 131.36 & $16977.15 \mathrm{~K}$ & $23732.03 E$ & 0.00 & 29179.33 AT 051.42 \\
\hline $\begin{array}{r}5.0 \\
10.0\end{array}$ & & 2 & $\begin{array}{l}-81.495 \\
-77.088\end{array}$ & & 129.76 & $\begin{array}{l}16974.18 \mathrm{H} \\
16971.26 \mathrm{H}\end{array}$ & $\begin{array}{l}23735.51 \text { E } \\
23739.01 \mathrm{E}\end{array}$ & 35.96 & 1.802918 \\
\hline 15.0 & 798.23 & 29182 & -72.528 & 74.15 & 131.89 & $16968.18 n$ & $23712.56 \mathrm{E}$ & 181.84 & 9.0929182 .67 it 054.45 \\
\hline 20.0 & 797.18 & 29183.84 & -67.810 & 82.16 & 127.40 & $26965.07 \mathrm{~K}$ & $23716.32 E$ & 160.32 & 8.0229183 .92 AT 051.46 \\
\hline 25.0 & 796.37 & 185.02 & -63.021 & 80.17 & 134.21 & $16961.85 \mathrm{~K}$ & 23750.0 & 135.84 & 6.7929185 .09 AT 054.17 \\
\hline 30.0 & 7 & 9185.85 & -58.138 & 84.25 & 135.78 & $16938.35 \mathrm{~K}$ & $23753.55 \mathrm{E}$ & 87.33 & 1.3729185 .90 AT 054.18 \\
\hline 35.0 & 795.29 & 29186.57 & -53.209 & 86.53 & 136.73 & $16954.75 \mathrm{~N}$ & $23757.00 \mathrm{E}$ & 69.38 & 2.4729186 .61 AT 054.49 \\
\hline 40.0 & 791.82 & 29187.32 & -48.286 & 82.68 & 135.14 & $16951.17 \mathrm{~K}$ & $23760.46 E$ & 83.25 & 4.1629187 .36 AT 054.50 \\
\hline 45.0 & 794.04 & 29188.21 & $-\$ 3.127$ & 79.54 & 133.21 & $16947.73 \mathrm{H}$ & $23764.00 \mathrm{E}$ & 73.47 & 3.6729188 .21 AT 051.50 \\
\hline 50.0 & 793.11 & 29189.34 & -38.650 & 78.93 & 129.28 & $26944.49 \mathrm{~K}$ & $23767.70 \mathrm{E}$ & 78.17 & 3.9129189 .36 AT 051.51 \\
\hline 55.0 & 792 & 29190 & -33.906 & 79.43 & 129.77 & $26941.36 \mathrm{~N}$ & 2377 & 13.88 & 0.692 \\
\hline 60.0 & 79! & 29191.99 & -29.206 & 77.40 & 126.82 & $16938.33 \mathrm{~K}$ & $23775.33 \mathrm{E}$ & 70.63 & 3.5329192 .01 AT 054.53 \\
\hline 65.0 & 790.29 & 29193.18 & -24.514 & 82.47 & 127.12 & $16935.37 \mathrm{~K}$ & $23779.26 \varepsilon$ & 101.57 & 5.0829193 .49 AT 051.54 \\
\hline 70.0 & 790.02 & 29195.10 & -19.797 & 91.15 & 124.23 & $16932.16 \mathrm{~N}$ & $23783.31 \varepsilon$ & 182.92 & $9.1529195 .11 \wedge$ AT 054.55 \\
\hline 75.0 & 790.33 & 29196.87 & -15.137 & 95.95 & 123.22 & $16929.69 \mathrm{H}$ & $23787.16 \mathrm{E}$ & 98.09 & 4.9029196 .88 AT 054.56 \\
\hline 80.0 & 79. & 29198 & 10 & 100. & 127.08 & $16926.84 \mathrm{~N}$ & 237 & .66 & 22 AT 054.57 \\
\hline 85 & 792 & 29200.09 & 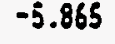 & 105 & 124.43 & $16924.00 \mathrm{H}$ & 2379 & 106.62 & 5.2329200 .09 AT 054.58 \\
\hline 90.0 & 793.63 & 29201.49 & -1.293 & 108.4 & 130.72 & $16921.08 \mathrm{~N}$ & 23799.25 & 135.76 & 6.7929201 .49 AT 051.59 \\
\hline 91.7 & 794.17 & 29201.86 & 0.276 & 108.36 & 131.48 & $16920.02 \%$ & $23800.16 \mathrm{E}$ & 13.23 & 0.7329201 .86 AT 054.59 \\
\hline
\end{tabular}

MAGNETIC OECLINATION: $31.71 E$

TIE-ON COORDINATES RT: O M.D.

TAKEN FROM: MARTIN MARIETTA

SURFACE $Y$-COORD: 16977.15

SURFACE $X$-COORD: 23732.03

SURF. ELEVATION: 804.01

\section{Explanation of Survey Spread Sheet}

Measured Depth: $\quad$ Actual depth of hole

Verrical Depth: Verical depth of hole

Vertical Section: Horizontal displacement from hole collar

L/R Closure: Distance left or right from proposed direction

Inclination: Hole angle, 0 being horizontal

Bearing Azimuth: Hole direction

Latitude: Distance North or South from hole collar

Departure: Distance East or West from hole collar

D-Leg/100: Dog Leg Severity per 100 feet

D-Leg/Course Length: Dog Leg between survey stations

Station Displacement: Distance and direction from hole collar 
APPENDDX A

WAG 6 DRILL ANGLE CORRECTION FACTORS

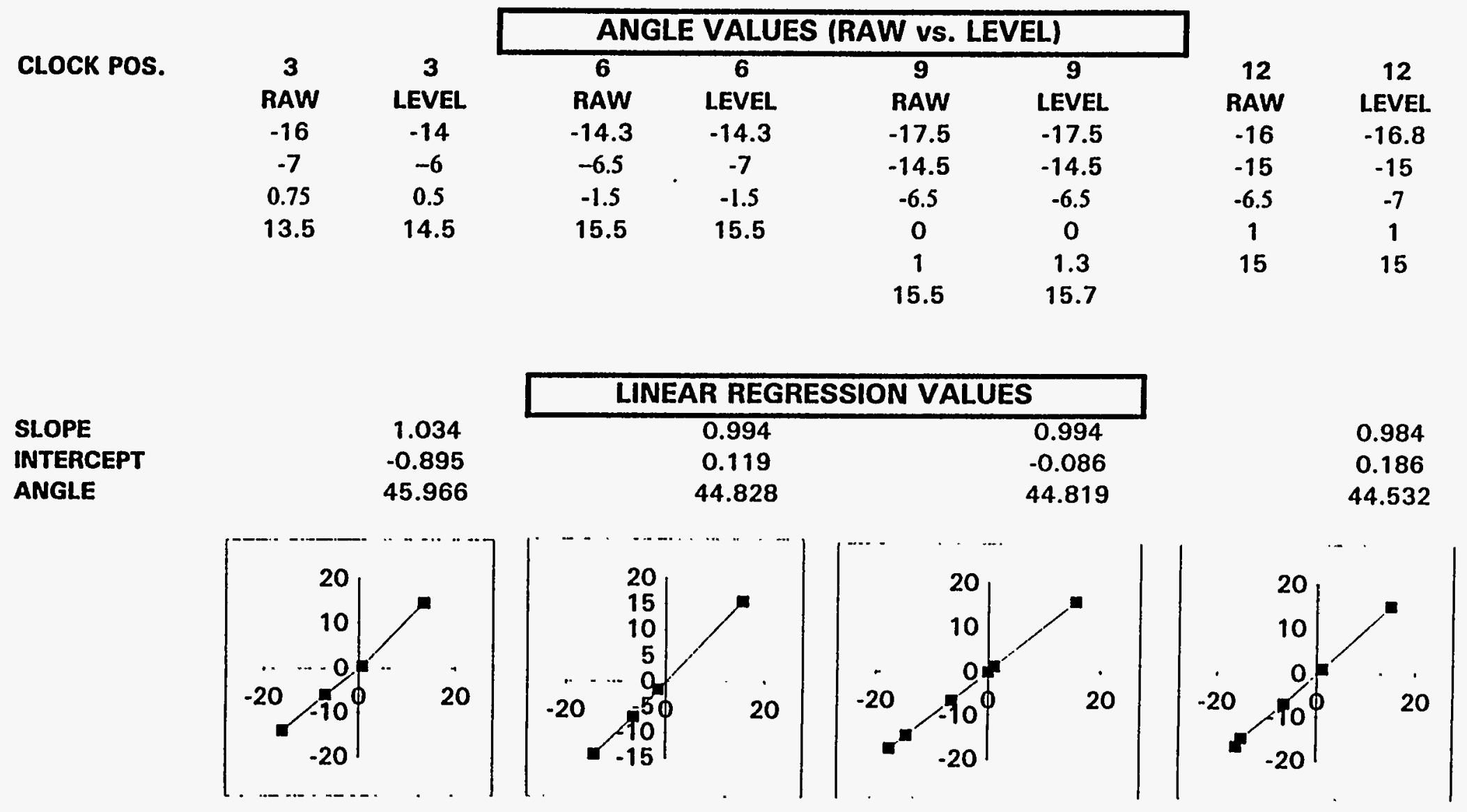


APPENDIX A (Con't)

RAW
ANGLE
1
2
3
4
5
6
7
8

\section{RAW \\ ANGLE}

9

10

11

12

13

14

16

17

18

19

20

21

22

23

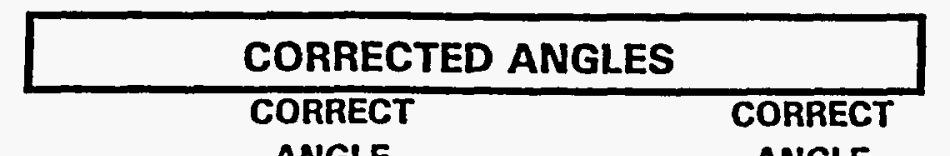

ANGLE

0.14

1.17

2.21

3.24

4.28

5.31

6.34

7.38

\section{ANGLE}

1.11

2.11

3.10

4.09

5.09

6.08

7.08

8.07
0.91

1.90

2.89

3.89

4.88

5.88

6.87

7.86

CORRECT
ANGLE
1.17
2.15
3.14
4.12
5.10
6.09
7.07
8.06

WAG 6 DRILL ANGLE CORRECTION FACTORS

$\begin{array}{cc}\text { CORRECT } & \text { CORRECT } \\ \text { ANGLE } & \text { ANGLE } \\ 8.41 & 9.06 \\ 9.45 & 10.06 \\ 10.48 & 11.05 \\ 11.52 & 12.05 \\ 12.55 & 13.04 \\ 13.58 & 14.03 \\ 14.62 & 15.03 \\ 15.65 & 16.02 \\ 16.69 & 17.02 \\ 17.72 & 18.01 \\ 18.76 & 19.00 \\ 19.79 & 20.00 \\ 20.82 & 20.99 \\ 21.86 & 21.99 \\ 22.89 & 22.98 \\ 23.93 & 23.97 \\ 24.96 & 24.97 \\ 26.00 & 25.96 \\ 27.03 & 26.96 \\ 28.06 & 27.95 \\ 29.10 & 28.94 \\ 30.13 & 29.94\end{array}$

$\begin{array}{cc}\text { CORRECT } & \text { CORRECT } \\ \text { ANGLE } & \text { ANGLE } \\ 8.86 & 9.04 \\ 9.85 & 10.02 \\ 10.84 & 11.01 \\ 11.84 & 11.99 \\ 12.83 & 12.97 \\ 13.83 & 13.96 \\ 14.82 & 14.94 \\ 15.81 & 15.93 \\ 16.81 & 16.91 \\ 17.80 & 17.89 \\ 18.79 & 18.88 \\ 19.79 & 19.86 \\ 20.78 & 20.85 \\ 21.77 & 21.83 \\ 22.77 & 22.81 \\ 23.76 & 23.80 \\ 24.76 & 24.78 \\ 25.75 & 25.76 \\ 26.74 & 26.75 \\ 27.74 & 27.73 \\ 28.73 & 28.72 \\ 29.72 & 29.70 \\ & \end{array}$



ORNL/ER-335

\section{DISTRIBUTION}

1. H. L. Boston

2. W. D. Brickeen

3. D. L. Garrett

4. C. S. Haas

5. C. M. Kendrick

6. A. J. Kuhaida

7. A. P. Malinauskas

8-9. D. M. Matteo

10-11. P. T. Owen

12. E. C. Phillips

12. P. A. Schrandt

13. P.S. Wood

14. Central Research Library

15-17. ER Central Document Management Center

18. Laboratory Records Department

19. Office of Assistant Manager for Energy Research and Development, DOE Oak Ridge Operations Office, P. O. Box 2001, Oak Ridge, TN 37831-8600

20-21. ORNL ER Document Management Center

22. ORNL Laboratory Records

23. J. Kubarewicz, Jacobs Engineering Group, Inc., 125 Broadway, Oak Ridge, TN 37830

24. Office of Scientific and Technical Information, P. O. Box 62, Oak Ridge, TN 37831 

Please do not forward or discard this document.

If this address is not correct for the the designated addressee, please return the document to

ER Document Management Center Lockheed Martin Energy Systems

P.O. Box 2003

Bldg. K-1002, MS 7243

Oak Ridge, TN 37831-7243

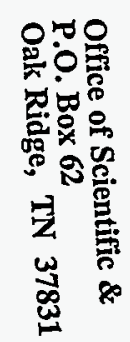

里

象圆邑

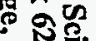

글

w

i) 